Florida International University

FIU Digital Commons

FIU Electronic Theses and Dissertations

University Graduate School

$3-27-2013$

\title{
A Phenomenological Exploration of Black Male Law Enforcement Officers' Perspectives of Racial Profiling and Their Law Enforcement Career Exploration and Commitment
}

Gregory A. Salters

Florida International University, GSalters1906@gmail.com

DOI: $10.25148 /$ etd.FI13042505

Follow this and additional works at: https:// digitalcommons.fiu.edu/etd

Part of the African American Studies Commons, Civil Rights and Discrimination Commons, Constitutional Law Commons, Criminology and Criminal Justice Commons, $\underline{\text { Human Resources }}$ Management Commons, Industrial and Organizational Psychology Commons, Labor and Employment Law Commons, Labor Relations Commons, Law and Psychology Commons, Law Enforcement and Corrections Commons, Legal History Commons, Organizational Behavior and Theory Commons, Personality and Social Contexts Commons, and the Urban Studies and Planning Commons

\section{Recommended Citation}

Salters, Gregory A., "A Phenomenological Exploration of Black Male Law Enforcement Officers' Perspectives of Racial Profiling and Their Law Enforcement Career Exploration and Commitment" (2013). FIU Electronic Theses and Dissertations. 877.

https://digitalcommons.fiu.edu/etd/877

This work is brought to you for free and open access by the University Graduate School at FIU Digital Commons. It has been accepted for inclusion in FIU Electronic Theses and Dissertations by an authorized administrator of FIU Digital Commons. For more information, please contact dcc@fiu.edu. 


\title{
FLORIDA INTERNATIONAL UNIVERSITY
}

Miami, Florida

\begin{abstract}
A PHENOMENOLOGICAL EXPLORATION OF BLACK MALE LAW
ENFORCEMENT OFFICERS' PERSPECTIVES OF RACIAL PROFILING AND

THEIR LAW ENFORCEMENT CAREER EXPLORATION AND COMMITMENT
\end{abstract}

A dissertation submitted in partial fulfillment of

the requirements for the degree of

DOCTOR OF EDUCATION

in

ADULT EDUCATION AND HUMAN RESOURCE DEVELOPMENT

by

Gregory A. Salters

2013 
To: Dean Delia C. Garcia

College of Education

This dissertation, written by Gregory A. Salters and titled A Phenomenological Exploration of Black Male Law Enforcement Officer's Perspectives of Racial Profiling and their Law Enforcement Career Exploration and Commitment, having been approved in respect to style and intellectual content, is referred to you for judgment.

We have read this dissertation and recommend that it be approved.

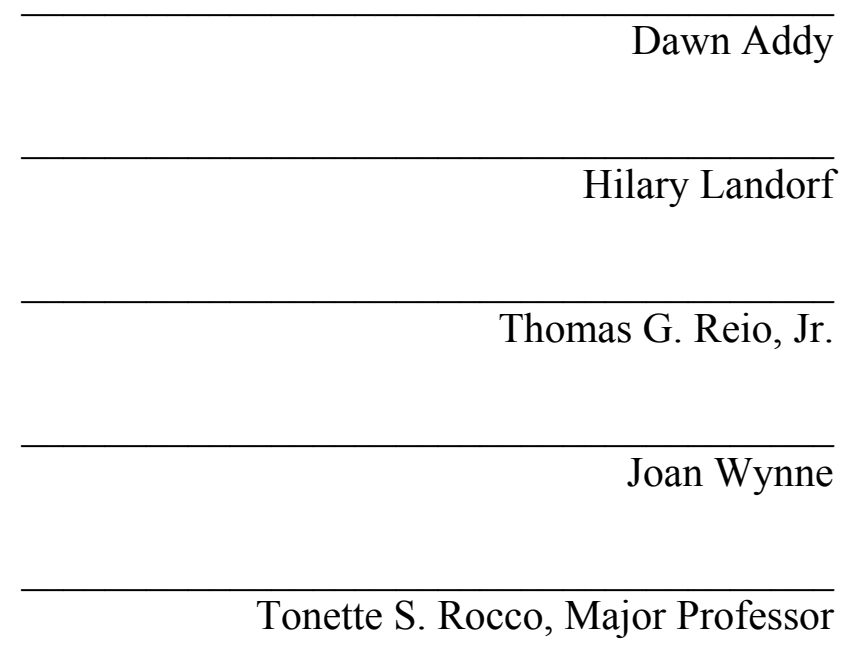

Date of Defense: March 27, 2013

The dissertation of Gregory A. Salters is approved.

Dean Delia C. Garcia

College of Education

Dean Lakshmi N. Reddi

University Graduate School

Florida International University, 2013 
(C) Copyright 2013 by Gregory A. Salters

All rights reserved. 


\section{DEDICATION}

I dedicate this dissertation to my family: Alex Salters, Jr. and Ethel Holmes Salters, parents; Stanley S. Salters, brother; Sheila H. Salters, wife; and Ciante' J. Salters, daughter. I am truly blessed to have the influence of both of my parents in my life. Dad is straightforward with no excuses, and mom is the calmer balancing force. Dad's favorite expression is, "Until the referee blows the whistle, hit somebody," whereas mom's is, "The least you can be is kind." I often tell individuals, if I would not have had my mom's influence, I doubt I would be as tolerable as I am. Stan, thanks for being the brain in the family. I truly used a lot of extrapolating to complete this program. Sheila and Ciante', I greatly appreciate your support through this process. Your continued support and encouragement are invaluable. I hope that the scholarly trip to Italy assisted in showing my appreciation.

I also dedicate this dissertation to the men and women of law enforcement who have and continue to serve honorably, especially those facing the challenges of being Black while wearing the blue, green, or brown uniforms. I would also like to dedicate this work to Trayvon Martin; Brian Banks; Dr. Henry Louis Gates, Jr.; Major Aaron Campbell; and the many other victims of racial profiling. 


\section{ACKNOWLEDGMENTS}

I would like to first thank God for this accomplishment. Without him guiding my steps and placing the right people at the right time in my life, this milestone would not have been possible. Some of the people who made the completion of this dissertation possible are my family, Dr. Rocco, the invaluable community of scholars, administrative and support staff, and participants. Dr. Rocco, my major professor, has been THE most influential person in this process. Without her guidance, patience, and encouragement, I would not be at this point in my life. Through this program, she has opened my eyes to opportunities I had never considered. She has truly been a godsend. When she arrived on campus, my educational career, along with others in the program, was stagnant at best. She reignited my desire to earn my doctorate. She understood my interest and opened my eyes to critical race theory and research areas addressing power and privilege. Because of her, my educational journey has allowed my family and me to travel to Italy as I presented a paper. This experience had a profound impact on my family and me.

My dissertation committee has been tremendously understanding and supportive during my process. Each of them has provided insight and perspectives that have improved my research. Based on your collective feedback, I was able to address the issue of racial profiling and human resource development better. Dr. Landorf's insight upon reviewing the proposal and identifying the need to address the commitment to the law enforcement career is an area I had not considered. Dr. Reio, as we discussed curiosity, it assisted me in my thoughts and research surrounding career exploration. Dr. Addy, I truly appreciate all of the time, energy, and insight you have provided me. 
The Office of Graduate Studies has been supportive and diligent in their commitment to serve the students of the College of Education. Drs. Barbetta, Bliss, Newman, and the OGS team, I appreciate your scholarly feedback and administrative guidance. I would be tremendously remiss if I did not acknowledge the invaluable services of Caprilla Almeida. She is the consummate professional. Without her guidance and patience, this journey would not have been as administratively smooth as it has been. She was always helpful, had all of the answers, and facilitated any administrative issue that arose.

My dissertation peer group of Claire, Rehana, Sunny, Masha, Judy, Regina, Vanetta, and Sue was tremendously inspiring. They are all doctors now. I greatly appreciate all of your individual and collective assistance during this process. You provided me with scholarly information, shared in the joy and pain of our respective research, and traveled to conferences together. I look forward to continuing our relationships.

This study would not have been possible without the participants who were candid, forthcoming, and generous with their time. I appreciate your commitment and interest in this study. Your shared experiences provided valuable insights into the complexity of racial profiling. Thanks for your dedication and participation. 


\begin{abstract}
OF THE DISSERTATION
A PHENOMENOLOGICAL EXPLORATION OF BLACK MALE LAW

ENFORCEMENT OFFICERS' PERSPECTIVES OF RACIAL PROFILING AND

THEIR LAW ENFORCEMENT CAREER EXPLORATION AND COMMITMENT

by
\end{abstract}

Gregory A. Salters

Florida International University, 2013

Miami, Florida

Professor Tonette S. Rocco, Major Professor

This phenomenological study explored Black male law enforcement officers'

perspectives of how racial profiling shaped their decisions to explore and commit to a law

enforcement career. Criterion and snow ball sampling was used to obtain the 17

participants for this study. Super's (1990) archway model was used as the theoretical

framework. The archway model "is designed to bring out the segmented but unified and

developmental nature of career development, to highlight the segments, and to make their origin clear" (Super, 1990, p. 201).

Interview data were analyzed using inductive, deductive, and comparative analyses. Three themes emerged from the inductive analysis of the data: (a) color and/or race does matter, (b) putting on the badge, and (c) too black to be blue and too blue to be black.

The deductive analysis used a priori coding that was based on Super's (1990) archway model: (a) biographical and geographical foundation, (b) personality and achievement, (c) social policy and employment practices, (d) social learning, and (e) self- 
concept. The deductive analysis revealed the participants' career exploration was influenced by their knowledge of racial profiling and how others view them. Many times, this knowledge was obtained via social learning such as (a) instrumental learning experiences (receiving positive or negative reinforcement), (b) associative learning experiences (associating a neutral event to something meaningful), and (c) vicarious experiences (learning from others experiences) (Mitchell \& Krumboltz, 1990). The information and confirmation they learned via social learning regarding racial profiling and law enforcement career opportunities caused them to want to explore and commit to a law enforcement career. This exploration and commitment was driven by their desire to make a positive difference in the community by treating people fairly and improving the image and professionalism of law enforcement. The participants also made an effort to build relationships; share information; and provide others the same type information, support, and encouragement they continue to receive.

The comparative analysis between the inductive themes and deductive findings found the theme "color and/or race does matter" was present in the relationships between and within all segments of Super's (1990) model. The comparative analysis also revealed an expanded notion of self-concept for Black males - marginalized and/or oppressed individuals.

Self-concepts, "such as self-efficacy, self-esteem, and role self-concepts, being combinations of traits ascribed to oneself” (Super, 1990, p. 202) do not completely address the self-concept of marginalized and/or oppressed individuals. The expanded notion of self-concept for Black men, marginalized and/or oppressed individuals, is described as duality (DuBois, 1995). Therefore, the self-concept of marginalized and/or 
oppressed individuals is self-efficacy, self-esteem, traits ascribed to oneself expanded by their awareness of how others view them. (DuBois, 1995; Freire, 1970; Sheared, 1990; Super, 1990; Young, 1990). Ultimately, self-concept is utilized to make career and life decisions.

The study implies the following: color and/or race does matter, and racial profiling negatively impacts Blacks' career options. Current human resource policies and practices do not take into consideration that negative police contact could be the result of racial profiling. Current human resource hiring guidelines penalize individuals who have had negative police contact, thus, perpetuating the discriminatory effects of racial profiling. Therefore, racial profiling is a discriminatory act that can effectively circumvent U.S. Equal Employment Opportunities Commission laws and serve as a boundary mechanism to employment (Rocco \& Gallagher, 2004). 


\section{TABLE OF CONTENTS}

CHAPTER

PAGE

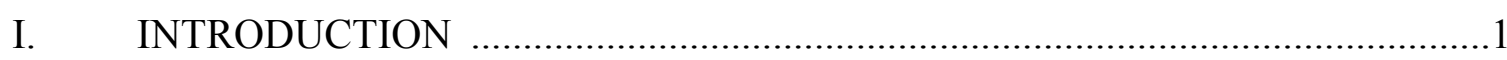

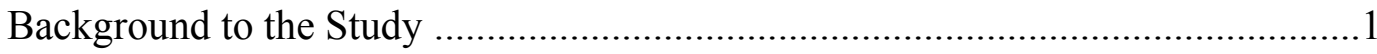

Problem Statement ……………………....................................................

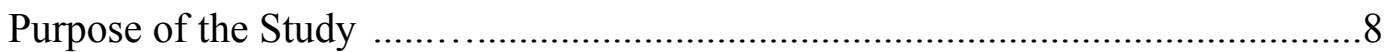

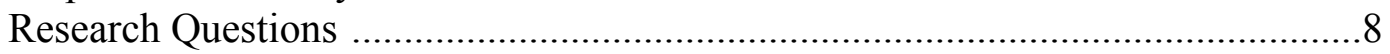

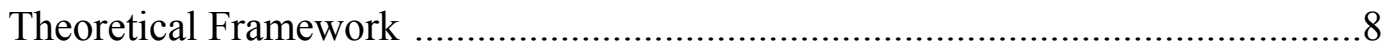

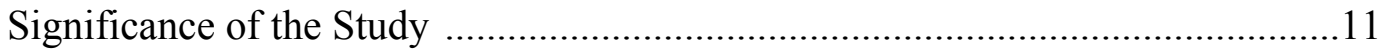

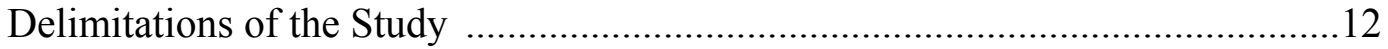

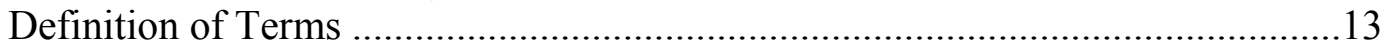

Organization of the Study …………………….............................................15

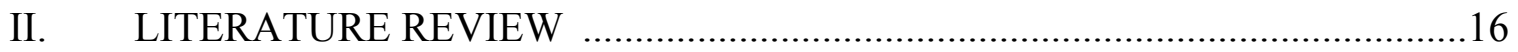

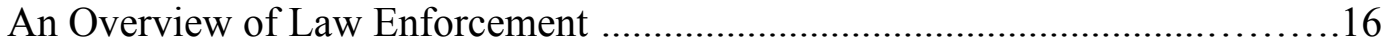

Purpose and Role in Society ...................................................................16

Uniform Crime Reports and Census Data ......................................................18

An Overview of Racial Profiling ................................................................19

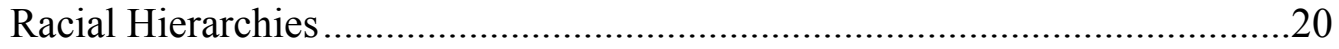

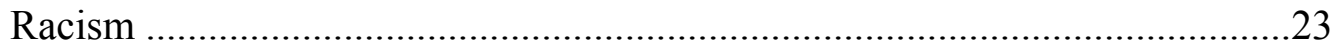

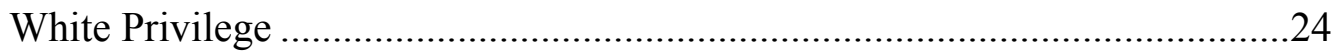

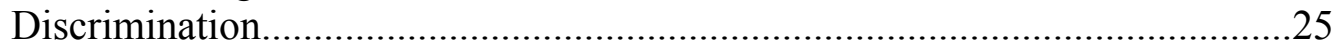

Racial Discrimination .............................................................................26

Racial Profiling as Legalized Discriminative Actions ......................................29

Racial Profiling as a Discriminatory Tool in Law Enforcement .......................30

Police Contacts and Racial Profiling Studies....................................................36

Employment and Career Development in Law Enforcement ......................40

Law Enforcement Hiring Process ......................................................................40

Career Development: A Developmental Tool in Law Enforcement .................41

Super and Career Development and Employment..............................................43

Black Males' Career Exploration and Development ……………………..........46

Black Males: More than a Mere Racial Profile ……………………………........4

Black Males' Perspectives-The Sounds of Silence................................................51

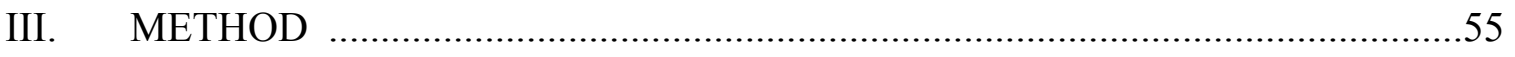

Purpose of the Study ..................................................................................5

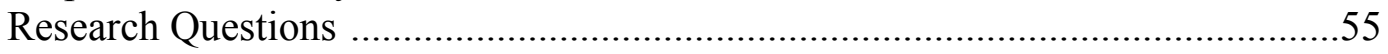

Phenomenological Framework ………………………................................56

Researcher's Autobiography and Assumptions ...............................................56

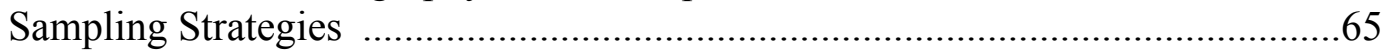

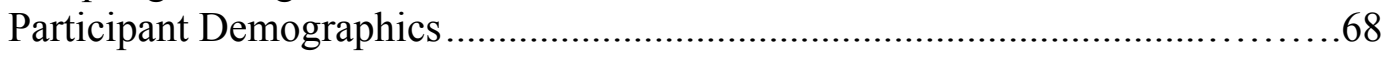

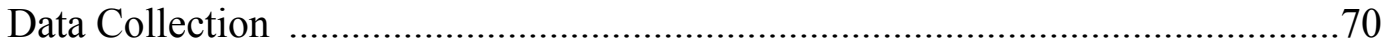

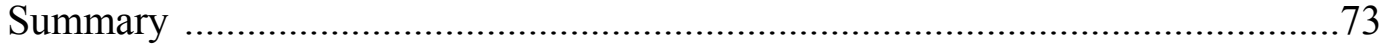




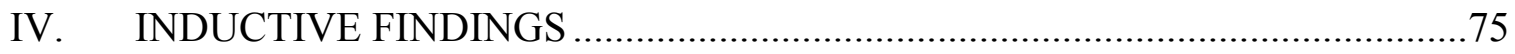

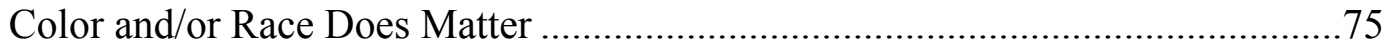

Casualties and the Cost of Being Black ........................................................79

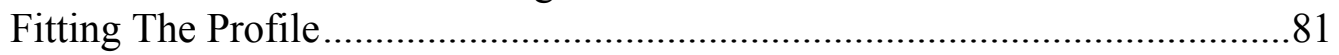

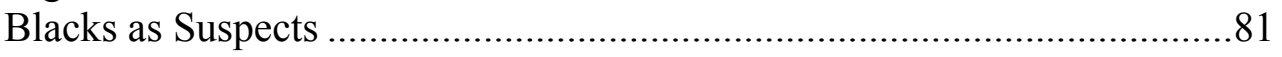

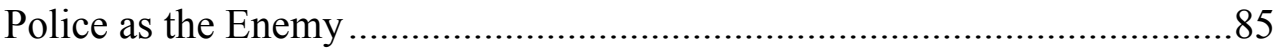

Feeling Blue Experiences of Racial Profiling..................................................85

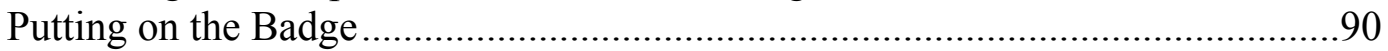

Too Black to be Blue and Too Blue to be Black ..................................................93

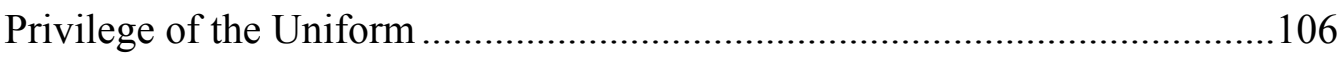

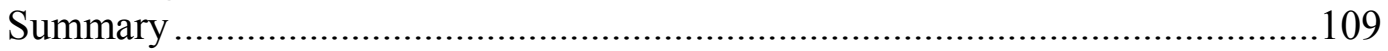

V. DEDUCTIVE AND COMPARATIVE FINDINGS ......................................110

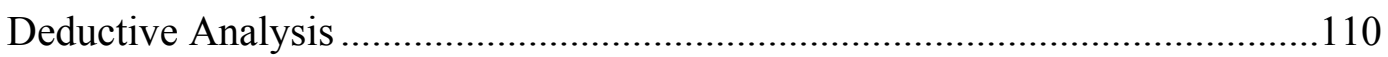

Biographical/Geographical Foundations of Human Development.......................112

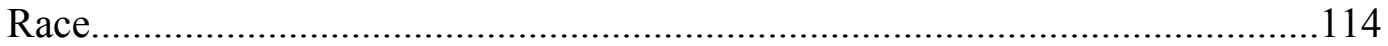

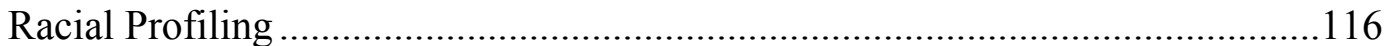

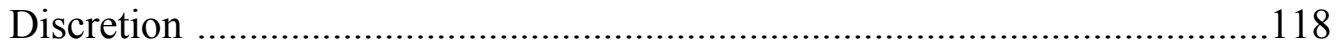

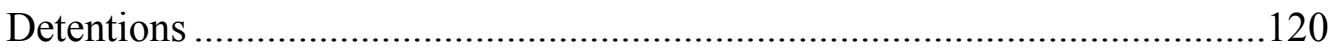

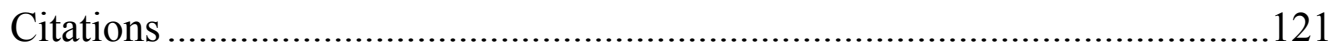

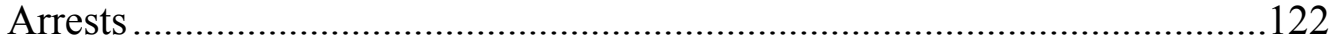

Personalities and Achievements ...................................................................123

Social Policy/Employment Practices ................................................................125

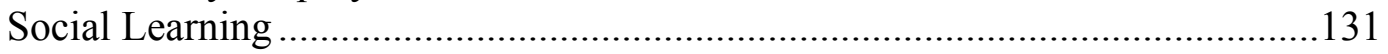

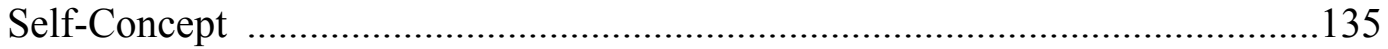

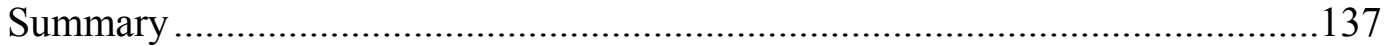

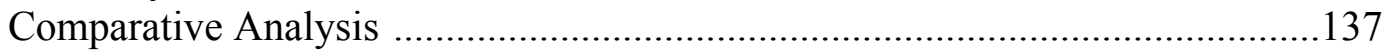

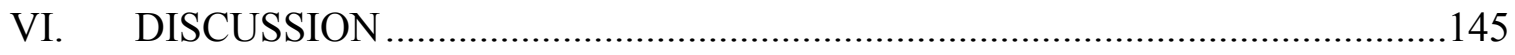

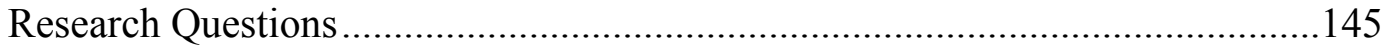

Implication for Research and Practice .........................................................153

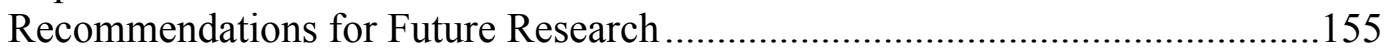

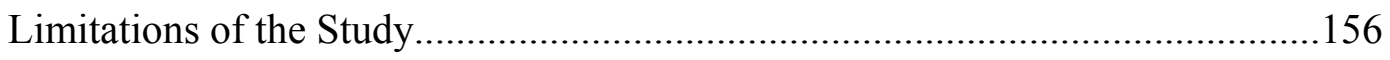

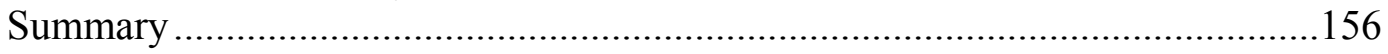

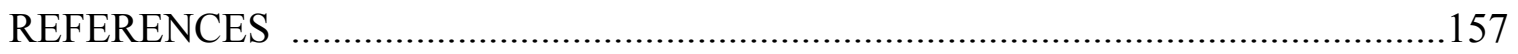

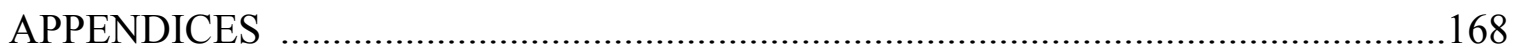

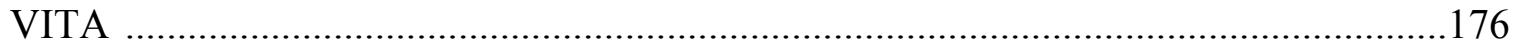




\section{CHAPTER I}

\section{INTRODUCTION}

The purpose of this phenomenological study was to explore Black male law enforcement officers' perspectives of how racial profiling shaped their decisions to explore and commit to a law enforcement career. This chapter begins with the background to the study, the problem statement, the purpose of the study, the research questions, and the theoretical framework. The significance of the study, delimitations of the study, definitions of terms, and organization of the study are also included in this chapter.

\section{Background to the Study}

Racial profiling is law enforcement's discriminatory targeting of "visible minorities, Black, Asian, Arab, Pacific Islander, or Latin American ancestry” (Mentzer, 2002, p. 91) by inappropriately considering one factor, the color of their skin (black or brown), and the fleeting thought that they committed a crime or are going to commit a crime (Fridell et al., 2001; Meeks, 2000). This targeting results in a self-fulfilling prophecy for the officers (Scoville, 2000). The detention, citation, or arrest based on race produce a conscious or sometimes unconscious self-fulfilling prophecy where the outcome or end justifies the means and further perpetuates the stereotype (Wang, 2006). Stereotypes are individual beliefs and attitudes that are established and perpetuated based on secondhand information (Sue \& Sue, 2003). Black men are most often stereotyped as criminals or suspects of criminal activity (Smith, Allen, \& Danley, 2007). These stereotypes exist regardless of the age, socioeconomic status, profession, or education of the Black man (Cose, 1995). 
As a result of these stereotypes, members of the community notify police when they perceive Black men are acting suspiciously. These suspicious acts have been documented as Black men shop, walk home, and drive (Meeks, 2000). When law enforcement officers respond to the calls of suspicious activities or conduct traffic stops, they use discretion to determine what actions they will take. Their use of discretion is based on knowledge gained through training and experience. The knowledge of Black males' high rate of incarceration causes society to stereotype them consciously and unconsciously as criminals or as individuals who are prone to commit criminal acts.

Black men constitute only $4 \%$ of the U.S. population; however, Black men constitute $41 \%$ of the nearly 2,042,100 individuals in prison (U.S. Department of Justice [USDOJ], 2006). These statistics, combined with media portrayals of Black men as criminals or suspects with aggressive tendencies, increase their chances of being placed into the institutionalized criminal justice system. Statistically, this leads to more detentions, citations, and arrests of Black men than any other racial and ethnic group. The disproportionately high number of Black men penalized by or incarcerated in the criminal justice system has created strained relationships between law enforcement agencies and the Black communities they serve (Newport, 1999).

In 2000, the institutionalized criminal justice system employed 440,920 full-time sworn local law enforcement officers; $77.4 \%$ were White, and only $9.0 \%$ were Black (Reaves, 2007). This is compared to increasingly multicultural U.S. communities that are 69.1\% White, 12.1\% Black, and 12.5\% Hispanic (U.S. Census, 2000). The disparity between the demographics of full-time, sworn officers and U.S. communities appears to show racial nepotism. Racial nepotism (Bell, 1992), preference for one's own race, serves 
as an institutionalized barrier for Black men as they seek employment in the White, maledominated career field of law enforcement. This preference is evident as informal networks are formed. Networks establish relationships that serve to benefit members of the network. The informal networks of White men who dominate the law enforcement profession establish valuable relationships that foster career exploration for White men and serve as a barrier to the career exploration of Black men. The network of White men in the law enforcement profession may also cause subjective discrimination of Black men. Subjective discrimination occurs when an individual or group avoids subjecting itself to negative consequences or failure because it perceives little or no fair opportunity. An individual's perception of opportunities for employment or advancement determines what careers he or she explores (Naff, 2001; Park, 1999). Racial profiling, combined with informal networks and subjective discrimination, perpetuates the racial and ethnic hiring patterns in law enforcement (Johnson, 2000; Park, 1999; Phillips, ChristopherSisk, \& Gravino, 2001; Super, 1990).

\section{Problem Statement}

Black men are underrepresented in the ranks of sworn law enforcement officers. Black men are also treated with suspicion, stereotyped, and treated as someone who has committed or will commit a crime. The percentage of Blacks in law enforcement agencies should mirror the increasing percentage of Blacks in the communities they serve (Goldstein, 1990). Law enforcement agencies are striving to fill critical staffing shortages as they combat crime and address the fear of crime (Johnson, 2000). As law enforcement agencies attempt to fill these vacancies, they must address issues such as compensation and benefits and the image of law enforcement nationally and locally that 
negatively impacts the recruitment efforts of underrepresented Black men (Bolton \& Feagin, 2004).

High profile incidents such as the April 1999 Columbine shooting (Lamb, 2008); the October 2002 Washington, DC, sniper shootings (White \& Glod, 2009); the April 2007 Virginia Tech massacre (Shapira \& Jackman, 2007); and the September 11, 2001, attack (“September 11: Chronology of Terror," 2001) sent fear through our communities and highlighted the need for increased law enforcement staffing. Fully staffed law enforcement agencies play an integral role in reducing crime and the fear of crime (Goldstein, 1990).

Twenty of the United States' 50 largest local law enforcement agencies, including those of New York City, Chicago, and Los Angeles, saw a decline in sworn personnel after the terrorist act of September 11, 2001 (Reaves, 2007). Due to recent budget cuts, some agencies have reduced recruiting and hiring, and some have laid off law enforcement officers (Wexler, 2009). This reduced staffing decreases law enforcement's presence in the communities and increases the fear of crime.

Other high profile incidents such as the 1997 racial profiling of Police Major Aaron Campbell (Salamone, 1998), the 2002 false accusation against Brian Banks of rape (Halley, 2012), the 2009 racial profiling of Dr. Henry Louis Gates Jr. (Trujillo, 2009), and the 2012 murder of Trayvon Martin ("Trayvon Martin's Friend," 2013) showed how Black men are tainted (i.e., detained, issued a citation, arrested, and killed) based on the color of their skin.

As a result of Blacks being tainted, their career opportunities are reduced. In 1997, Major Aaron Campbell, a 27-year veteran of the Miami Dade County Police 
Department was stopped in Orange County, Florida, for allegedly failing to signal a lane change. The initial charge of improper lane change was dismissed, the traffic stop was declared illegal, and other charges were also thrown out. He ended up serving probation and retiring earlier than planned.

In 2002, Brian Banks, a promising athlete, was falsely accused of rape and kidnapping. After serving more than 5 years in prison followed by 5 years probation and being required to register as a sexual predator, his accuser contacted him via face book and recanted her story (Halley, 2012).

In 2009, the Cambridge police responded to the home of Harvard Professor Dr. Henry Louis Gates, Jr. regarding two Black males attempting to break into the home. Dr. Gates was returning home from a trip, and he was attempting to get into his home. The police arrived, met with a frustrated Dr. Gates, and arrested him. This incident outraged numerous individuals, including the first Black President of the United States, President Obama. President Obama criticized the police actions. The President hosted a meeting at the White House among Dr. Gates; the arresting White policeman, Sergeant Crowley, Vice President Biden; and himself. The meeting became known as "Beer Gate." No one during the meeting admitted fault. After the meeting, Sergeant Crowley (as quoted in Trujillo, 2009) stated that President Obama was "way off base wading into a local issue without knowing all the facts" (p. ). On a national, arguably international stage, a White male Sergeant told the Black leader of the free world that he was wrong.

In 2012, Treyvon Martin paid the ultimate price for being Black; he was killed by a White male acting as security for a neighborhood. All of these incidents show how the careers of these Black men were negatively impacted: Major Campbell retired early; 
Brian Banks' spent 5 years in prison falsely accused, and his football career was tremendously delayed; and Dr. Gates' incident began by a citizen calling the police and resulted in Dr. Gates' image being tarnished.

The White male put in the same spotlight publicly challenged the judgment of the first Black President of the United States. The White male's image was arguably heightened in the White male-dominated law enforcement community. These incidents tend to further the divide between the Black community and law enforcement. Yet, crime and the fear of crime have increased the demands for security and law enforcement resources.

The violent crime rate in the United States is decreasing; however, due to the media and other unsubstantiated information, the fear of crime has increased (Saad, 2006). This fear causes citizens and law enforcement officers to take action against individuals they perceive as suspicious or different.

We live in a society that nurtures and maintains stereotypes; we are all bombarded daily, for instance, with the portrayal of the young Black man as a predator. When we see a group of young Black men, we lock our car doors, cross to the other side of the street, or clutch our handbags (Delpit, 1995).

"Discrimination acts as a boundary mechanism that denies access to employment, education and political, civic, and social opportunities” (Rocco \& Gallagher, 2004, p. 30). The negative stereotype of Black men marginalizes them (Sue \& Sue, 2003). Therefore, Black men exist outside of, are marginal to, or are oppressed within the system (Freire, 1970). 
This marginalization refers not only to "physical space [jail/prison], but also to historical, social, cultural and economic realities [reduced employment opportunities]" (Freire, 1970, p. 10). Marginalization, as a result of stereotyping and discrimination, is so pervasive in the United States that laws (e.g., Title VII of the Civil Rights Act of 1964) were passed to protect people from employment discrimination while exploring career options.

Exploring Black male law enforcement officers' perspectives of how racial profiling shaped their decisions to choose law enforcement as a career option reveal the essence of racial profiling in human resource development (HRD). Research surrounding racial profiling and its intersection with human resource management (HRM) is scant. The psychological and tangible effects of racial profiling affect the individual seeking employment and the hiring policies and practices of organizations, especially law enforcement.

Employers, especially law enforcement agencies, do not typically recruit individuals with traffic citations and arrests. This research explored the subtleties and complexity of this discriminatory intersection.

Title VII of the Civil Rights Act of 1964 was enacted to prevent discrimination and employment policies that appear neutral from disproportionately excluding minorities from jobs; this minority status included race, color, national origin, sex, or religion. Of the 69,064 charges (receipts) filed under Title VII of the Civil Rights Act of 1964 in 2008, 61.4\% resulted in a finding of no reasonable cause (U.S. Equal Employment Opportunity Commission [EEOC], n.d.c). 
"EEOC's determination of no reasonable cause to believe that discrimination occurred based upon evidence obtained in investigation. The charging party may exercise the right to bring private court action" (U.S. EEOC, n.d.a, para. 3). The large percentage of no reasonable cause findings could be the result of the ultimate burden of persuasion remaining with the individual making the allegation.

The burden of proof for employment discrimination as a result of racial profiling also falls with the individual filing the claim (U.S. EEOC, n.d.b). The individual filing the claim must prove the officer racially profiled him or her with the intent of impacting his or her job opportunity negatively.

The detentions, citations, and arrests of Black men as a result of racial profiling may cause victims to fail background investigations, and rank lower on hiring (eligibility) lists due to law enforcement hiring standards. These experiences will, then, be shared with other Black men. The failures, rankings, and sharing of the information between marginalized victims is a social learning process, confirming preconceived notions of law enforcement and law enforcement career opportunities, thus, negatively impacting the desire of Black men to apply for these positions.

Hiring standards and eligibility lists are used to notify individuals of the minimum standards for employment and establish the rank for processing qualified individuals to fill a finite number of career positions. Although Title VII of the Civil Rights Act of 1964 was enacted to combat employment discrimination, detentions, citations, and arrests based on race, it reduces Black men's employability (Bell, 1992; Rocco \& Gallagher, 2004) and facilitates the use and implementation of organizational policies that deny individuals of color access to employment (Super, 1990; Wang, 2006). 


\section{Purpose of the Study}

The purpose of this phenomenological study was to explore Black male law enforcement officers' perspectives of how racial profiling shaped their decisions to explore and commit to a law enforcement career.

\section{Research Questions}

The primary research question was, What are Black male law enforcement officers' perspectives of how racial profiling shaped their decisions to explore and commit to a law enforcement career? The subsidiary research questions were

1. How do Black male law enforcement officers define racial profiling?

2. What role has racial profiling played in Black male law enforcement officers' career exploration?

3. What career adaptive mechanisms do Black male law enforcement officers believe enhance their integration into law enforcement?

4. How has racial profiling influenced Black male law enforcement officers' process of career decision making within the organization?

\section{Theoretical Framework}

The archway model "is designed to bring out the segmented but unified and developmental nature of career development, to highlight the segments, and to make their origin clear" (Super, 1990, p. 201; see Appendix A). This model uses an archway to illustrate how the complexities of individuals' lived experiences, achievements, and organizational employment practices are all connected by the cement of social learning. Social learning theory identifies three main areas that influence an individual's decisionmaking process: (a) instrumental learning experiences (receiving positive or negative 
reinforcement), (b) associative learning experiences (associating a neutral event to something meaningful), and (c) vicarious experiences (learning from others experiences; (Mitchell \& Krumboltz, 1990). Mitchell and Krumboltz (1990) identified four factors that influence an individual's career decision making: (a) genetic endowment and special abilities, (b) environmental conditions and events, (c) learning experiences, and (d) task approach skills. Individuals are born with certain genetic endowments and special abilities, race, sex, and irreversible physical handicaps. Environmental conditions and events include issues beyond the mere privilege of birth such as socioeconomic and political forces. Learning experiences facilitate career decisions. Task approach skills are an outcome of individuals' lived experiences, and they determine how an individual will approach career choices.

The archway model is constructed of two bases, a doorstep and two pillars that are supported by the bases and are connected via a rainbow arch with the center of the arch being the capstone. The biographical and geographical foundation of human development context of the individual and phenomenon forms the doorstep of the archway, establishing the foundation for the psychological characteristics of the person (left pillar) and the society that acts on the individual (right pillar). The left pillar illustrates how needs, intelligence, values, aptitudes, interests, special aptitudes, and personality support a person's achievement. The right pillar illustrates how the economy, school, family, society, peer groups, labor market, and social policy support employment practices.

The interaction between these two pillars (the arch) encompasses one's lived experiences and the various roles and stages in an individual's life (Super, 1980). These 
lived experiences formulate one's self-concept and determine what educational, familial, occupational, civic, and leisure career options an individual will explore.

Self-concepts "such as self-efficacy, self-esteem, and role self-concepts, being combinations of traits ascribed to oneself"' (Super, 1990, p. 202) do not completely address the self-concept of marginalized and/or oppressed individuals. Black men and marginalized and/or oppressed individuals have a self-concept described as duality (DuBois, 1995; Freire, 1970; Sheared, 1990; Young, 1990). Therefore, the self-concept of marginalized and/or oppressed individuals is self-efficacy, self-esteem, traits ascribed to oneself expanded by their awareness of how others view them. (DuBois, 1995; Freire, 1970; Sheared, 1990; Super, 1990; Young, 1990). This self-concept is used to make choices regarding career exploration.

\section{Significance of the Study}

Empirical research on Black male law enforcement officers' perspectives of racial profiling, career exploration, and career commitment is scant. Their experiences with racial profiling are unique. They have experienced racial profiling, received law enforcement training, and served and protected the same communities that continue to profile them racially when they are not in uniform. Career exploration theories have been criticized for using marginalized individuals as objects of the research and not obtaining their voices or perspectives and, therefore, failing to address the needs or the unique issues facing marginalized individuals and their career exploration (Howard, 2003; Super, 1990).

Black male law enforcement officers are uniquely positioned to understand racial profiling and the intricacies, strategies, and techniques of law enforcement (Barlow \& 
Barlow, 2002; Bolton \& Feagin, 2004). Obtaining Black male law enforcement officers' perspectives of racial profiling, career exploration, and career commitment will contextualize racial profiling and advance the discourse of racial profiling beyond merely defining, quantifying, and pontificating.

This discourse may encourage critical reflection on the part of Black male law enforcement officers, human resource professionals, and educators. This critical reflection must be combined with actions geared to effect change-praxis (Freire, 1970, 2000). Black men should critically reflect on how they determine what career fields they explore. Law enforcement officers should make conscious efforts to determine what role race plays in their interactions with the community.

Allowing the voice of Black male law enforcement officers to be heard may provide a more complete understanding of racial profiling. This understanding may assist HRM professionals as they critically review existing human resource policies and recruitment practices and reveal how they may be unconsciously or consciously circumventing Title VII of the Civil Rights Act of 1964. Black males' voices will facilitate praxis on the part of Black men, law enforcement officers, and human resource professionals when filling critical vacancies. The archway model frames career exploration and intersects with HRM in "the recruitment, selection, retention, development, and utilization of an accommodation to human resources by organizations" (Gilley, Eggland, \& Gilley, 2002, p. 9).

\section{Delimitations of the Study}

Racial profiling occurs in numerous areas of life such as shopping, purchasing homes, and obtaining public transportation and victimizes more than Black men (Meeks, 
2000). Victims of racial profiling are not only Black men, but also they may include White individuals and Black females. Black females are subjected to racial profiling (racism) and sexism when coming into contact with law enforcement officers and seeking employment as law enforcement officers. However, this study was delimited to Black male law enforcement officers in the United States.

\section{Definitions of Terms}

\section{Black Man}

A Black man is anyone who is visibly assumed to be a male and due to the complexion of his skin such as Black, Asian, Arab, Pacific Islander, or Latin American ancestry (Mentzer, 2002) and adoption of customs, mannerisms, or traditions associated with being Black.

\section{Career Exploration}

Career exploration is "encompassing those activities, directed toward enhancing knowledge of the self and the external environment, that an individual engages in to foster progress in career development" (Blustein, 1997, p. ).

\section{Criminal Justice System}

The criminal justice system is an institution comprised of "noncriminal justice agencies, including agencies with primary concern for public health, education, welfare, public works, and housing individual citizens as well as public and private sector organizations" (USDOJ, n.d., para. 4). 


\section{Criminal Profiling}

Criminal profiling is the process of combining numerous factors to identified traits of a suspect or patterns of criminal behavior to identify the persons responsible for crimes (Harris, 2002).

\section{Human Resource Management}

HRM is "the recruitment, selection, retention, development, and utilization of and accommodation to human resources by organizations" (Gilley et al., 2002, p. 9).

\section{Passion of Experience}

Passion of experience is "a way of knowing that is often expressed through the body, what it knows, what has been deeply inscribed on it through experience" (hooks, 1994, p. 91).

\section{Race}

Race is a social and cultural construct manipulated arbitrarily to discriminate after determining the difference between individuals or groups. "Not objective, inherent or fixed, they correspond to no biological or genetic reality; rather, races are categories that society invents, manipulates, or retires when convenient” (Delgado, R., \& Stefancic, J., 2001, p. 7).

\section{Racial Profiling}

Racial profiling is law enforcement's discriminatory targeting of visible minorities of "Black, Asian, Arab, Pacific Islander, or Latin American ancestry" (Mentzer, 2002, p. 91) by inappropriately considering one factor, skin color, and the fleeting thought that they committed a crime or are going to commit a crime (Fridell et al., 2001; Meeks, 2000). 


\section{Self-concept of the oppressed}

The self-concept of marginalized and/or oppressed individuals is self-efficacy, self-esteem, traits ascribed to oneself expanded by their awareness of how others view them. (DuBois, 1995; Freire, 1970; Sheared, 1990; Super, 1990; Young, 1990)

\section{Subjective Discrimination}

Subjective discrimination is an internal barrier where individuals perceive that a

work-irrelevant criterion (race) affects how they are evaluated or treated for employment opportunities. As a result of this barrier, their motivation and desire to seek employment is reduced or eliminated (Naff, 2001).

\section{Organization of the Study}

In this study, Black male law enforcement officers' perspectives of how racial profiling shaped their decisions to choose law enforcement as a career option were examined. This chapter introduced the background to the study, problem statement, purpose of the study, research questions, Super's (1990) archway model as the theoretical framework, significance of the study, delimitations of the study, and definition of terms. The next chapter reviews the literature that supports this inquiry, including research into race, racism, discrimination, and privilege. Chapter 3 covers the phenomenological research design. Chapters 4 and 5 present the data and findings of the study. Chapter 6 provides conclusions and recommendations. 


\section{CHAPTER II}

\section{LITERATURE REVIEW}

In this chapter, a review of the relevant literature on racial profiling within the context of Black men, their employment, and their career development in law enforcement is presented. The chapter is divided into four major sections: (a) law enforcement, (b) racial profiling, (c) employment and career development in law enforcement, and (d) Black males' career exploration and development.

The section on law enforcement provides insight into the operation of law enforcement and community interaction. The section on racial profiling provides insight into the complexity of racial profiling. The section on employment and career development in law enforcement focuses on law enforcement and career development. The concluding section, Black males' career exploration and development, focuses on defining Black men and exploring their perspectives.

\section{An Overview of Law Enforcement}

This section begins with an overview of the law enforcement system, including its purpose and role in society. The section concludes with a discussion of uniform crime reports and census data.

\section{Purpose and Role in Society}

Most of modern world history has been affected by conceptions of race, and more than a little of that history exhibits patterns of racial supremacism, sub speciation (the claim that some people, because of color or gender or ethnicity, are a subspecies and less than fully human), and racial injustice. The history of the United States contains all three of these, from slavery and racial lynching to racially motivated abuses of police authority. (Delattre, 2006, p. 318) 
In the Black community, law enforcement literally means enforcing the law, many times at the expense of Black men (Anderson, 1990). This fear or awareness of law enforcement power caused and still causes Blacks to avoid or become invisible to law enforcement as a means of self-preservation and marginalization (Anderson, 1990). Crime and the fear of crime have heightened the desire for security and law enforcement. The violent crime rate in the United States is decreasing; however, due to the media and other unsubstantiated information, the fear of crime has increased (Saad, 2006). It is this fear that causes citizens and law enforcement officers to take action against individuals they view as suspicious or different.

In an effort to enforce the law, the concept of community-oriented policing has evolved. Community-oriented policing states that the demographics of law enforcement agencies must mirror the community they serve if they wish to reduce crime efficiently and improve the quality of life in the community (Goldstein, 1990). These concepts work in concert and use a team approach to addressing crime and quality of life issues in the community. The team consists of members of the community and members of the police department working together to identify issues and individuals that may negatively impact the quality of life in the respective community. The teams also identify patterns of behavior and activities of concern to the community.

When patterns of crime are identified, law enforcement resources are focused on that area (Goldstein, 1990). These patterns could include increased speeders, individuals running stop signs, vehicle burglaries, residential burglaries, and robberies. The additional resources will increase the likelihood of citations, detentions, and arrests in an effort to improve the quality of life and reduce crimes. In many instances, the lower 
income urban neighborhoods have higher crime rates and larger minority populations (Anderson, 1990). As a result, the minority population will receive more citations and arrests (Withrow, 2004). This process can result in law enforcement officers being accused of racial bias, racial profiling, and discrimination. Suburban neighborhoods begin to view others as suspicious. Therefore, Black men in the urban environment and in the suburbs are statistically more prone to have contact with the criminal justice system.

Contact with the criminal justice system could be direct (e.g., being stopped by a police officer for an alleged traffic infraction or as the victim of a crime) or indirect (e.g., via conversation with others and media accounts of other individuals' contacts with the criminal justice system; Bolton \& Feagin, 2004). Direct contact could lead to citations, entry into the criminal justice system, or deaths. Individuals enter the criminal justice system as a result of a law enforcement officer responding to a crime or allegation of a crime. These allegations can come from individuals who belong to neighborhood associations, are employed by a business in the neighborhood, or own their own businesses and can be influenced by the news media (USDOJ, Office of Justice Programs [OJP], Bureau of Justice Statistics [BJS], 2010). As a result of this contact, Black males' employability can be reduced, and negative impressions of the criminal justice system and individuals employed in the system are formulated (Pager, 2003).

\section{Uniform Crime Reports and Census Data}

Cureton (2000) analyzed uniform crime reports and census data of 442 cities for 1980 and 435 cities for 1990 from municipalities with populations of 25,000 and over. These statistics were utilized to "gain some insight into whether the disproportionately 
higher number of Blacks being arrested was the result of justifiable arrest or

discrimination" (Cureton, 2000, p. 715). According to Cureton (2000), analysis revealed that

the criminal justice system may at times be both partial and impartial by nature of its design or because of the interdependency between established laws and the application of legal sanctions by relatively imperfect, value laden legal agentsinfluenced by social, economic, and cultural factors - who may not always be error free in the administration of justice. (p. 716)

As society continues to shape our norms, we will constantly search for differences in members of society. As the differences are identified, we will discriminate and take action based on how we view the differences.

\section{An Overview of Racial Profiling}

Law enforcement officers have a daunting task as they strive to reduce crime and the fear of crime in our increasingly diverse communities. While striving to reduce crime and the fear of crime, law enforcement officers have detained, issued citations, and arrested Blacks in larger percentages than other races (Whitaker, 2000). Although these actions may reduce the fear of crime in one segment of the community, they create fear and alienation of law enforcement in the Black community (Jonsson 2009; Laine, 2009). In many instances, members of the Black community perceive this alienation to be a result of racial profiling. Racial profiling is a complex phenomenon that has proven difficult to document, quantify, and eliminate accurately (Alpert Group, 2004; American Civil Liberties Union [ACLU], 2005; McMahon, Garner, Davis, \& Kraus, 2002). The complexity of this phenomenon occurs due to the intersection of the race color line and how discretion is used when determining which laws to enforce (Tillyer, Engel, \& Wooldredge, 2008). Racial profiling is a form of discretionary law enforcement that 
hinders Black males' desires and abilities to explore law enforcement as a career (Bolton \& Feagin, 2004; Fridell et al., 2001). This section covers six issues relevant to racial profiling: (a) racial hierarchies, (b) race, (c) racism, (d) White privilege, (e) discrimination, and (f) racial discrimination.

\section{Racial Hierarchies}

Asumah (2004) noted that Whites have been placed at the top of the racial hierarchy since Carolus Linnaeus established the racial hierarchy in his 1735 "Systema Aturae." Racial hierarchy views race as a fixed characteristic, thus, allowing races to be categorized based on the intelligence or behavior, civilized or uncivilized, associated with the race (Peregrine, 2008). Linnaeus identified four categories: American, European, Asiatic, and African. In 1755, Johann Blumenbach (as cited in Peregrine, 2008) was the first to use the term Caucasian as one of five race categories of Caucasian, Mongolian, Malayan, Ethiopian, and American. The term Caucasian is used to refer to individuals that came from the Caucasus land between Russia and northwestern Iran. Some believe this is where Noah's ark landed and, thus, established the original form and color of humans (Brace, 2008). These categorizations can facilitate racism. For example, as early as 1854, a discussion between Arthur De Gobineau and Thomas Jefferson inferred the inferiority of Blacks.

In 1890, the U.S. Census (as quoted in Diller, 2004) categorized individuals as

"white, black, mulatto, quadroon, octoroon, Chinese, Japanese, and Indian" (p. 60). Four of these categories were used to identify individuals with Black ancestry while denying or ignoring the fact that an octoroon is seven-eighths White. During the 1940s, there were only two racial categories in the U.S. Census (as cited in Colon, Appleby, \& 
Hamilton, 2001): White and non-White. Historically, individuals categorized as other than White (e.g., Native American Indians, Chinese, Irish, Jews, and Blacks; Omi \& Winant, 2005) were also believed to be inferior and were discriminated against in housing, education, and jobs (McCarthy, Crichlow, Dimitriadis, \& Dolby, 2005).

The racial category of Black evolved after slavery to categorize dark-skinned citizens from African countries (Omi \& Winant, 2005) and, thus, identifying them as other than White. In an effort to determine the race of light-skinned Black men, the onedrop-rule was applied. The one-drop-rule states that, if an individual has one drop of Black blood, he or she is Black (West, 2000). The issue of Blacks living as Whites was so prevalent in Louisiana that "race clerks" (Twine, 2008, p. 460) were employed to enforce the one-drop-rule; individuals known to be of African decent or visible African heritage were categorized as Black.

Researchers have also attempted to identify race as a biological phenomenon and associated this phenomenon with intelligence (Peregine, 2008). During colonial times, race became more important because it was used to determine who was not White. This was especially true in regard to Native American Indians and Black slaves. Soldiers and slave patrols detained individuals they identified as slaves based on visible factors. The easiest way to identify slaves was by their skin color. "Only by acknowledging the full extent of slavery's grip on U.S. society—its intimate connections to present-day wealth and power, the depth of its injury to millions of black Americans, the shocking nearness in time of its true end - can we reconcile the paradoxes of current American life" (Blackmon, 2012, p. 402) 
In terms of law enforcement, officers make their decisions based on visible or perceived factors. It is this visible appearance or perception of race and how officers utilize their discretion to enforce various laws that create issues in the Black community and bias-based policing (Fridell et al., 2001). In some instances, factors associated with particular ethnicities or cultures are used to categorize individuals along the color line. Ethnicity encompasses characteristics that individuals acquire by birth that are transmitted by bloodlines (Sue \& Sue, 2003). Culture is composed of learned behaviors, values, and orientations associated with a particular group (Diller 2004; Freire, 1975, 2000, 2005; Sue \& Sue, 2003). These terms are similar and, in some instances, utilized interchangeably to categorize individuals. If a person is treated differently solely or primarily because he or she is Black or is perceived to be Black based on his or her visible appearance, ethnic traits, or cultural mannerisms, he or she is a victim of racial profiling (Fridell et al., 2001; Meek, 2000).

DuBois (1995), Bell (2001) and West (2001) understood race matters. "The problem of the twentieth century is the problem of the color line" (DuBois, 1995, p. 41) and remains with us into the 21 st century (Bell, 2001; West, 2001). Race has also become a factor in an individual's employment and job opportunities. The U.S. EEOC (n.d.c) is responsible for "enforcing federal laws that make it illegal to discriminate against a job applicant or an employee because of the person's race, color . . . national origin" (para. 1). However, the U.S. EEOC (2006) neither defined race nor adopted a definition of race. The U.S. EEOC (as cited in Tabulation Working Group of the Interagency Committee for the Review of Standards for Data on Race and Ethnicity, 2000) provides six socially and politically constructed categories for classification that do 
not consider genetics, biology, or anthropology: American Indian or Alaska Native, Asian, Black or African American, Native Hawaiian or other Pacific Islander, White, and Hispanic or Latino. The definition of race changes, depending on the social and political needs of the majority. Therefore, race is a social and cultural construct manipulated arbitrarily to discriminate after determining the difference between individuals or groups. "Not objective, inherent or fixed, they correspond to no biological or genetic reality; rather, races are categories that society invents, manipulates, or retires when convenient" (Delgado, R., \& Stefancic, J., 2001, p. 7). Race serves as a "marker of the infinity of variations we as humans hold as a common heritage" (Omi \& Winant 2005, p. 10). When discrimination is based on race, it is referred to as racism.

\section{Racism}

Racism is any action, program, or practice of discrimination, segregation, persecution, or mistreatment, whether consciously or unconsciously, based solely or primarily on an individual's race, ethnicity, skin color, or cultural attributes associated with a particular race (Brace, 2008; Hamilton, 2001; Sue \& Sue, 2003). Racism implies an individual, group, or organization have the requisite power to accompany any prejudices it may harbor (Asumah, 2004). The result of racism is subordination or marginalization of a person or group because of skin color or perceived ethnic group affiliation.

Racism occurs on individual, institutional (Hamilton, 2001), and cultural (Sue \& Sue, 2003) levels. On the individual level, the act is referred to as racist. This individual racist act may be in accordance with institutionalized policies based on organizational culture. A racist act is displayed by an individual's conscious or unconscious attitude 
that leads to actions that subordinate another individual or group because of race (Sue, 2003). Unconscious actions are the most dangerous because the perpetrators are unaware of their actions and the impact of their actions. A critical review of unconscious actions will reveal the essence of racism and racial profiling. The essence of racism and racial profiling can, then, be brought to the consciousness of individuals, institutions, and cultures accused of racism or racial discrimination. Once the essence of the phenomenon is revealed and brought to the conscious level, individuals and institutions can no longer claim they are unaware of racism and racial profiling. Ideally, this consciousness in an ideal world will cause individuals to make the necessary changes to reduce or eliminate the phenomenon.

Institutional racism is any institutional policy, practice, or structure in governments, business, unions, schools, churches, court, and law enforcement organization by which decisions are made as to unfairly subordinate persons of color while allowing other groups to profit from such actions performed by one person or a group. (Sue, 2003, p. 33)

The institutionalized criminal justice system consists of lawmakers, law enforcement officers, lawyers, judges, and juries. This institution works in concert to enact, enforce, and adjudicate the law. Cultural racism is the individual and institutional expression of the superiority of one group's cultural heritage (i.e., arts, crafts, language, traditions, beliefs, and values) over another group's and its imposition on racial/ethnic minority groups" (Sue, 2003, p. 33) in the form of discrimination. This form of racism and discrimination marginalizes Blacks and privileges Whites.

\section{White Privilege}

Because of its invisibility, it has helped foster the illusion that those who succeed do so because of their superior intelligence, their hard work or their drive, rather than, at least in part, their privilege. The power of whiteness is that it gives 
certain people an advantage without ever acknowledging that this is the case. (Rothenberg, 2002, p. 2)

White privilege is occurs on the individual, cultural, and institutional levels (Rothenberg, 2002). White privilege provides White individuals with unearned benefits while, simultaneously, marginalizing others (i.e., Blacks). In our society, this privilege appears normal, often going unquestioned or unrecognized. Some conditions that indicate or highlight the presence of White privilege are as follows:

I can go shopping alone most of the time, pretty well assured that I will not be followed or harassed. ... If a traffic cop pulls me over or if the IRS audits my tax return, I can be sure I haven't been singled out because of my race. ... I can be sure that if I need legal or medical help, my race will not work against me. (McIntosh, 2002, p. 98)

Being able to be free from harassment and able to drive without the fear of being stopped due to the color of your skin is truly a privilege. Thus white privilege creates and encourages racism. Individuals who are subject to suspicion and do not receive favorable discretion when possible are facing racism; a form of discrimination.

\section{Discrimination}

Discrimination is "the behavioral manifestation of prejudice and racism" (Scott, 2003, p. 238). It is this behavioral manifestation or effect of discrimination along the color line that privileges individuals who are not Black while, at the same time, marginalizes those who are Black or perceived to be Black. Discrimination serves as a boundary mechanism for employment opportunities and social networking opportunities necessary to foster career exploration (Rocco \& Gallagher, 2004). This boundary depends on one's ability to recognize difference. When actions are taken based on an actual or perceived difference, the act is discriminative. 
Discriminative actions serve as an unearned asset or privilege to the individual or group in power and a liability that marginalizes others (Mcintosh, 2002; Rocco \& West, 2001; Sheared, 1999). Discrimination is used to distribute wealth, power, resources, and opportunity, thus, creating racial apartheid (Massey \& Denton, 1993) and perpetuating a racial caste system, benefiting Whites and marginalizing others-Blacks (Omi \& Winant, 2005; West, 2001).

Discrimination has become a default for "the expected, the accepted, the standard. Once it becomes the standard, we take it for granted and fail to recognize the extent to which it influences how we operate in the world" (Wang, 2006, p. 8). The only way to change this default is by making a conscious effort to reduce the use of race as a discriminatory tool.

Social psychologists describe discrimination as being largely situational because it facilitates bias against various groups while masking individual discriminatory acts (Wang, 2006). The individual detentions, citations, and arrests of Black men as a result of racial profiling facilitate the low number of Black men in law enforcement. When discriminatory actions are based on the race or perceived race of an individual or group, it is racial discrimination.

\section{Racial Discrimination}

According to Title VII of the Civil Rights Act of 1964, racial discrimination includes discrimination based on an individual's ancestry, physical characteristics that may be associated with a particular race, his or her culture, perceptions of his or her race, and his or her association with a particular racial group (U.S. EEOC, 2006). Federal laws have been enacted to prohibit racial discrimination in terms of employment. Some of the 
laws are as follows: Equal Pay Act of 1963, Title VII of the Civil Rights Act of 1964, Civil Service Reform Act of 1978, and Civil Rights Acts of 1991. After these laws were enacted and enforced, organizations implemented policies and procedures to reduce and shift financial liability from the organization to individuals (Delgado \& Stefanic, 2001). This shift allowed organizations to distance themselves from the actual act of racial discrimination by identifying the individual perpetrators of the act; however, the victim remains the same.

Racial discrimination has a victim and perpetrator perspective (Bell, 1995; Freeman, 1995). Victims perceive that the issue of racial profiling will not be corrected or eliminated until it is commonly understood and outlawed, and the effects and affects associated with it are neutralized. Victims view racial discrimination as a systemic issue that benefits others while, simultaneously, keeping them at a disadvantage socially and economically (Freeman, 1995). In contrast, alleged perpetrators of racial discrimination do not view discrimination as a systemic or social phenomenon; they view it as an act or action taken by an individual against another individual (Freeman, 1995). Marginalized individuals and victims believe as though they are viewed as members of a group and not as individuals (Freire, 2000).

The victim and perpetrator perspective utilizes a fault and causation analysis to determine the presence of discrimination (Bell, 2001). In terms of racial discrimination, fault occurs when an individual intentionally commits an act to cause a discriminatory effect based on an individual's race (Wang, 2006). If individuals fail to prove that actions were taken against them with the intent of creating a discriminatory effect, there is no discrimination (U.S. EEOC, n.d.b). 
Title VII of the Civil Rights Act of 1964 specified four types of non-harassment discrimination: (a) individual disparate treatment cases in which an employee claims that an employer treated the employee less favorably than other employees because of race, religion, age, sex, and so forth; (b) retaliation cases in which the employee claims that the employer retaliated against the employee for opposing discrimination practices; (c) disparate impact or adverse impact cases in which the employee claims that the employer's employment practice has an unfavorable impact on a protected class of employees; and (d) cases involving a class-wide pattern or practice of systemic disparate treatment where a plaintiff shows a statistical difference between protected class members and, similarly, qualified members of the majority group (U.S. EEOC, n.d.b). Citations and arrests as a result of racial profiling serve as quantifiable factors that contribute to the disparate impact and adverse impact of Black males' law enforcement careers. "Disparate treatment occurs when individuals or groups are intentionally treated differently by a superior or by organizational policies. Disparate impact occurs when employers consistently apply policies that appear fair to all employees but adversely affect one group" (Slonaker, Wendt, \& Kemper, 2001, p. 294). Employment discrimination in the forms of disparate treatment, disparate impact, and retaliation, as specified by Title VII of the Civil Rights Act of 1964, has been documented within the law enforcement profession (Slonaker et al., 2001).

Another form of discrimination—subjective discrimination—occurs when individuals perceive there is little opportunity for employment or advancement, resulting in their retreating to the margins and not pursuing the opportunity (Naff, 2001). Although these discriminatory acts negatively impact and further marginalize Black men, 
they have the equal and opposite effect of privileging the majority. Therefore, these acts serve as a self-fulfilling prophecy by maintaining the status quo-a White, maledominated organization wherein staffing does not mirror the community it serves and impedes Black males' law enforcement career exploration (Bjerk, 2004; Park, 1999).

\section{Racial Profiling as Legalized Discriminative Actions: Historical Perspective}

When we [Whites] hear about things like racial profiling, we [Whites] think of it in terms of what people of color go through, never contemplating what it means for Whites and what we [Whites] don't have to put up with. We might know that ... it elevates the same in Whites, much to our advantage in the job market. (Wise, 2005, p. )

Allegations of criminal activity, combined with the lived experiences of officers, shared stories, and the proportionately high number of Black males in the prison system, cause law enforcement officers to take action as they uphold the law. Simultaneously, the same issues cause Black men to avoid contact with law enforcement officers. Various discriminative actions continue to relegate Black men to a perpetual underclass (Browne-Marshall, 2007). The creation of the charter for the city of Washington, DC, in 1820 was one such action forbidding anyone of color, slaves, free Negroes, and mulattos (mixed Negroes) from holding nightly meetings and being disorderly (Scott v. Sandford, 1856). Black codes and Jim Crow (separate but equal) laws were legally sanctioned discriminative actions. These laws were enacted to utilize incarceration, the only legalized form of slavery, as a means to control Blacks physically and mentally (BrowneMarshall, 2007; Walker, 1998).

Slaves were property and assets of their owners. As assets, they provided labor and status; therefore, their owners had a vested interest in their continued status as slaves. They were physically and mentally shackled and confined to specific areas, effectively 
dehumanizing them. This dehumanization served as a controlling mechanism and as a reminder to the slaves and the slave community to remain in their place and provided an unearned benefit of an elevated socioeconomic status to Whites, especially White males. The combined effect of these actions served to instill fear, loyalty to the oppressor, an inferiority complex, and hatred for anything connected to the slaves' Blackness (Kunjufu, 2004). All of these tactics were not enough to alleviate the Whites' fear of slaves.

As a result of the economic gain associated with slave ownership and labor, slave patrols were established (Browne-Marshall, 2007). Slave patrols enforced the Black codes and Jim Crow laws and returned slaves to their rightful owners.

The enforcement of these codes/laws was conducted by trusted slaves and groups of males who were appointed to these coveted upwardly mobile positions based on their political or kinship ties. These patrols served as a boundary mechanism to uphold the laws of the racist, White male dominated social order in the communities. (Walker, 1998, p. )

Today, this practice, referred to as racial profiling, hinders Black males' hiring process and serves as a barrier to Black males' law enforcement career exploration.

\section{Racial Profiling as a Discriminatory Tool in Law Enforcement}

"Racial Profiling — what is it? Is it a recent phenomenon, growing problem, established law enforcement practice or something else entirely?" (Scoville, 2000, p. 16). Racial profiling should not be confused with the legal longstanding law enforcement practice of profiling. Racial profiling has generally been defined as solely or primarily using race as a factor or indicator that an individual committed or will commit a crime. Using racial profiling to guide investigations is viewed as racist and tends to stigmatize officers and police agencies, stir emotions, and polarize minority communities and law enforcement (Scoville, 2000; Thomann, 2001). 
Emotions and debates are further fueled by the numerous definitions of racial profiling and reasons for profiling. Racial profiling, defined as law enforcement activities that are initiated solely on the basis of race, is a narrow definition and does not include racially biased activities that are termed reasonable suspicion or probable cause and does not consider the use (impact) of police discretion (Fridell et al., 2001). The term racially biased policing is more encompassing to mean "when law enforcement inappropriately considers race or ethnicity in deciding with whom and how to intervene in an enforcement capacity" (Fridell et al., 2001, p. 5) or "the act (intentioned or unintentional) of applying or incorporating personal, society or organizational biases and/or stereotypes in decision-making, police actions or the administration of justice" (National Organization of Black Law Enforcement Executives [NOBLE], 2001, p. 4). NOBLE (2001) viewed racial profiling as a symptom of biased-based policing. Meeks (2000) defined racial profiling as "the tactic of stopping someone only because of the color of his or her skin and a fleeting suspicion that the person is engaging in criminal behavior" (p. 4).

When discussing racial profiling and law enforcement, some individuals believe hiring more Black officers will reduce the incidents of racial profiling. Merely hiring Black officers without addressing the institutionalization of race and racial profiling, however, will not eliminate racial profiling.

The existing hierarchy disciplines newcomers, requiring them to exercise power in the same old ways and play by the same old rules in order to survive... This uncomfortable fact creates strong incentives for minority officers to deny, to rationalize, or to be willingly blind to [racial profiling] the role of law enforcement in creating a racial undercaste" (Alexander, 2012, p. 250). 
Regardless of the officer's race, he or she can commit the act of racial profiling. Targeting individuals based on color can occur even if the officer is Black.

Wilkins and Meek (2008) analyzed a sample size of 96 traffic forms from 168,901 stop forms compiled between January 1, 2000, and December 31, 2000, by the San Diego Police Department. These 96 stops (dependent variable) represented the disparate number of Black drivers stopped in the division (difference between the percentage of stops in the division involving a Black driver and the percentage of the Black driving-age population in the division; Wilkins \& Meek, 2008). The independent variable was the percentage of Black sworn officers in each division in 2000.

Wilkins and Meek (2008) controlled for median income of the division, racial composition of the population, and monthly overall crime rate of the city. Using a least squares regression, they tested the relationship between racial profiling and the presence of minority officers. Wilkins and Meek's test revealed that

the pressure to conform to the organization or to achieve the goals of the organization weighs heavily on black officers and affects their attitudes and ultimately their behavior ... organizational socialization can hinder the translation of passive representation into active representation. (p. 8)

"People do not enter the police because they are racist; rather, they acquire racial prejudice through a process of professional socialization" (Zauberman \& Le'vy, 2003, p. 1065).

Wilkins and Williams (2008) reviewed literature in the areas of racial profiling, representative bureaucracy, and police socialization. They found racial profiling actually increased in the areas that employed Black police officers (Wilkins \& Williams, 2008). Representative bureaucracy theory addresses how the demographic characteristics of 
decision makers affect individuals that share their same demographic characteristics. The decision makers may have either passive representation or active representation. Passive representation occurs when individuals representing various demographics are simply present. If these individuals would critically review their organizations, note issues of disparate impact, and actively seek to remedy the issues, they would be viewed as having active representation.

Wilkins and Williams (2008) hypothesized that "organizational socialization can hinder the link between passive and active representation" (p. 1). The law enforcement socialization process formally begins with the police academy. The socialization process continues with the field training officers (FTOs) training, the probationary period, and the remainder of their careers. During the 22-week police academy, recruits must prove proficiency in academic and physical areas of competency, including firearms and driving (Broward College, Institute of Public Saftety, n.d.).

Upon graduation, the recruits report to their respective agencies for agency specific training. They are, then, assigned to FTOs. FTOs are veteran officers who have received additional training regarding the training and evaluation of new hires. FTOs evaluate the recruits' performances and provide them with a solid foundation for their law enforcement careers. Once the recruits successfully complete the FTO program, they begin working as solo officers. As solo officers, the individuals use all information they have gained to perform their duties. The predominately White male law enforcement community is sworn to serve and protect. In this capacity and role of protector, solo officers work in partnership with the public as they utilize a combination of their training and lived experiences to serve the public, prevent crime, and apprehend criminals. All of 
these experiences are combined with training as officers develop profiles of suspected serial rapists, killers, and terrorists (Fridell et al, 2001).

"Whites have often failed to acknowledge the widespread mistreatment of black people, especially black men, by law enforcement agencies" (West, 2001, p. 8). This lack of acknowledgement can be caused by numerous factors (e.g., the ever-changing definition of race, racial profiling, and stereotypes of Black men). Law enforcement officers rely on their training and experiences as they serve and protect. Their decisions result in Black men being statistically stopped, searched, arrested, and imprisoned more than other members of society (Harrison, Minton, \& Sabol, 2007; U.S. Census Bureau, 2000).

Discussions of racial profiling increased in visibility after the 1999 revelation that the New Jersey State Police had an explicit policy of racial profiling (Alter, 2001). These discussions revealed that racial profiling is sometimes seen as an effective law enforcement tool and as a way for individuals to make informed decisions regarding other groups of individuals (Fridell et. al., 2001). However, the effects of racial profiling have resulted in African American men being underrepresented in almost all aspects of American society, other than as inmates in the criminal justice system. After the September 11, 2001, terrorist attack by Middle Eastern Muslims, discussions and allegations of racial profiling extended to Middle Eastern and Muslim individuals (ACLU, 2004).

Racial profiling allows existing human resource policies and practices to maintain the social order and demographics of the respective organizations, particularly law enforcement. Pretext traffic stops of visible minorities based on the color of their skin is 
the root of racial profiling (Abramovsky \& Edelstein, 2000; Mentzer, 2002). Pretext stops "occur when police officers ostensibly stop motorists for traffic violations but are in fact motivated by the desire to obtain evidence of other crimes" (Abramovsky \& Edelstein, 2000, p. 726). These stops, resultant citations, and arrests reduce Black males' employability and socioeconomic status and cause Black men to view law enforcement negatively. The negative view of law enforcement diminishes Black males' desire to explore law enforcement careers and contributes to the shortage of Black males in law enforcement (“How Your Driving Record,” 2008; Lynch \& Sabol, 2004; The Unofficial Division of Motor Vehicles Guide, n.d.).

Profiling is a viable law enforcement tactic, whereas racial profiling is illegal and racist and stigmatizes officers and police agencies while also polarizing communities of color and law enforcement (Scoville, 2000; Thomann, 2001). Consciously and unconsciously, police officers protect their own class and neighborhood interests. In some instances, this protection results in racially profiling individuals. The awareness Black men have of racial profiling, regardless of their jobs, socioeconomic status, or education, causes Black men to develop a negative attitude toward police officers and the law enforcement profession (Newport, 1999).

Racial profiling has contributed to Black men being underrepresented in the law enforcement profession. Law enforcement is largely comprised of White men, and its culture reflects their lived experiences. They are sworn to interpret and uphold laws that have been passed and implemented by institutions. Although it is impossible to enforce all laws, race becomes a factor as law enforcement officers develop criminal profiles and use their experience and training to enforce the laws they elect to enforce. This 
enforcement can negatively impact Black males' education, employment, and socioeconomic status. Well-intentioned law enforcement officers could follow institutionalized laws and cultural practices, consciously or unconsciously, that result in individuals of color being targeted merely by the color of their skin and a fleeting suspicion that they are engaged in or will be engaged in criminal activity (Meeks, 2000).

\section{Police Contacts and Racial Profiling Studies}

This section covers police contacts and racial profiling studies published by the USDOJ and NOBLE, respectively. USDOJ is the Executive branch of the U.S. government that is responsible for law enforcement and impartial administration of justice in the United States (USDOJ, n.d.). NOBLE (2001) is an organization of Black law enforcement officers who have risen to management levels within their respective agencies. The purposes of the organization are as follows:

1. To unify Black law enforcement officers at executive and command levels.

2. To conduct research in relevant areas of law enforcement.

3. To establish linkages and liaisons with organizations of similar concern.

4. To evaluate and recommend legislation relating to the criminal justice process.

5. To establish effective means and strategies for dealing with racism in the field of criminal justice.

6. To develop communication techniques for sensitizing police executives, police officers, institutions, and agencies in the criminal justice system to the problems of the Black community.

7. To develop mechanisms that will facilitate the exchange of information among Black police executives. 
8. To articulate the concerns of Black executives in law enforcement.

Utilizing information and analyses from these two organizations provides a broad perspective of racial profiling. USDOJ provides the perspective of the overall law enforcement community, whereas NOBLE provides the perspective of Black law enforcement officers and executives.

USDOJ (as cited in USDOJ, OJP, BJS, 2002) published the findings from the 2002 national survey of contacts between police and the public. The survey revealed that nearly 45.3 million U.S. residents, age 16 or older, had at least one direct face-to-face contact with a police officer. Nearly $60 \%$ of the contacts were police initiated compared to approximately $41 \%$ of the contacts being initiated by someone other than the police.

The research indicated that the total U.S. population in 2002 was $73.0 \%$ White, $11.9 \%$ Black, $11.1 \%$ Hispanic, and $4.0 \%$ other races. The majority of the police contacts were a result of traffic infractions. Most research surrounding racial profiling is concentrated in the area of traffic stops, only one area of law enforcement in which race has been identified as a factor when Blacks have contact with the criminal justice system. The USDOJ, OJP, BJS (2002) research also noted that Whites had contact with law enforcement $15.0 \%$ more than Blacks and $26.0 \%$ more than Hispanics. The likelihood of White, Black, or Hispanic individuals being pulled over for a traffic offense is nearly the same $(8.7 \%, 9.1 \%$ and $8.6 \%$, respectively).

Once the individuals were pulled over, White drivers received $27.4 \%$ of the nonpunitive traffic warnings compared to Blacks who received $18.3 \%$ of the traffic warnings. Blacks represented $11.0 \%$ of the individuals stopped for traffic violations and $23.8 \%$ of the arrests. Whites represented $76.5 \%$ of the individuals stopped for traffic violations and 
$58.0 \%$ of the arrests. Reasons for the arrests included, but were not limited to, the following: failing sobriety tests, using drugs or carrying an illegal weapon, having warrants, or assaulting a police officer (USDOJ, OJP, BJS, 2002). Blacks also represented the largest portion of handcuffing and searching of driver and vehicle although they were not the largest portion of the driving community.

In 2002, the Community Oriented Policing Services (COPS) of the U.S. Department of Justice acknowledged that the majority of Blacks believed that racial profiling existed and that they had been victims of racial profiling (McMahon et al., 2002). The CNA Corporation, with the assistance of NOBLE and COPS, identified cities to be used in their study. The research was designed to address racial profiling: "Is there evidence of racial profiling in making traffic stops or in conducting searches?" (McMahon et al., 2002, p. 27). The criteria for selecting the cities included the following:

Geographic diversity, potential for union and community involvement, having a data collection process getting underway or in progress (but not yet completed), not being under a court order mandating data collection, willingness to commit to sending department, union, and a community representative to two national conferences. (McMahon et al., 2002, p. 18)

McMahon et al. (2002) identified 24 published reports containing more than 3 million records of police stops from more than 700 federal, state, and local law enforcement agencies. McMahon et al. noted differences in the methodology between various reports and the base data of each study. Some of the base data was obtained from a single municipality, whereas other data were obtained from a statewide police agency. The statistics from these reports were, then, compared to the racial characteristics of the 
motorists stopped or searched by police to the racial composition of the residents of the area.

Sixteen studies (67\%) analyzed traffic stops and searches. Four studies (17\%) collected data regarding the traffic stops and not the searches. Three studies (13\%) analyzed the searches but not the traffic stops that led to the searches. Every study utilized the race of the suspect in the study; however, how the race and ethnicity was determined and documented varied among the various agencies.

The race of the driver was largely determined based on the officer's perception. In some instances, Hispanics were considered a racial group and were excluded from being counted as Black or White.

In other instances, "unknown race" (McMahon et al., 2002, p. 35) was used, whereas some reports did not supply an answer for the racial category. "No two studies used the same exact design" (McMahon et al., 2002, p. 27). Table 1 summarizes the findings of McMahon et al.'s (2002) study as to whether there is evidence of racial profiling in making traffic stops or in conducting searches. 
Table 1

Evidence of Racial Profiling in Making Traffic Stops or in Conducting Searches

\begin{tabular}{lllc} 
Type of finding & Stops & Searches & Total \\
\hline Racial profiling & $4(16.6 \%)$ & $4(16.6 \%)$ & $8(16.6 \%)$ \\
No racial profiling & $9(37.5 \%)$ & $4(16.6 \%)$ & $13(27 \%)$ \\
Mixed evidence & $2(8.3 \%)$ & $3(12.5 \%)$ & $5(10.4 \%)$ \\
Cannot determine & $3(12.5 \%)$ & $3(12.5 \%)$ & $6(12.5 \%)$ \\
No statement & $3(12.5 \%)$ & $3(12.5 \%)$ & $6(12.5 \%)$ \\
Issue not addressed & $3(12.5 \%)$ & $6(25 \%)$ & $9(18.8 \%)$
\end{tabular}

According to this research, racial profiling existed in $16.6 \%$ of traffic stops (New Jersey, New York City, Richmond, and St. Paul), 16.6\% of searches (Maryland, New Jersey, St. Paul, and Washington state), with mixed evidence of racial profiling in $8.3 \%$ of traffic stops (Missouri and North Carolina), and 12.5\% of searches (Maryland, Missouri, and North Carolina). No racial profiling was found for traffic stops $(37.5 \%)$ in California, Connecticut, Florida, Lansing, Oakland, Sacramento, San Jose, Texas, and Washington State. No racial profiling was found for searches (16.6\%) in Connecticut, Lansing, Richmond, and Sacramento.

\section{Employment and Career Development in Law Enforcement}

This section provides a discussion of the law enforcement hiring process, career development, a developmental tool in law enforcement, Super $(1980,1990)$, career development and employment, and Black male career exploration and development. 


\section{Law Enforcement Hiring Process}

The hiring process is political and can legitimate and perpetuate a social hierarchy (Young, 1990). Florida Department of Law Enforcement (FDLE) sets minimum standards for certified law enforcement, corrections, and corrections probationary officers in the state of Florida.

Minimum standards for law enforcement officers include the following: Officers must (a) be a U.S. citizen, (b) not have been convicted of any felony or misdemeanor involving perjury or false statements, (c) never have been dishonorably discharged from the military, (d) have good moral character, and (e) have successfully completed a background investigation (FDLE, n.d.). The background investigation includes a review of the applicant's driving history, the focus of many racial profiling claims, and other subjective areas of investigation (e.g., reference checks, employment history checks, and education checks). During this hiring process, whether it is the actions of a law enforcement officer who racially profiled a Black man, a biased test (e.g., written or swimming), a biased oral board, or a biased background investigator or management, a Black man would need to prove that individuals acted purposefully and intentionally to create a disparate employment treatment (Wang, 2006) to legitimate an U.S. EEOC or discrimination claim utilizing Title VII of the Civil Rights Act of 1964. All of these actions impact career development.

\section{Career Development-A Developmental Tool in Law Enforcement}

Career development is a process requiring individuals and organizations to create a partnership that enhances employees' knowledge, skills, competencies, and attitudes required for their current and future job assignments. Career development is a quintessential developmental activity of an organization allowing for improved individual proficiencies while concurrently enhancing 
organizational renewal and improving performance capacity. (Gilley et al., 2002, p. 94)

Career development has five stages: (a) employee orientation, (b) individual selfanalysis, (c) reality check, (d) options stage, and (e) career goals (Gilley et al., 2002). Each stage has employee and organizational responsibilities. Employee orientation targets the newly hired employees. During this stage, individuals tend to focus on what they see and observe regarding demographics of new hires, overall organization, and nonverbal communication. These observations are compared to what the various representatives are stating. In some instances, these two forms of communication conflict. In the individual self-analysis stage, the individual analyzes his or her career performance and opportunities, consciously or unconsciously, based upon others identified as role models (Bandura, 1977). These individuals may include coworkers, senior officers, supervisors, and managers. This analysis will assist the employee in choosing which career to explore. Career choice is based on an individual having options, being motivated to choose, and possessing the freedom to choose. It is this choice that begins one's career development (Osipow \& Littlejohn, 1995).

During the reality check, individuals begin to review critically how they are received in the organization and their chances of success within the organization (Gilley et al., 2002). This can include reviewing the various assignments and opportunities they have had compared to other employees. Perceived fairness of the experiences will shape their career decisions and lead to the next phase—options. Armed with information obtained in the reality check, the employee begins to analyze and explore options within and outside the organization (Super, 1980). Relationships with mentors, managers, and 
other co-workers also influence the decisions individuals make during this stage (Beard, 2005). This information and feedback will, then, assist the employee in forming aspirations and establishing career goals. "The social learning perspective of career development tends to raise many of the issues that are faced by ethnic minorities within the vocational context" (Osipow \& Littlejohn, 1995, p. 259).

As minorities go through their various life stages, they also go through identity stages. During the identity stages, minorities determine to what extent they will conform to mainstream societal norms at the expense of cultural norms or how they will balance the two (Osipow \& Littlejohn, 1995). The self-concept of Black men has two components - internal (self) and external (larger society) factors. Aspirations and goals of Black men must be contextualized considering their history, education, social, political, and economical experiences (Osipow \& Littlejohn, 1995).

\section{Super and Career Development and Employment}

Super began contributing to the evolving field of career development in 1939. Due to his contributions, a special issue of the Career Development Quarterly (Nevillo, 1997) was dedicated to the life-span, life-space theory of Super. An analysis of the articles revealed three common themes: (a) his impact on career development theory, research and application; (b) his usage of multiple disciplines to ensure that his theories were comprehensive; and (c) how he and his theories responded to change (Nevillo, 1997).

Super (1980) understood that, as individuals go through various stages during their lives, life span, issues, context, and evolution of the issues also change. All of these changes interact as individuals progress through developmental stages and multiple 
career decisions. In an effort to capture the contexts and evolution of issues, Super (1980) incorporated sociology, political science, and economics literature to inform and continue the evolution of his work.

When analyzing employment practices, one will discover that the employer relies on relationships of existing employees to recruit new workers. These relationships such as family, friends, churches, and community organizations are overwhelmingly race and ethnic specific. These events further intensify the racial and ethnic hiring patterns, promotions, and assignments within an organization (Park, 1999).

We live in a society that nurtures and maintains stereotypes: we are all bombarded daily, for instance, with the portrayal of the young Black male as monster. When we see a group of young Black men, we lock our car doors, cross to the other side of the street, or clutch our handbags. (Delpit, 1995, p. xiii)

Most research and discussions surrounding discretion center on the negative discretionary actions: which driver or car to stop and cite for speeding, who or what actions create a fear of crime and cause citizens to call the police, or which equally qualified applicant an employer will reject. These negative discretionary actions marginalize the victims. The opposite, positive discretionary action of these scenarios is one speeder (or more) does not get stopped and ticketed, one individual does not have a possible negative contact with law enforcement, and someone obtains employment. Therefore, one singular discretionary act marginalizes one individual or group while also privileging another (Rocco \& West, 1998). Individuals who benefit from this privilege tend to defend the current process and may even justify why law enforcement officers should have discretion.

First, Freudian theory states that the human mind defends itself against the discomfort of guilt by denying or refusing to recognize those ideas, wishes, and 
beliefs that conflict with what the individual has learned is good or right. Second, the theory of cognitive psychology states that the culture-including, for example, the media and an individual's parents, peers, and authority figures - transmits certain beliefs and preferences. The individual is unaware, for example, that the ubiquitous presence of a cultural stereotype has influenced her perception that blacks are lazy or unintelligent (and/or criminal). (Lawrence, 1995, p. 237)

An analysis of the relationships and perspectives that influence career exploration of Black men is a weakness in existing career exploration research. (Minority recruitment in criminal justice: Targeting Alaska Natives p. 260 Diversity Mag and Kunju survival strategies). "Research approaches which are aimed at developing our understanding of psychotherapy [racial profiling] which fail to address the client's [victim's] interpretation [voice] of events will only provide a limited picture of its true nature" (Gordon, 2000, p. 1).

The personal day-to-day experiences, accomplishments, and struggles of diverse peoples have meaning and importance ... it is also important to appreciate that, as people share their personal story, similarities and differences between the teller's world and that of the listener are discovered. Such an approach enables people to make connections between adverse conditions in the fabric in society and the problems experienced by them in everyday life, and through action, to overcome those conditions. (Colon et al., 2001, p. 241)

Phillips et al. (2001) identified three themes that describe how others influence career exploration: action of others, the recruitment of others, and pushing others away. Phillips et al. stated,

Career exploration is a process of acquiring self-knowledge and awareness of one's skills, abilities, interests, values, goals, and dreams, and career knowledge (information about the world of work and the skill and education requirements, conditions, and outlook of specific jobs). (p. 198)

Exploration varies with each individual's polyrhythmic realities and life

experience within a sociocultural, political, and historical context (Sheared, 1999).

Muharrar (1998) stated, 
There is a need for a broader understanding of "racial profiling." As a general concept and not just a specific police policy, racial profiling may best be understood as a politically acceptable and very American practice of defining a social problem in "blackface" - i.e., in racial terms - through indirect association. Once portrayed in blackface, the "blackness" of the problem encourages suspicion, polarizing antagonism, and typically leads to the targeting of the racial group for punitive (public-policy) action. (para. 3)

Obtaining a police department that mirrors the community it serves is only one small step toward eliminating racial profiling (Zauberman \& Le’vy, 2003). Racial profiling pits the personal day-to-day struggles of law enforcement officers against the personal day-to-day experiences of Black men. Black families have strong kinship relationships that extend beyond the nuclear family or blood relatives (Diller, 2004; Sue \& Sue, 2003). Utilizing a relational context to examine the essence of racial profiling and how career decisions are made by Black men will value the importance of others in facilitating or hindering decisions (Phillips et al., 2001). This is nearly synonymous with institutional racism - “a set of policies, priorities, and accepted normative patterns designed to subjugate, oppress and force dependence of individuals and groups on a larger society" (Sue \& Sue, 2003, p. 71). The invisible veil recognizes that everyone is a victim of their culture, we all have been exposed to various cultural lessons, all have polyrhythmic realities (Sheared, 1999), or lived experiences.

\section{Black Males' Career Exploration and Development}

Dialogue between Black men and law enforcement HRD professionals as equally knowing subjects that includes the real, concrete context of facts and the social reality in which both parties exist is necessary to obtain liberation (Freire, 1970). This liberation will facilitate the transformation of racial profiling and shape Black males' law enforcement career exploration. 
The participation of Black men in the labor force is lower in counties characterized by the removal of large numbers of Black men through incarceration and "tainting" them with a prison record .... effects could be caused by racial profiling, where all black males are tainted regardless of their prison experience. (Lynch \& Sabol, 2004, p. 279)

Black males' career exploration is based on the following relationships: management demonstrating a commitment to diversity, Black males' inclusion in informal networking channels, recruiter prejudices and biases, Black males' lived experiences, Black males' law enforcement officer role models, and early identification and guidance (Karunanayake \& Nauta, 2004; Shusta, Levine, Harris, \& Wong, 2002). Fathers and male role models are the most influential relationships in Black males' career decisions (Chung, Baskin, \& Case, 1999). Unfortunately, many of the Black male role models are in prison, have had negative encounters with law enforcement, or are employed in careers other than law enforcement. Successful Black men in law enforcement are not widely known. Some notable Black men are Charles Moose, retired Chief of Police of Montgomery County, Maryland, during the Beltway sniper attacks of October 2002; Anthony Kevin “Tony” Dungy, the first Black National Football League coach to win a Super Bowl on February 4, 2007; Russell Wendell Simmons, media and fashion entrepreneur; Dr. Benjamin Carson, Director, Division of Pediatric Neurosurgery; and Barack Hussein Obama II, the first Black President of the United States.

The influence that these individuals and other role models have on Black men can promote or hinder Black males' decisions to explore law enforcement as a career option. If the role model believes law enforcement will provide an opportunity for the Black man to succeed and is a rewarding career, more Black men may explore law enforcement as a career option. However, if Black male role models believe that racism exists within the 
law enforcement ranks, racial profiling is an issue, and Black men should seek other careers, Black men may be reluctant to explore law enforcement as a career option.

\section{Black Men-More Than a Mere Racial Profile}

Education researchers, psychologists, criminologists, sociologists and economists have tried keeping the study of Black males segmented within distinctive academic disciplines ... [however] it is virtually impossible to isolate and study one phenomena, [such as racial profiling and career exploration] without considering the fact that Black males are experiencing difficulties in all aspects of society. (Boehm-Hill, 1993, p. 35)

Black men have routinely been defined by others via the media and various stereotypes. These stereotypes range from the proverbial athlete stereotype of tall or physically fit Black men with pants hanging low, loud music, and cars with 22-inch rims. Each stereotype can serve as a self-fulfilling prophecy. When we define Black men, our definition must encompass the full range of skin color and lived experiences to obtain the essence of being a Black man. Black men range in skin color from the light and fair complexion of Supreme Court Judge, Thurgood Marshall, and jazz great, Cab Calloway, to the dark complexion of Wesley Snipes. As Black men are defined, cultural and ethnic attributes associated with being Black must be identified. Identifying these attributes and cultural norms (e.g., arts, language, traditions, beliefs, and style) will assist in determining who is culturally and politically classified as a Black man.

The cultural and political classification of Black men is a result of the high concentration of Black men residing in, working in, or visiting the urban and inner city. The urban and inner city is densely populated and contains images of both extremes of the socioeconomic stratus: wealth and poverty (Martin, 2004). "The city embodies immorality, disorder, crime, deviance and danger" (Young, 1990, p. 227). In this 
environment, Black men learn to develop a swagger, air of confidence, or toughness. Black men's swagger is portrayed by their confident walk and disregard for the presence of others while they discuss intimate details of their lives as they attempt to survive (Anderson, 1990). Citizens and police officers may associate this swagger with socially deviant behavior and utilize their discretion to determine if this visual display of manhood identifies someone who is going to commit a crime or has committed a crime.

Given the history of police harassment and brutality, Black men view police officers as a source of possible danger, if not injury. As these Black men explore career options, they encounter a web of institutional power structures. The institutional structure is composed of policies and procedures that are interpreted by individuals as they perform their jobs. Institutional power occurs structurally on multiple levels and subordinates one population while privileging another (McIntosh, 2004; Rocco \& West, 1998; Wright, 2003). Subordination, based on skin color, contributes to stereotypes and allows the concrete discriminatory effects of racial profiling (e.g., citations and arrests) to circumvent Title VII of the Civil Rights Act of 1964 (as cited in Scoville, 2000) and, thus, marginalize Black men. Blacks who have not committed crimes develop a deepseated rage when treated as though they will commit a crime or have committed a crime based merely on their skin color (Cose, 1995).

The Eurocentric (White culture) world view values competition, effort optimism, and individualism. Competition encompasses an emphasis on social comparisons and a focus on winning. Similarly, effort optimism encompasses a quest to succeed and the importance of sweat and sacrifice. Finally, individualism encompasses a focus on 
individual achievement and the importance of the independence of thought and action (Boykin, as cited in Scott, 2003).

The Afrocentric world view (Black culture) values togetherness or a collective mindset. This mindset assists in the formation of an individual's self-concept. Whites form their self-concepts based on their individualism and how they view themselves. Blacks form their self-concepts based not only on their individualism and how they view themselves but also on their knowledge of how others view them. It is this self-concept that will ultimately be used to determine what career an individual explores (DuBois, 1995; Freire, 1970, 2000).

Minorities, then, would believe that inequitable, unjust and differential treatment in employment practices, the workforce, and the work environment are not the result of their incompetencies, but the result of discrimination and prejudice of the larger society. The onus for change however rests in their (minorities') hands. (Osigow \& Littlejohn, 1995, p. 258)

An individual's world view influences his or her self-concept. World views refer to group members' values, attitudes, and beliefs and how they perceive, interpret, and respond to incidents (Osigow \& Littlejohn, 1995).

Scott (2003) explored how cultural attributes distinctive of Black culture (e.g., communalism, affect, and spirituality) influence Black youth as they cope with perceived discrimination. During the study, Scott utilized a convenience sample of 120 Black youth (69 females and 51 males), ages 14 to 18 , from private, religious-oriented high schools in Alabama and three urban public high schools in Ohio. Results indicated that "communalism from an African-centered perspective encompasses (a) an awareness of the interdependence of people, (b) a social orientation, and (c) feelings of duty to one's social group" (Scott, 2003, p. 237). Additionally, "affect [was] suggested to encompass 
(a) the integration of feelings with thoughts, (b) the importance of emotional

expressiveness, (c) the value of affective information, and (d) particular sensitivity to the emotional cues of others" (Scott, 2003, p. 240).

Black men are keenly aware that they are viewed with suspicion and, due to racial profiling, may not meet the minimum hiring standards for law enforcement. They are additionally aware that, if they meet the minimum hiring standards, they will have a difficult task of passing the numerous subjective steps in the hiring process. This subjectivity will continue throughout their careers (Bolton \& Feagin, 2004). Therefore, law enforcement agencies should critically review their staffing shortages and the reasons Black men are not exploring the rewards of a law enforcement career (Scholarios, Lockyer, \& Johnson, 2003).

Even those herculean efforts we hail as successful will produce no more than temporary 'peaks of progress,' short-lived victories that slide into irrelevance as racial patterns adapt in ways that maintain White dominance. This is a hard-toaccept fact that all history verifies we must acknowledge it, not as a sign of submission, but as an act of ultimate defiance. (Bell, 1992, p. 12)

\section{Black Males' Perspectives-The Sounds of Silence}

If you make a man feel that he is inferior, you do not have to compel him to accept an inferior status, for he will seek it for himself. If you make a man think that he is justly an outcast, you do not have to order him to the back door. He will go without being told; and if there is no back door, his very nature will demand one. (Woodson, 1933, p. 84)

During Black males' life spans, they begin to develop perceptions of educational, employment, and economic barriers (Anderson, 1990; Dyson, 2004; Kunjufu, 2004). These perceptions are formulated based on first-hand experiences and experiences role models and mentors and others have shared with them. In many instances, these shared 
experiences confirm research findings that indicate Black men have lower educational attainment and have a higher rate of unemployment than their White counterparts.

Most racially, ethnically, or linguistically diverse schools share three common characteristics: the majority of students come from low income families, students' academic performance on standardized tests typically fall below state and national norms, and student mobility rates and absenteeism are high. (Martin, 2004, p. 11)

This phenomenon has a tremendous impact on an individual's employability.

Due to largely segregated education that marginalized individuals receive, scoring low on standardized tests could have a negative impact on their employability and options for continued learning. Statistically, these marginalized individuals will not perform as well on law enforcement entrance, academy, or certification-written examinations. This poor performance will reduce their employability and chances for promotion.

Without jobs or incentives to be productive citizens, Black men become even more prone toward criminality, drugs, and alcoholism (West, 1993). As organizations take stride to address underrepresented Black men, a "deeper issue is how much blame do we place on the perceived oppressor and how much do we place on ourselves; human beings always want to exonerate themselves from responsibility and place the blame elsewhere" (Kunjufu, 2004, p. 22). Once Black men begin to take responsibility for their representation within the law enforcement profession, they may begin to explore the career field.

"I learned as a child that to be 'safe,' it was important to recognize the power of Whiteness, even to fear it, and to avoid encounter" (hooks, 2002, p. 23). Racial profiling and other discriminatory acts can cause Black men to lose hope and develop feelings of despair and low self-esteem (nihilism), which is more harmful to Black men than the 
actual acts (West, 2001). "Nihilism is ... the lived experience of coping with a life of horrifying meaninglessness, hopelessness, and (most important) lovelessness" (West, 2001, p. 22). Even when Black men have self-respect, self-respect in and of itself will not resolve the complex politicized issues based on race. Therefore, Black men must address issues of self-respect while also critically analyzing the systemic and institutionalized causes of Black male stagnation and reduced employability.

"Black law enforcement officers regularly report that many white police officials and officers see them more or less as intruders into white networks and comfort zones" (Bolton \& Feagin, 2004, p. 35). This unwelcome intrusion creates tension within the profession and hinders relationships necessary for recruitment and retention of Blacks. Some Blacks are relegated into the margins of the profession, whereas other Blacks may seek safety by moving into the margins, seeking invisibility and solace. These margins effectively reduce Blacks' full participation in law enforcement operations, decisions, promotions, and benefits.

In an effort to obtain the perspective of Black high school students' perceptions of their own academic identities, Howard (2003) selected 10 male and 10 female Black students from two urban high schools in ninth to 12th grades in the western and midwestern areas of the United States to participate in the study. "Adolescents become increasingly aware of their identities along racial, gender, and academic lines as they enter high school" (Howard, 2003, p. 7). As this awareness increases, adolescents begin to explore various career options by speaking with family members, friends, and guidance counselors to gain insight into various career options. This insight, combined with the likelihood of success, based on race, socioeconomic status, and academic 
performance is critical in identity formation (Howard, 2003). Three themes were noted in this research: "the role of parents, the influence of teachers and counselors, and the overall interest in attending college" (Howard, 2003, p. 8). When individuals perceived a hostile or non-caring environment, they became disruptive or withdrawn (Howard, 2003). This can be paralleled to the influence of racial profiling by law enforcement officers and Black males' overall interest in becoming law enforcement officers.

The fact is that, despite what we designate as progress wrought through struggle over many generations, we remain what we were in the beginning, a dark and foreign presence, always the designated other. Black and brown individuals are often tolerated in good times, despised when things go wrong, and scapegoated and sacrificed to facilitate the resolution of political differences or relieve economic adversity (Bell, 1992). 


\section{CHAPTER III}

\section{METHOD}

This chapter begins with the purpose of the study and the research questions repeated from Chapter 1. The phenomenological framework is discussed followed by the researcher's autobiography and assumptions related to the study. Next, sampling strategies and procedures for data collection and data analysis are described. Data management and integrity measures for the study are also discussed.

\section{Purpose of the Study}

The purpose of this phenomenological study was to explore Black male law enforcement officers' perspectives of how racial profiling shaped their decisions to explore and commit to a law enforcement career. This study provided insights into the intersection of racial profiling and career exploration.

\section{Research Questions}

The primary research question was, What are Black male law enforcement officers' perspectives of how racial profiling shaped their decisions to explore and commit to a law enforcement career? The subsidiary research questions were

1. How do Black male law enforcement officers define racial profiling?

2. What role has racial profiling played in Black male law enforcement officers' career exploration?

3. What career adaptive mechanisms do Black male law enforcement officers believe enhance their integration into law enforcement?

4. How has racial profiling influenced Black male law enforcement officers' career decision making process within the organization? 


\section{Phenomenological Framework}

"Qualitative techniques allow researchers to share in the understandings and perceptions of others and to explore how people structure and give meaning to their daily lives" (Berg, 2001, p. 7). Phenomenology, as a qualitative research method, seeks to identify the essence, structure, and reality of human experiences concerning a phenomenon (Creswell, 2003; Merriam, 2002). The essence of one's experience is "the essential, invariant structure or central underlying meaning” (Schram, 2003, p. 71). These meanings are socially constructed based on the geographical and historical contexts of individuals (Gibson \& Hanes, 2003). These contexts influence individuals' perceptions and, thus, their realities. Phenomenological researchers are interested in understanding the essence or meanings of an experience through individuals' understandings of their reality. The phenomenon of interest in this study was Black male law enforcement officers' perspectives of how racial profiling shaped their decisions to choose law enforcement as a career option.

\section{Researcher's Autobiography and Assumptions}

This section begins with the researcher's autobiography, which describes how the researcher's lived experiences influenced his decision to explore and commit to law enforcement as a career. Next, the researcher's assumptions of Black male law enforcement officers' perspectives of how racial profiling shaped their decision to choose law enforcement as a career are discussed.

\section{Autobiography}

Law enforcement was neither my initial career nor on my list of possible careers. I always explored the option of a career in business. This desire was fueled by my father 
who worked in the world of finance and by my exposure to others in the field of business and finance. However, today I represent a small minority: Black male law enforcement executives. I am a Major with a south Florida law enforcement agency that has over 500 law enforcement officers.

The issues of race, my self-concept, which includes my awareness of how others view me as a Black man have guided my career exploration. I have learned that no matter what we as Blacks (especially Black men) do, we need to be three times as good as the next person to receive the same opportunities. For instance, I just received a promotion to Major. However, this promotion occurred after the testing eligibility qualifications were lowered and allowed a less credentialed White Captain who had served as the Chief Executive Officer to take the exam. The exam was a panel interview, consisting of Department managers from within the city. His responsibilities as the Chief Executive Officer allowed him to network informally with the department managers within the city. Previously, the panel consisted of department managers from outside the city. Ultimately, he received a double promotion to Major and to Assistant Chief.

I had earned a bachelor's degree in business administration and a master's degree in public administration. The other candidate, a White male, recently earned his Bachelor's degree. Although this may have angered some, it fueled my desire to succeed and assist others in overcoming and understanding these motivational moments. Conversations with other coworkers, Black and White, revealed that this process gave the perception that the informal network is more valuable than education, especially for Black men, and reinforced the notion that Blacks must be three times as good to be given the same opportunities. 
A sentiment among Black men is that society will always view us as a $\mathrm{N}^{* * * * *}$. To paraphrase the joke, What do you call a Black man with an Ed.D.? N***** (Dyson, 2004; X, 1964). This sentiment and others like it serve as constant reminders to me of the significance of race in our society.

My earliest recollection of law enforcement was Officer Friendly, the police officer who came to our suburban middle class, predominately White elementary school in Wheaton, Maryland. He was warm, friendly, and comforting. My parents discussed issues involving law enforcement and the rules for my brother and me when we went shopping_- “DON'T TOUCH!!" anything, unless you are going to buy it (neither he nor I had money). My first negative law enforcement contact occurred when I was 8 years of age. I was with my mother in a grocery store in our predominantly White neighborhood. As we were waiting in the checkout line, an older White male security guard asked me to step out of the line and accused me of stealing gum. When I denied stealing anything, he patted me down and checked my pockets in front of the store. Prior to this incident, I had never had a negative contact with an authority figure, teacher, principal, or law enforcement officer. This was a tremendously embarrassing experience to my mother and me, which gave me a negative impression of law enforcement and further reinforced the negative impression my father had of law enforcement. My mother and I are still angered by memories of this incident.

This negative impression contributed to my hesitant exploration of law enforcement as a career option. Friends' and relatives' law enforcement stories also influenced my hesitancy. I never considered law enforcement as a career option. My choice of university, major, and profession and my desire for a doctoral degree were all 
influenced by my immediate and extended family—my village. My mother and father attended Florida A \& M University (FAMU). My mother is a retired educator, and my initial career in finance was influenced by my father's career as an auditor. A friend of my deceased cousin earned her pharmacy doctorate at age 23 and inspired me to pursue my doctoral degree.

While attending FAMU, I joined Alpha Phi Alpha Fraternity, Inc. (AФA), the first U.S. Black male Greek-lettered organization. These two institutions reinforced a sense of pride in my Blackness and provided an environment that demanded excellence and service to the community. After graduating from FAMU, I began my professional career in finance. While working in finance, a fraternity brother began to recruit me into law enforcement. As he informed me of all of the rewards of a law enforcement career (e.g., benefits and job security), I countered with the risks (e.g., dangerous and no Blacks in management). These discussions continued for approximately 5 years.

Due to my decreasing income from commission insurance sales, increasing number of conversations with my fraternity brother, and the remaining inherent dangers of a law enforcement career, I applied for a part-time law enforcement position. The requirements and job description for this position were the same as for a full-time law enforcement position with one major difference - no pay. Two Black individuals, one a detective and the other a civilian employee, learned of my intentions. I vividly remember the detective asking me, "Why you gonna do this for free? You might as well get paid!" The civilian employee was a part-time records clerk and worked full time with me in banking. She arranged for me to meet with the highest ranking Black, a Captain, to gain 
more insights into the agency and profession. Because of this network, I decided to pursue a full-time sworn law enforcement career.

Prior to submitting an application to a local law enforcement agency, one had to pass the Criminal Justice Basic Ability Test (CJBAT), a physical agility test, and a swim test. These exams were designed to determine if applicants met the minimum educational and physical standards necessary to be a law enforcement officer. Candidates' CJBAT scores are utilized to rank them on employment lists at the agencies to which they elect to apply (the higher the score, the higher your rank). Although my score on the CJBAT was $100 \%$ and I passed the physical agility exam, I failed the swim test. In order to pass the swim test, an individual had to swim 100 yards (any recognizable stroke other than the backstroke) and tread water for 5 minutes immediately thereafter. A disproportionate number of minorities failed and continue to fail this portion of the application process. Due to this failure, I could not submit my application. Once an individual overcomes this obstacle, there is no other reference to swimming during the academy or his or her career.

My failing the swim test and the disparate impact this exam has on Blacks seeking a career in law enforcement further fueled my desire to become a law enforcement officer. I began taking swimming lessons and practicing daily. I retook and failed this same exam twice. Then, I began testing with other agencies with different swim exams. After failing the swim test with one of the agencies, I eventually successfully completed the Fort Lauderdale Police Department's (FLPD, n.d.) required 50 yards in my clothing and treaded water for 3 minutes; I also successfully passed the written and physical agility examination. This allowed me to continue in their hiring process. 
Four of the five remaining phases were subjective: the oral board (panel interview), polygraph exam (lie detector), psychological exam, background investigation, and the medical exam and drug screen. The oral board consisted of a panel of three individuals: a human resource representative, a police Sergeant, and a police Captain. The scores of the oral board are subjective based on the board's impression of the candidates. There are no definitive, consistent characteristics used to determine the degree or score an individual receives in the various dimensions (i.e., command presence, initiative, communication, integrity, tolerance for stress, and judgment). The subjective oral board scores represent $60 \%$ of a candidate's score (FLPD, n.d.). The remaining $40 \%$ is the CJBAT score. However, if the candidate is a sworn officer, the oral board score comprises $100 \%$ of his or her overall score, and he or she is ranked with other certified applicants.

After I successfully passed the oral board, I was administered a polygraph examination. Although the results of polygraph examinations are not admissible in court, a failure of this portion of the process would have eliminated me from the hiring process. The polygraph examination consisted of being strapped to a chair having monitors attached to me as a polygraphist (polygraph detective) asked questions and as a machine measured my pulse, breathing, sweating, body movement, and other physiological reactions. The machine and polygraphist were intimidating. My first test results were deemed inconclusive regarding my usage of marijuana. The term inconclusive was confusing to me. I asked, "Do you mean you can't tell if I did or didn't use marijuana?" I have never used marijuana; therefore, this result caused me to question the subjectivity of this process further. As I spoke with other Blacks regarding the polygraph 
examination and questions regarding marijuana, many shared my same sentiments of intimidation and believed that the polygraphist did not believe they had little or no involvement with drugs.

As a result of my inconclusive rating, I was rescheduled for another polygraph exam to address the issue of drugs specifically. Realizing this exam could end my hiring process, I was very nervous. Upon arriving and meeting another older White male polygraphist, I became more nervous. Prior to being connected to the polygraph machine, we talked and reviewed my application just as before. However, during the conversation, we discovered we lived on the same street in Wheaton, Maryland, and attended the same elementary school, 15 years apart. He administered the exam, and I passed.

The next subjective stage of my hiring process was the psychological examination. The psychological examination was designed to measure my suitability for the job. During this exam, I responded to approximately 1,000 written questions and had an interview with White male psychologists. Although I passed this portion of the process, many others did not for various reasons. The next step in the hiring process was my background investigation, which I successfully completed. This portion of the hiring process focused on my driving history, arrest record, education, references, and other personal information. The last phase of my hiring process was the medical examination and drug screening. I successfully passed this phase and was hired.

The subjectivity of the process, discretion of the administrators, and absence of Blacks continued to reinforce the negative sentiment of law enforcement in the Black community. Upon reporting to human resources on the 1st day of work, there were four 
new law enforcement recruits; two of us were Black. Prior to our being hired, the agency was approximately $7 \%$ Black compared to a Black population of approximately $10 \%$.

Once in law enforcement, I learned about the amount of discretion law enforcement officers exercise when determining who to detain, to whom to issue citations, and to arrest. Discretion allows officers to take action and not be penalized for how the discretion was used. This discretion is two-way to detain, cite, arrest, or not to take any action. In order to utilize discretion, the individuals must determine or discriminate a difference between the individuals or situations based on their training and experience.

My knowledge of the impact of discretion in the hiring process and my interest in power and privilege fueled my desire to participate in and learn more of the hiring process. I am a Black male Major in a south Florida law enforcement agency with authorized staffing of approximately 510 sworn law enforcement personnel and a member of the NOBLE. I have served as the Administrative Captain with responsibility for the following units: Recruiting, Training, Background Investigations, Finance, Payroll, and Alarm. This assignment allowed me to network with human resource professionals and other law enforcement entities regarding hiring practices and policies. I have also served on numerous hiring oral board panels and promotional assessment centers throughout the state for positions up to and including Commander and participated in the restructuring of our hiring process and the updating of scenarios and questions for my agency's oral board. I was able to review critically this agency's policies and recommend changes to enhance the transparency of the hiring process. I have also been identified as a subject matter expert (SME) by the FDLE, the overseeing 
body for law enforcement in the state of Florida. As an SME, I have worked with other SMEs to update the curriculum for police recruits. I have also served on promotional assessment panels across the state of Florida for positions up to and including Commander, and I have also facilitated courses for police and civilian recruits and inservice training for this and other agencies.

As a result, I have participated in and supervised the entire hiring process of recruiting, polygraph (lie detector), application, oral board, psychological exams, medical exams, and background investigations. Any of these steps are subject to bias in some form and can impact an individual's chances of being hired. My participation allowed me to have members of the process critically reflect on the presence of bias.

I noticed that subtle bias occurs when background detectives write their summaries of the applicant's background. This bias could be unconscious or simply attributed to their training and experience and culture of the agency. An example of the summary is as follows: "The applicant claimed he or she had only one ticket" versus "The applicant stated he or she had only one ticket." I observed how the terms can slant the hiring decisions. I attempted to eliminate suggestive words in favor of more objective statements (e.g., said vs. claimed).

As a law enforcement officer, I have also had the opportunity to teach at various police academies and facilitate other law enforcement agencies' trainings. In this capacity, I have seen how the facilitators' lived experiences have impacted the students, new recruits, and veteran law enforcement officers. The students use the training and experiences of the facilitators as a basis for how they use discretion and enforce the law. One clichéd phrase often seen in police reports is, "Based on my training and 
experience." If this training and experience are consciously or unconsciously influenced by the facilitator's lived experiences, they could perpetuate issues such as racial profiling under the guise of serving and protecting the community.

\section{Assumptions}

This study was based on the following assumptions:

1. Black males' experiences of racial profiling are different based on their geographical and historical contexts.

2. Racial profiling plays a role in career exploration of Black men.

3. Racial profiling polarizes the perpetrators (law enforcement professionals) and victims (Black men).

4. Black men do not trust law enforcement officers.

\section{Sampling Strategies}

Black male law enforcement officers were selected for this study. These Black men were able to provide unique, valuable insights into the essence of racial profiling and issues regarding law enforcement organizational policies and practices.

Participants in this study met the following criteria (see Appendix B for Screening Questionnaire): (a) be a Black man, (b) be aware of racial profiling, and (c) have sworn law enforcement experience. Individuals were excluded if I had supervised them, if they had supervised me, or if we were employed by the same agency. These exclusions reduced the undue influence between the participants and me and, thus, increased the credibility of the study.

I obtained 17 participants for the study by notifying organizations, law enforcement professionals, and acquaintances of my intended research. I informed them 
of the criteria for participants and asked them for referrals to participate in my study. During my initial attempts to obtain participation, everyone commented on the relevance of the study.

A minimum sample size of 12 was reasonable to explore the phenomenon and purpose of this study. Patton (2002) suggested that qualitative sampling designs should specify minimum samples, rather than maximum samples, to account for emerging information or sample size inadequacies. Moreover, a minimum sample size of 12 is also consistent with phenomenological studies sample sizes of about six to 12 participants (Guest, Bunce, \& Johnson, 2006).

Criterion sampling, followed by snowball sampling, allowed me to identify individuals that met a predetermined characteristic and to be referred to other individuals who were able to provide significant information for my research (Patton, 2002). Snowballing added to my participants. Pseudonyms were given to the participants to protect their true identities. Maasai's recommendations allowed me to interview Barak and Jabari. A Black female Sergeant who served as my mentor referred me to Ghalib. I was referred to Kamal by a professional associate.

Many individuals agreed to participate in the study. However, five individuals who met the criteria and were in command and policy-making positions were unable to allocate time to participate in my research. During conversations with individuals who were unable to allocate time, they mentioned my research was needed; however, they were apprehensive to participate. Some mentioned the sensitive nature of the study and possible political consequences if they were identified as participating. I was initially most successful in locating individuals who were not in command and policy-making 
positions. My initial contacts allowed me to complete interviews with Kuumba, Jamal, Maasai, Kenji, Trey, Kunta, Isaac, and Chaka. After extended time delays and numerous follow-ups, I was able to interview Kwame, Kobe, Maalik, and Martin. Kenji, Trey, Kunta, Isaac, and I are fraternity brothers. Maalik, Kuumba, and I attend the same church. Kobe, Kwame, and I are in professional organizations together. I spoke with professional associates regarding my research. As a result, they referred me to Kamal. Maasai referred me to two of his law enforcement and childhood friends, Barak and Jabari. Obtaining participants for the study proved more difficult than expected, particularly with individuals in management positions.

The pool of potential participants in this study included Black men who may or may not have risen to the executive level in their respective organization. The participants also included individuals with experience at the city, state, and federal levels of law enforcement. This diversity allowed me to capture the essence of racial profiling and Black male law enforcement officers' career exploration and commitment from multiple levels of the profession. I initially targeted 15 participants for the study. However, after having scheduling conflicts with some individuals, they expressed an interest in providing their insight after I had concluded my 15 interviews. One of the individuals was Ghalib, and the other was Omari. Ghalib had recently retired from another agency and was referred to me via a coworker. I had originally contacted Omari; however, his schedule did not originally provide him time to be interviewed. He was also scheduled to retire within 2 months of our interview.

Both of these men had served in various command and policy-making experience, along with having over 20 years of law enforcement experience. Therefore, I had a total 
of 17 participants in this study. Kamal was retired, and Omari was approaching retirement. Maalik had also retired from law enforcement, and Trey had separated from law enforcement.

\section{Participant Demographics}

The sample for this study included 17 Black men who were aware of racial profiling and had sworn law enforcement experience (see Tables 2 and 3).

Table 2

Participant Demographics for Years in Law Enforcement

\begin{tabular}{lcccl}
\hline Pseudonym & Age & $\begin{array}{c}\text { Years in law } \\
\text { enforcement }\end{array}$ & $\begin{array}{c}\text { Experienced in } \\
\text { racial profiling }\end{array}$ & \multicolumn{1}{c}{$\begin{array}{c}\text { Highest rank } \\
\text { attained }\end{array}$} \\
\hline Ghalib & 61 & 30 & Yes & Sergeant \\
Omari & 52 & 29 & Yes & Major \\
Maalik & 54 & 29 & Yes & Sr. Special Agent \\
Isaac & 48 & 25 & Yes & Sergeant \\
Kamal & 47 & 22 & Yes & Deputy Chief of Police \\
Chaka & 44 & 20 & Yes & Lieutenant \\
Kobe & 42 & 20 & No & Captain \\
Kwame & 45 & 20 & Yes & Chief \\
Martin & 49 & 17 & Yes & Lieutenant \\
Trey & 45 & 15 & Yes & Officer \\
Kunta & 38 & 14 & Yes & Officer \\
Jamal & 31 & 9 & Yes & Officer \\
Jabari & 31 & 8 & Yes & Officer \\
Maasai & 33 & 7 & Yes & Officer \\
Barak & 31 & 5 & Yes & Officer \\
Kenji & 32 & 5 & Yes & Officer \\
Kuumba & 39 & 16 & Yes & Special Agent \\
& & & & \\
\hline
\end{tabular}


Table 3

Participant Demographics for Previous Employment

\begin{tabular}{|c|c|c|c|c|c|}
\hline Pseudonym & $\begin{array}{l}\text { Self-identified } \\
\text { as }\end{array}$ & $\begin{array}{c}\text { Previous } \\
\text { employment }\end{array}$ & $\begin{array}{l}\text { Entry level } \\
\text { education }\end{array}$ & $\begin{array}{c}\text { Current level } \\
\text { education }\end{array}$ & $\begin{array}{c}\text { Employment } \\
\text { status }\end{array}$ \\
\hline Kamal & Black & Military & Assoc. of Arts & 2 Master's & Retired \\
\hline Kobe & Black male & Corrections & High School & 2 Master's & Employed \\
\hline Kenji & Black male & Investigator & Bachelor's & Master's & Employed \\
\hline Martin & Black male & Military & College & Master's & Employed \\
\hline Omari & Black & Student & Bachelor's & Master's & Employed \\
\hline Trey & Black male & Student & Bachelor's & Master's & Separated \\
\hline Chaka & Black male & Corrections & Bachelor's & Bachelor's & Employed \\
\hline Jamal & Black male & Corrections & Bachelor's & Bachelor's & Employed \\
\hline Kunta & Black & Security & Bachelor's & Bachelor's & Employed \\
\hline Kwame & Black & Student & Bachelor's & Bachelor's & Employed \\
\hline Isaac & Black & Security & Assoc. of Art's & s Bachelor's & Employed \\
\hline Maalik & Black & Intern & Bachelor's & Bachelor's & Retired \\
\hline Maasai & Black male & Security & Bachelor's & Bachelor's & Employed \\
\hline Barak & Black & Security & High School & Assoc. of Arts & Employed \\
\hline Ghalib & Black & Corrections & High School & Assoc. of Arts & Retired \\
\hline Jabari & Black & Military & High School & College & Employed \\
\hline Kuumba & Black & Military & Bachelor's & Bachelor's & Employed \\
\hline
\end{tabular}




\section{Data Collection}

Data collection consists of the interview guide construction and interview administration.

\section{Interview Guide Construction}

The interview guide (see Appendix C) consists of issues and questions to uncover the essence of the phenomenon and to address the problem via a consistent, systematic process (Patton, 2002). The guide was used to encourage open-ended responses during my discussions with participants (Merriam, 2002). The main issues explored were racial profiling and law enforcement career exploration. Probes were used as necessary to gain clarity, depth, and the essence of the participants' responses to the issues and questions (Patton, 2002).

First, the interview guide was reviewed by my dissertation peer group, which consisted of approximately four doctoral students and candidates. Feedback from this review was used to improve the interview guide. Second, three Black male law enforcement officers reviewed the interview guide and provided feedback. Then, I responded to each interview question. Each one of these steps provided feedback on the clarity of the questions, the organization of the interview guide, and the relevance to the problem statement.

\section{Interview Administration}

Before interviewing the participants, I informed them that the purpose of the study was to understand their perspectives on how racial profiling shaped their decisions to explore and commit to a law enforcement career. Participants were asked to allocate approximately 2 hours for the interview; however, the length of the interviews varied. 
Interviews were conducted face-to-face at quiet locations, free from distractions. Due to the geographic location of Kamal, a face-to-face interview was not possible. Therefore, his interview was conducted via telephone. Interviews were recorded with a digital voice recorder and a backup cassette tape recorder. Recorded interviews were transcribed verbatim by a transcriber. I checked each transcript for accuracy by listening to the audiotapes while reading the transcripts (Merriam, 1998).

Each participant signed two informed consent release forms that were approved by Florida International University Institutional Review Board (see Appendix D). The participants kept a copy, and I kept the second copy.

\section{Data Analysis}

Data were analyzed using (a) inductive analysis, (b) deductive analysis, and (c) comparative analysis. Inductive analysis involved searching for meaning in the data to discover what patterns, themes, and categories emerged (Patton, 2002). This was in keeping with searching for the essence of a phenomenon. Deductive analysis is a "confirmatory stage of qualitative analysis ... [to test and affirm] the authenticity and appropriateness of the inductive ... analysis" (Patton, 2002, p. 454). As the first step in deductive analysis, a rubric of a priori codes based on Super's (1990) archway theory was used as themes (see Appendix E). In the second step, I searched the transcripts and identified patterns, themes, or categories that provided evidence of the a priori codes.

Comparative analysis involved comparing and contrasting the findings from the inductive and deductive analyses to identify patterns and to answer the research questions (Strauss \& Corbin, 1998). Then, I generated reports of the identified codes that were used during the thematic analysis. The coding reports were analyzed within and between 
codes to identify patterns, similarities, and differences within and between the reports and to generate themes. The themes from the inductive analysis were compared to the a priori codes to check for similarities and differences. The similarities and differences were illustrated using Super's (1990) archway model. Upon completion, the similarities and differences were compared to the literature reviewed for Chapter 2. This comparative analysis improved rigor and thoroughness in the study.

\section{Data Management}

The Florida International University (2007) provided the guidelines used to manage the data. Participants and law enforcement agencies were given pseudonyms to protect their identities when reporting all findings. Interview recordings and transcripts were organized and stored in a locked cabinet in my home. Electronic files were password protected and stored on my personal computer and on a thumb drive as a backup. The thumb drive was stored in a locked cabinet in my home. All data will be kept for 3 years after the end of the study.

\section{Integrity Measures}

The integrity of qualitative research findings can be questioned based on the assumption that the findings have been shaped by the researcher's assumptions and biases (Patton, 2002). Other terms that have been used to describe the integrity of the research are trustworthiness, authenticity, credibility, and verification (Creswell, 2003). These factors must be considered, regardless of the reviewer, the researcher, the participant, or the reader. Creswell (1998) recommended using a minimum of two verification procedures in a study. 
I used the following strategies to address the issue of verification procedures in this study: rich, thick descriptions and peer review. Rich, thick descriptions were obtained from the participants via the semistructured interviews. My biases toward racial profiling are stated in my autobiography and in my responses to the interview guide questions. Epoché is a process utilized to become aware of and remove prejudices, viewpoints, or assumptions of the given phenomenon (Patton, 2002).

I read each transcript and compared them to the taped semistructured interviews of the participants. I asked the participants if they would like to read their transcripts for accuracy. None of them wished to read their transcripts of their interviews.

Transferability of findings was enhanced through the inclusion of thick descriptions or information rich data so that readers can determine if the findings can be transferred to their settings (Lincoln \& Guba, 1985). Transferability of findings permits readers to make connections to their experience and knowledge base (Gallagher, 2006). Dependability or the reliability of the study was facilitated by doctoral students and candidates who meet to review each other's dissertation. My dissertation chair also provided detailed feedback on every aspect of the study. Additionally, my dissertation committee provided feedback on the study. The multiple perspectives, reviews, and input from everyone involved in this study improved the consistency of the process (Miles \& Huberman, 1994). This consistency allowed the study to stand the rigors of auditing. In auditing the study, others could examine the data, findings, and interpretations to attest that the study was supported by the data and was internally logical. 


\section{Summary}

This chapter provided the phenomenological research design I used for the study. Black males with law enforcement experience who had knowledge of racial profiling were interviewed regarding their perspectives of how racial profiling shaped their decision to explore and commit to a law enforcement career. An interview guide was used to facilitate the interviews. All interviews were recorded and transcribed verbatim. Data were analyzed using inductive, deductive, and comparative analysis. Integrity measures for the study were also included in this chapter. The findings of the study are presented in the next chapter. 


\section{CHAPTER IV}

\section{INDUCTIVE FINDINGS}

This phenomenological study explored Black male law enforcement officers' perspectives of how racial profiling shaped their decisions to explore and commit to a law enforcement career. When the effects of racial profiling are combined with the subjectivity of HRD practices, Blacks will remain underrepresented in law enforcement. The findings in this chapter emerged from the inductive analysis of data collected from participants' interviews. Pseudonyms, page numbers, and line numbers were combined to identify quotes from the participants' transcripts (e.g., Cornell, 4/15). This means participant Cornell on page 4 , line 15 . These quotes were used to support the findings and themes. The themes that emerged from the inductive analysis were (a) color and/or race does matter, (b) putting on the badge, and (c) too black to be blue and too blue to be black.

\section{Color and/or race does matter}

As we discussed the participants' careers each of them mentioned how color and/or race makes a difference in various situations. They focused on color and/or race as the only or main reason for individuals taking action, not just law enforcement officers taking law enforcement action. The participants also noted citizens initiated police action when they saw something or someone suspicious. This action could range from watching individuals to some individuals losing their lives. The participants provided various situations where color and/or race were the only or main reason for action being taken. These situations based on color and/or race have been grouped into the term of racial profiling. 
Jabari discussed how the fair complexion of his wife may have caused officers to assume he was with a White female. This assumption may have been a factor for them being stopped twice in one evening by two separate White officers. Jabari stated, "She's pretty light skinned, but I guess if you see her from a distance, they might think she's a White girl" (Jabari, 25/13-15). Jabari continued,

Maybe a minute left later, I got stopped again second time on the same stretch of highway by another White officer, you know, and he came up to the vehicle and I already knew. I already knew he profiled me, you know, he saw a Black male. He saw the vehicle. He saw the rims, and, you know, I'm pretty sure he thought it was a White female in the vehicle. (Jabari, 25/20-23-26/1-3)

Although individuals discuss racial profiling differently, the main issue is race and preconceived notions based on race. Kamal discussed the complexity of racial profiling:

Racial profiling is a lot several things to different people but basically racial profiling is just having a preconceived notion or a preconceived idea that someone's up to something or doing something wrong just based on their racial characteristics or ethnic characteristics. (Kamal, 18/1-5)

Chaka said racial profiling is an individual's decision and stated,

Racial profiling is that officer's individual decision to stop everybody that looks a certain way. He's not stopping the vehicle. He's not stopping for the infraction. He's stopping the person. (Chaka, 20/23)

Kwame continued this sentiment by stating,

Racial profiling is basically when you pick out a certain ethnic group just because he's Black or he may not live in this upscale neighborhood. In a way, that's racial profiling because just 'cause you were rolling through the city they quote unquote thought you were up to no good. (Kwame, 25/10-21)

Omari further stated,

Racial profiling to me means that an officer or an individual or a group of individuals are out there specifically targeting people of a certain, a race and they 
are not doing it to everybody. They are enforcing and imposing their will on certain groups and races of people and that's not right. (Omari, 14/4-12)

Kwame additionally stated,

For me, I defined it as the actions taken by not just law enforcement with anyone that prejudges and reacts just based solely on the color, the nationality, or the creed of an individual. (Kwame, 33/20-22)

Regardless of how racial profiling is defined, racial profiling causes Blacks to be marginalized. When individual members of society see someone or something that appears suspicious, their suspicions can foster a sense of fear for their safety and overall insecurity. As a result of the sense of fear and insecurity, members of society will call the police and provide a profile of the suspicious individual and activity. Therefore, society determines who fits the profile, thus, consciously or unconsciously playing a role in racial profiling.

Racial profiling increases when there is a large rate of crime or a large perception of crime. Law enforcement resources are sent to the area to reduce crime and improve the quality of life. These areas are normally the Black communities. This increased crime rate and the high concentration of Blacks in the area increase the chances of a negative contact being made with a Black individual in the Black community.

Jabari also mentioned his superiors directed their specialized crime teams to patrol the high crime areas in an effort to reduce crime. Many times, these neighborhoods were Black communities. Jabari stated, "We do get, you know, marching orders from higher ups hey, you know, what we gotta go hit this, you know what I mean. We gotta go check out with all these guys, and we do" (Jabari, 41/7-9). Additionally, he 
noted that, when officers are having issues with their productivity and need to increase the number of tickets or arrests, they go into certain neighborhoods.

Ghalib noted a similar issue with traffic enforcement in school zones. Officers would be in the Black neighborhoods; therefore, the traffic enforcement would be higher around the Black high schools. Ghalib stated, "The officer that was running the radar would stop the Black kids going to school and ... they were picking up the Blacks" (Ghalib, 24/7). When supervisors were notified of the actions, the officers stopped or changed their tactics. Jabari discussed how officers would routinely talk about going to certain high crime (Black) neighborhoods to get arrests:

Man I need a good arrest let's roll through 19th or 18th . . cause those are certain neighborhoods ... . where it's majority Black you know. Does crime go on there? Yeah absolutely but, you know, ... you're gonna get something good out of there. (Jabari, 42/7-14)

Maalik discussed the issue of law enforcement on a federal level. He mentioned that, when individuals travel internationally, they are subject to different search and seizure guidelines than local, county, and state guidelines. Local, county, and state law enforcement guidelines surrounding searches and seizures mandate that officers articulate the reason for their searches. He stated that U.S. Customs has very broad guidelines regarding searches.

In a border situation, you are subject to inspection. They don't have to articulate the reason for their search. At borders and ports, drug-sniffing dogs are used to locate contraband--drugs. . . . there were some officers that, you know, always went toward the Black ... passengers and not only search their luggage but search their person, had dogs sniffing all over them, and, for no reason, I would . . . ask ... what are you looking for. (Maalik, 24/7-19)

Black law enforcement officers understand and are frustrated by these types of activities. We understand the need to reduce crime and improve the quality of life. 
However, using race as the only or primary reasons for the actions being taking is wrong.

Knowing there is no way to prove certain groups of people are being targeted is

frustrating. This frustration occurs because some individuals simply do not understand

racial profiling. Wise (2005) stated,

When we [Whites] hear about things like racial profiling, we [Whites] think of it in terms of what people of color go through, never contemplating what it means for Whites and what we [Whites] don't have to put up with. We might know that ... it elevates the same in Whites, much to our advantage in the job market. (p. 133)

Even if racial profiling is not understood, the detentions, citations, and arrests have been deemed a cost of being Black. These costs create casualties.

\section{Casualties and the Costs of Being Black}

Casualties and the costs of being Black address the negative law enforcement consequences associated with being Black. Simply being Black can cause one to fit the profile and become a casualty. Casualties occur when individuals are harmed due to no fault of their own. Individuals are harmed by being in the wrong place at the wrong time and not receiving the benefit of favorable discretion. This discretion determines the costs, who is detained, who receives citations, or who is arrested. When one realizes the consequences, these can be looked upon as a cost of being Black. If there were no costs associated with fitting the profile, research regarding racial profiling and its intersection with HRD would not be necessary.

Research involving racial profiling should continue to explore how racial profiling intersects law enforcement career exploration and career commitment. Kobe discussed the issue of racial profiling and the casualties it has created: 
I don't wanna say casualties but . . . when I say casualties, I think loss . . . I mean they were just in the wrong place at the wrong time. You know, that's the way I see it. I see they were just there, and it was just the wrong place or wrong time for them to be there. There are some good people out there who are just amongst bad people, you know, good people amongst bad people and that's it. You know and, unfortunately, they get that residual effect you know of this guy's bad workings and business dealings or whatever it may be and, then, becoming subject victims to the situation. (Kobe, 41/17)

Being a casualty means you have been harmed. When speaking with the other participants, although they did not use the term casualty, they were able to cite incidents where they knew Blacks had negative contact with law enforcement due to their skin color or perceived race being Black.

Chaka stated that, although he is a law enforcement officer, he is not sheltered from becoming a casualty; "I have to prove myself to get respect. Other than that, I'm just another young Black guy. I'm gonna go through the same process as everybody else" (Chaka, 28/10).

If individuals were merely stopped because they were in the wrong place at the wrong time, there would only be affective or mental and psychological damage, nothing tangible. However, citations and arrests provide tangible evidence of fitting the profile or racial profiling. The tangible evidence taints the victim and increases the severity of the casualty.

During my interview with Kobe, he further discussed how the tangible evidence or record of the contact with law enforcement can magnify the casualty and negatively impact career exploration and progression.

Some type of record of some sort that documents that that individual was stopped by an officer whether it's a field interview, whether it's a traffic ticket, whether it's a loitering or prowling arrest, or something to that effect, regardless, it's something that connects that individual with in a derogatory way with law 
enforcement and that, ultimately, could be their demise in future job pool (Kobe, $32 / 11)$.

The future job pool extends beyond law enforcement; there are very few employers who seek to hire or promote casualties, individuals with traffic tickets or arrests. These casualties and the knowledge of them strain relationships within the criminal justice system as well as the relationships between the criminal justice system and the Black community. Although Kwame used the term casualty, others view this practice as biased and term it racial profiling. Many times, this practice results in casualties, innocent individuals being harmed or individuals not receiving the benefit of discretion as a result of law enforcement attempting to battle crime. Ultimately, racial profiling negatively impacts the victims' career exploration and opportunities.

\section{Fitting the Profile}

Fitting the profile addresses issues where the participants believed that they were stereotyped and treated as though they had committed or were going to commit a crime merely because they were Black. Profiles are used to narrow down or discriminate. These profiles include time of day, location, clothing description, physical description, and race. These factors are used in their totality to establish a pattern or profile to identify suspicious activity and a suspect who has committed or will commit a crime. When someone fits the profile and are treated as a suspect, they and their community are negatively impacted. This negative impact becomes a barrier to seeking and summiting to a law enforcement career. 


\section{Blacks as Suspects}

Blacks and groups of Blacks or brown-skinned individuals are treated as suspicious and, therefore, fit the profile of someone suspected of committing a crime or are likely to commit a crime. This treatment affects Blacks in various ways. Some want to make a difference, and some others may be affected by being detained, receiving citations or being arrested. During the interviews, the participants discussed race, their experiences associated with them being Black, their encounters with law enforcement, and their experiences that intersect their law enforcement careers.

The participants' complexion ranged from very light brown (fair skin), medium light brown, to dark brown (black skin). Even with this range of complexion, all of them stated that their complexion has never caused them to be mistaken as being any other race than Black.

The participants noted Blacks are accused of being overly sensitive to issues of race and the way they are treated. When participants discussed their lives, they often mentioned incidents where they or individuals they knew where treated negatively as a result of their race being Black. Oftentimes, this mistreatment is based on visible differences such as skin complexion and items stereotypically associated with Blacks. One participant discussed how he was treated because he is Black and his wife appeared to be White. The participants also discussed how they were treated based on their association with items stereotypically associated with being Black, including, but not limited to, loud music from their cars, gold teeth (due to dental work), or large chrome wheels on their cars. 
Martin stated that he would never forget how he felt when he was stopped by police while riding in Tennessee. He stated that he was riding in an old beat up Grand Am with $24 \mathrm{~s}$ on it; it was a hooptie with dark tinted windows, and he was stopped by the police. I fit what you would call a profile

To this day, I can't say that I was speeding, doing anything wrong, but the vehicle that I was in and the color of my skin. ... I can't figure out no other reason. ... I have the experience I was racially profiled. It was based on the type of car that I was driving and me period. (Martin 20/6-23)

Chaka explained how officers will racially profile by looking for things associated with Blacks (e.g., dread locks, gold teeth, and nice rims on a car), and, then, they look for a legal reason to stop the individual.

That officer is gonna look for color. He's gonna look for who's driving, is it a young Black male. That's probably gonna be first on his list. He's gonna look for a description dread locks, gold teeth, wheels, you know, nice rims on a car, especially an old car with nice rims on it; he's gonna find something. So, in other words, he's gonna look at that person first; then he's gonna find a violation whether it exists or not. (Chaka, 16/7)

As a supervisor, Kamal dealt with individuals who were upset because they believed that they had been racially profiled. When confronted with these issues, he stated that he would

listen to their story, but, you know, at the same time you listen to the officer and find out they had a legitimate reason for stopping that person and not only the person may have equipment out or did some kind of improper traffic violation, but, on top of that, they may have had a suspended license or whatever, but the persons, you know, the persons being stopped they swear, hey, it's racial profiling. ... Sometimes I think what happens is that we have been discriminated against so much that a person may have experiences with discrimination that they believe and suspect everything is racial profiling or discrimination. (Kamal, )

When speaking with Omari, I asked how he has addressed the issue of racial profiling. He began to discuss this issue from an organizational standpoint such as 
training, their mission statement, and their standard operating procedures (SOP). Their SOP states that racial profiling is not right. He stated they do not tolerate racial profiling.

On an individual basis, he stated,

When I hear of instances or when I heard of circumstances if I'm in an environment where I can comment on it or where I can say my thoughts on it, I usually get that out.... A lot of times you hear stuff second and third hand when you're not there you can't do anything about it, you know, if I'm in the classroom or it comes up to my squad or my division on the road or something like that, yeah, you address it right there; you address it head on. ... In my position as a major, I do get a chance to speak a lot in front of different types of organizations, peoples, and cultures have sometimes those things, and I'm just as well as I can try to express my feelings on it truthfully, and it depends on the type of group that I'm speaking to. (Omari, 21/8-23)

Neither of these participants had proof or evidence that these stops were racially motivated. However, these incidents demonstrate how society treats Blacks. It is this same society that calls police when they see someone they deem suspicious. It is these members of society who make hiring and promotional decisions. As they make these decisions, they can consciously or unconsciously give the other candidates more consideration if all factors are equal. If the candidate is tainted by citations or arrests, they can be eliminated from the pool of eligible employees. If they are still eligible, the organization may hire a better qualified applicant (one that has not been tainted).

The participants view these acts by police officers based merely on race or the perception of race as a form of discrimination. Discrimination is "the behavioral manifestation of prejudice and racism" (Scott, 2003, p. 238). It is this behavioral manifestation or effect of discrimination along the color line that privileges individuals who are not Black while, at the same time, marginalizes those who are Black or perceived to be Black. The examples provided situations where individuals' color caused 
them to become a casualty because they fit the profile. According to Jabari, "simply living in a high crime area increases a person's chance of fitting the profile and becoming a casualty" (Jabari, 42/7-14).

\section{Police as the Enemy}

Because Blacks are viewed as suspicious and someone who has or will commit a crime, their contact with police tends to be negative. These negative contacts contribute to Blacks' lack of trust and fear of how law enforcement officers utilize their power. In general, the Black community does not like the police. Barak stated, "Our view, the way we were growing up the negativity around this. Growing up like I told you ... nobody liked the police" (Barak, 41/8-10). The participants confirmed this lack of trust and overall dislike of law enforcement. The lack of trust and dislike was expressed toward the mere presence of the officers and the sense of helplessness the individuals had when dealing with the officer. The participants wanted to put on the badge to help people, uphold the law, and make a difference by serving the community.

\section{Feeling Blue Experiences of Racial Profiling}

Feeling blue experiences of racial profiling discusses Black male law enforcement officers experiences of being racially profiled. Black males that have aspirations of being a law enforcement officer or that have already become law enforcement officers are not immune or exempt from being victimized by racial profiling. The participants were able to provide occasions where law enforcement officers have racially profiled them. This section discusses personal racial profiling incidents of some of the participants. The first section is divided into earning two sections prior to earning the badge and after earning 
the badge. All of these encounters fueled the participants' desires to become officers and commit to a law enforcement career and share their experiences with others.

Barak provided the description of two incidents where he was racially profiled prior to earning the badge.

I was coming from the laundry mat with bags in the backseat. So they thought the bags were things that were taken out of the house and they stopped me. They made me lay prone down. They put their legs on my back or slapped the handcuffs on. They cleared the car and, you know, only one officer came. I felt like I was being profiled, not understanding the job prior to becoming a police officer. I thought they were jerks. ... I was like this is some bullshit.... I didn't do anything wrong why are you stopping me.... I thought I was being racially profiled. I'm like why are you guys stopping me. I didn't do anything wrong. (Barak, 28/12-30/23)

Barak stated that, on another occasion, he got into a "pissing match" with an

officer.

I got in a pissing match with him. He arrested me for trespassing. Charges were dropped. My record was expunged. I received traffic tickets, and I think that made me a better officer now seeing the way I was treated in that aspect when I either got the ticket or when I was arrested. I think that made me a better officer. . .. It made me wanna become a police officer. In the sense that, you know, what I felt I was done wrong. (Barak, 42/13-22)

Chaka also discussed another incident where he believed that he was a victim of racial profiling

But I was a young Black male. I was a young Black officer in a regular car in plain clothes, and I had to prove myself before I could make before that officer treated me with respect, but, even with that, he still wasn't honest totally to say that he stopped me because of the Black male in the raggedy ass car. (Chaka, 27/7)

Chaka was the victim of another similar circumstance. He believed his race was the reason for him being stopped by the police on a trip home from college. The stop left him feeling victimized. 
We already know the speed traps. We were past the officer. We know we're not speeding. So we think we're okay. About 10 miles down the road from the time that he saw us, he caught up with us and pulled us over pulled, and he said he pulled us over because we were speeding. (Chaka, 22/2)

When they asked the officer why they were stopped, Chaka stated,

His response was, oh so you're gonna get smart with me. At that point, as a young Black male, you are taught to shut the hell up. So who's gonna dispute the rest of the process. As a college student that's what you did. You shut up, and you let them do whatever they wanted to do. You knew there wasn't any drugs in the car, but who's gonna challenge that. Instead of him going back and writing a ticket which it would've taken about 10 minutes, we were on the side of the road for about an hour and a half. He had two other deputies show up and, then, about 20 minutes later a K-9 officer showed up. Now, if you're in law enforcement, you know that you can only hold a person for a reasonable amount of time, especially on a traffic stop because it's just a traffic violation. Well, he held us until the K-9 officer got there. We were ordered out of the car, ordered to sit on the side of the road while the officer and K-9 officer go through the car. Put all our shit out 'cause we're college students on the side of the road while they go through the trunk. Guess who had to put the stuff back in the car when they were done? Of course, they found nothing, but, at the time, it was just a simple tag. (Chaka, 22/10-24/19)

When I asked Omari to describe an instance where he had been racially profiled,

he hesitated and thought of a response. When I asked if he was trying to remember an instance or decide which one he wanted to use, he replied, "Probably a little of both. I'm trying to see which one ticked me off the most." Then, he described the following incident when he had come home from college and was stopped by the police:

I was fairly young and I come home from college one day and had a law enforcement officer stop me and he said he had stopped me because of some type of transaction that had gone on in a pharmacy and my car matched that description of the person who had committed the deed. I had just gotten off the bus to go to my grandmother's house from college probably about three hours away. When he pulled me over, he pulled me over almost in a church parking lot that my father was one of the ministers on staff. I remember that being very demeaning to me. Most of the people who witnessed this were outraged. I remember feeling sort of like disgusted that I was going through this. So it made me know things are real out there [cops do target Blacks]. (Omari, 18/15-19/23) 
This incident demonstrates how the power of law enforcement affects Black males. It also shows how dehumanizing the experience was for these Black males. These stories also show how these incidents affect Black males who are attending college and doing what is right. However, many individuals who have not experienced this treatment cannot relate to the experience. Kamal stated,

If you're on the receiving end of the racial profiling not only does it leave a bad taste in your mouth about law enforcement officers in general but the community also should be concerned ... unless you experience that a lot of people don't fully understand so. (Kamal, 19/3-9)

Racial profiling has created casualties that have tangible evidence of their negative interaction with law enforcement. There has also been some affective impact on the individuals who were racially profiled and those who were aware of the incidents. The difficulty in proving racial profiling is also tremendously frustrating.

Kwame, Maalik, Omari, Ghalib, Martin, and Kunta have all worked in Internal Affairs or have handled racial profiling complaints. During his assignment in Internal Affairs, Kwame stated that he does not recall any sustained racial profiling complaints. He stated,

Well it's really nine times out of 10 you have to have some type of evidence, witnesses or videos or some type of evidence material to show that it was intentional. It's very difficult to prove very difficult ... virtually impossible. (Kwame, 39/4-17)

Kobe discussed the difficulty of proving racial profiling due to the numerous definitions and legally justifiable reasons to stop individuals that may mask racial profiling. In some instances, the law enforcement officers may think they are doing their job and, unwittingly, use their law enforcement power to further racial profiling. 
It's kind of a way to get around racial profiling. It's almost impossible, and, like I say, you know they might wanna stop you because you are Black but as long as they got a legal reason for stopping you. (Kobe. 23/17-24)

Kobe continued by stating, "The only way to reduce your chances of becoming a casualty is ... don't give them legal justification to stop you" (Kobe, 24/13-14). Trey also discussed how existing laws can be combined with officer discretion to provide reasons for stopping individuals. These laws and discretion add to the difficulty of proving racial profiling.

If there's no reason to have stopped you ... an officer can make up a reason ... . because of the laws on the books. You might have a tail light that's out so that's good enough reason to stop you. So they say I didn't just stop them because of racial profiling. Then, you don't write 'em a ticket but you stopped 'em for that violation. Yes, you're using discretion, but why you asking about drugs and all these other things. (Trey, 23/9)

Kamal also mentioned the difficulty in proving racial profiling without hard evidence.

A lot of times, you're not gonna have hard evidence in one particular case someone uh may think they're being profiled or they may actually be profiled, but a lot of times you don't have hard evidence in one specific case, but that's why it's important to collect data. (Kamal, 18/13-17)

Maasai stated that short of the officer stating they racially profiled, without evidence, it is difficult to prove.

To say that there is evidence of racial profiling is really hard ... unless the person that did the profiling says that ... I was wrong for doing that.... The only way you will be able to prove it, is if that officer stated that that was what he was doing cause it's ... real hard based on the training and everything that that officer has learned to determine if racial profiling occurred. (Maasai, 13/1-13)

During our discussions, none of the participants were able to identify a viable reason for racial profiling. When I asked the participants to provide a viable reason for 
racial profiling, all of them took a long pause, repeated my question, asked me to repeat

it, and stated that they could not think of a viable reason for racial profiling.

\section{Putting on the Badge}

Putting on the badge addresses the personal events, the race of the applicants, and their quest to become sworn law enforcement officers. Kobe relocated in an effort to begin his law enforcement career.

Coming out of New York obviously New York is a very tight knit family when it comes down to law enforcement and firefighting. Getting into those businesses, being out on the street, being able to make decisions, and being an instrument to young children.... You had to know someone to get you note into those types of jobs. If not corrections was an easy job. They will give you that hands down because I felt personally, in my own opinion, that you would just in one position cage built in lot down and they would have no problem input and, you know, hiring you for those positions but positions were you out and the general public to be seen that was a different animal and in New York they were very, very, I don't wanna say tight knit, but they weren't; they were very forthcoming with information on how you can obtain those jobs.... The regular application process had approximately 5,000 individuals applying for a position. So, if you don't have anyone to speak for you or speak on your behalf, it's you against those 5,000 people; if you had someone speaking up on your behalf, then, it was those 5,000 people against you. (Kobe, 8/19-9/15)

Upon starting the hiring process Martin was approached by a sergeant who told him that we need good qualified minority officers. Based on his desire to succeed, combined with the message from the Sergeant, Martin inspired to excel in the police academy and earning the honor medallion. The recipient of the honor medallion is determined by a vote of "their peers, along with the advisor, that exemplifies leadership. I had to have an overall grade point average of 90 and above to be considered, and I also had to be in a leadership role, and, at the time, I was the Platoon Sergeant at the academy" (Martin, 8/5-10). 
Prior to seeking a job in law enforcement, Kunta's friend told him how helpless he felt when he was informed he had failed the polygraph. Kunta's experience with the polygraph examination confirmed what he had been informed. Regarding this issue, he expounded by stating,

Really, there was no way, no shape, no how that I thought I had any recourse of action because, like I said, a good friend of mine a month or two prior to me going through a polygraph interview had the worst outcome because they told him that he failed the polygraph. So here am I, here I am sitting down in front of the same machine and for a person to tell you that we're finding deception and for you being a man, you know, telling it like no I'm telling you this is, you know, I'm telling you the truth regardless of what your machine says, I felt that, hey, I'm in a no win situation. So, at that point, my last statement to him was really a statement of, hey, if it was meant to be, it would be, but I guess it's not meant to be because your machine is telling you one thing, and I felt that, hey, that's what I had to live with. So, there was no way for me to win that battle. I think the individual interprets what he wants to interpret out of those machines. (Kunta, 6/4-18)

Kunta further expounded on how this process made him feel. He stated,

I'd have to say it was probably one of the worst experiences that I had ever been through in my life and that was approximately 14 years ago. To be totally honest, having to sit across from somebody and for them to tell me that there was deception in particular questions that they were asking me. So, I felt that and I still feel that, you know, the, uh, process that they use the machines could be flawed in some cases. Because of what I had to go through personally and from what the close friend that I was referring to earlier had just got blackballed out of the process for the same thing. (Kunta, 5/3)

Although this experience occurs with numerous individuals, this situation was very upsetting to both of these individuals because the main issue they failed was dealing with the use of marijuana. Kunta knew his friend had never used marijuana. Then, when he faced the same issues, he knew he had never used marijuana. This is what added validity to what his friend had shared with him. 
Kwame received insight from a relative that proved helpful for him. Kwame

stated,

Fortunately, I had a relative that worked in law enforcement federal law enforcement. He said hey FBI is hiring. They opened up a new Intel Center. Unfortunately though, it's in the mountains of Pennsylvania. It's your way in you can learn a lot, and he said that they have analysts positions that they're hiring. He said that would be your foot in the door. So, he says apply [and] see what happens. So I applied, got interviewed. They flew me in to Washington DC for my interview. I did well, passed, they hired me. I wanted to be an agent. (Kwame, 2/4)

So I applied with DEA and I got hired. I got hired as a diversion agent. I work in pharmaceutical fraud in New Jersey. Being from New Jersey that's not where I wanted to work but I said hey let me use that as a stepping stone. (Kwame 3/11, $3 / 13)$

Jabari entered law enforcement as a result of his brother. He stated,

When I went to the Marine Corps, I did military police, and the only reason why I got into it at that point in time was because my brother got hired by a police department, and I as kind of trying to mold myself after him. ... I got into it initially because of him. (Jabari, 5/18)

As we discussed how he became a law enforcement officer, Kamal mentioned

that was a long story. As we began to discuss it, he stated that the police field was the quickest way for him to get into the military. So, he chose that profession to get into the air force quickly. He further stated,

I didn't know how it all worked because I didn't know anybody in the military but the recruiters that first thing is to try to field their shortages, and, at that particular time, they had a shortage in military police officers. So that's kind of the direction that the recruiter was directing me towards. ... He presented the option of police work and matter of fact at that time and didn't want anything to do with police work. ... He highlighted the fact that it would be a good way for me to get into the air force quickly and, after I get in and if I wanted to, I could retrain for a different job later time but took that option.... Upon completing his military service, he was still trying to avoid the police work. (Kamal, 5/2-7/9) 
He eventually began applying for law enforcement jobs. One of the jobs was with an agency that did not have any Black officers at the time. Some of his friends who were already in law enforcement told him that they did not think he would get hired; however, he believed that he was qualified. He applied and was first Black hired by the agency.

The majority of the participants had insight or a relationship that was key to their career exploration. Although the participants had various incidents occur as they attempted to put on the badge, they persevered and earned the right to live with the badge.

\section{Too Black to be Blue and too Blue to be Black}

Too black to be blue and too blue to be black addresses the participants' experiences as they live with the badge and serve as Black male sworn law enforcement officers. Martin stated, in his community, there was a saying, "You are too black to be blue or blue to be black.",

A lot of people have a negative connotation, you know, in your own community of police officers; you have to deal with your own community. ... Then you also have to deal with ... things in the office ... you are catching it from both sides. . .. And different types of occupations you might only have to deal with one part of that, but, in this line of work, you have to deal with it on both.... You have to deal with it at home, and you have to deal with it at work at the same time. (Martin, 41/23-42/11)

The low percentage of Black males in law enforcement and management ranks allows them to be disregarded or overlooked in many of the processes within law enforcement.

The participants discussed the vast experiences they had after becoming law enforcement officers. When I was speaking with Kobe regarding his experiences on the 
police department, he stated that, when he was hired, he was one of four Blacks in the

entire agency of approximately 100 individuals. He stated,

We didn't get much respect obviously. We didn't have any friends. Nobody trusted you. Nobody even wanted to talk to you. So we had to talk to each other. That was it. But I got my foot in the door and, then, worked my way up from there. No connections whatsoever. Nobody help me in this business. I didn't have a phone call and nothing. Everything that I did was completely based on merit and merit only; everything was done by me.... I had to do it myself and, believe me, I got criticized. Some like you some didn't like you know. They didn't trust you, and you were different. (Kobe, 14/7-22)

Kamal discussed an incident that occurred when he was transferred to the

detective bureau. He stated, Oftentimes, he and his co-workers would have discussions

about different racial issues. However, because they didn't experience it or ... they had never experienced racial discrimination, they would think that he was just using the race

card. He provided an account of an incident which highlighted the issue of race

. "I went to call one time as a detective to a lady's house. It was my case, and I was following up on a telephone call I had with her. She just assumed that I was a Caucasian guy over the phone, and, when I showed up to the house, she was so shocked that I was Black that she just didn't accept that I was a detective and wanted to put me out of the house. Her maid had actually let us in, me and my partner, another detective out of the detective bureau. We went to the house together, and the maid let us in and the lady came around the corner and she saw me as an African American and said, "You are no detective, get out of my house." My partner was so taken aback by it. He couldn't believe it. His eyes were like stretched open and stuff, and I had to ease my badge out. I said, yes ma'am, I am a detective with.... I spoke with you before and so on to calm her nerves, but it just goes to show how perception sometimes can just take over a person's thought pattern of what a criminal should be or look like. (Kamal, 19/15-20/16)

Even after earning the position of detective, Black officers still are faced with having to prove themselves merely because of the color of their skin. They were all keenly aware they needed to exceed standards to be successful. Reverend Moses General Miles (a mentor) stated, "If you can't be Number 1, be ahead of whoever is Number 2." 
The participants understand to obtain the same opportunities as their White counterparts they must be ranked Number 1 or be ahead of whoever is ranked Number 2. The need to perform better and have more education and training are essential to a successful career. This is known prior to joining law enforcement, and it continues during their career progression. The participants provided statements supporting this sentiment. Chaka stated,

So, just like anything else that ... we have to do as a people as minorities not just Black as minorities; we gotta be twice as good ... work twice as hard. You can't just be a little bit better.... We gotta almost make our counterparts insignificant for us to get the position. (Chaka, )

The sentiment was also echoed by Martin who stated,

One thing I have learned, ... I have to do things a lot better than my counterparts that are of a different race. I don't know if it's because I have to prove that I belong or if it's because I know that I can do it. However, I do know that I have to be better. I maxed out on educational points within 5 years of being hired here. ... The average officer probably won't max out at all. They're missing out on the money part of it, but they also are missing out on the experience part they would get from taking the classes. I'm also state certified in every high liability training course that is taught in the state. I have instructor certification for all of them and just an abundance of training. I'll go out on a limb and say I have more than 60 or 70 classes under my belt and that includes everything from internal affairs, street crimes classes, investigative classes, contact classes; you name it, I've probably taken it. (Martin 9/8-10/13)

The participants had a keen sense of awareness of the need to take the initiative,

be proactive, and eliminate barriers to their career. Kamal earned two master's degrees after being hired as a law enforcement officer. He stated, "I did get in I always tried to . . . not only be the best officer I could be, but try to prepare myself for the next level" (Kamal, 9/6-8). “It was just a matter of time, so I didn't want that to be a barrier for me progressing" (Kamal, 10/3-4). This issue is very important to Kamal. He elaborated further by stating, 
I definitely didn't want me not having the required educational background to be a barrier for me to keep moving up within the department. So, my focus was on doing a good job, taking all kind of training classes to help better myself in my profession, and also prepare myself not only for police work but life after police work. (Kamal, 10/6-11)

Kamal also discussed how discretion by supervisors and management determine who attends training. The type training one obtains impacts one's career path. Some courses are required for various positions and promotions.

Well, the ultimate decision is the chief's, but all of the sergeants that I worked with at that time had the opportunity either to go to the one in Louisville, Kentucky, or they have the one that rotates around to the different training academies and go 2 weeks on and 2 weeks off type of thing, so I elected to go 'cause I heard it was a lot more challenging to go to the one in Louisville, Kentucky, where you're there and immersed in the work, and I wanted to be totally immersed in the work, and I chose to go to the training in Kentucky. (Kamal, 35/15-22)

Realizing the subjectivity of assignments and promotions, Kamal emphasized the need for individuals to be proactive with their careers.

You gotta be proactive in your own career. So, I would personally meet with my supervisors on a quarterly basis and say, you know, I'd like to set up a meeting with you. I'd like to know how I'm doing now, what am I doing good. (Kamal, 41/11-15)

Kamal took responsibility and made sure he notified his supervisors of his career desires.

At least you're putting your supervisors and all the way up to the chief on notice. I put it in writing, this is what I would like to do, you know, this is how I'm preparing myself for it. Don't think somebody just owes you something 'cause you say that's what you wanna do. You got to make sure that you're taking the necessary steps to get yourself promoted and are doing the right things out there now in the position you are in. (Kamal, 42/3-11)

Barak mentioned some positions and job assignments that would be advantageous if someone was considering seeking a promotion. 
If you wanna become a supervisor, it'll probably be a good idea for you to become an FTO [Field Training Officer]... . you're an FTO, and you could use that to apply for a sergeant's position. ... sometimes, you may not get the opportunity. I just recently became one, an FTO. Timing is everything. (Barak, $37 / 22-38 / 18)$

Kwame discussed the importance of relationships and learning from those individuals who preceded him.

Stepping out there, learning from the Blacks that precede us, and showing them we have the credentials, we have the education, we have the experience, we passed the test, we're right here to be able to show 'em, look, we have all these people right here, what are you saying, you know. Showing him not just talking to him, showing him, and, you know .... we first started in law enforcement, we had the qualifications to go in to these specialized units, and we were overlooked, and you know one thing that I think both of us can attest to this, we didn't get discouraged. We didn't let it stop us. (Kwame, 32/16)

Going through the career is not easy. The key is to continue excelling through the troubles. The participants also understood that timing and the discretional subjectivity of others play a role in the career commitment. Discretion and subjectivity served as a veil for being selected for these positions. Martin began to get extremely serious and angry and even balled his fist as he began discussing some of the struggles he has had with his agency. He stated, "When I tell you I had to fight internal affairs investigations. I had anonymous letters saying I was corrupt. . . it was crazy for a while. It was crazy, and I persevered" (Martin, 14/20-23). He does not fault the agency; he placed the fault on the individuals involved and noted that "the Police Chief, a White male, addressed the issue by bringing in outside investigators to investigate his complaint" (Martin, /15).

During my interview with Maalik, he mentioned another side of the discretion and subjectivity and stated,

I like to tell people nobody said anything bad about you, but the flipside is that there was nobody saying anything good about you either. There was nobody 
championing your cause when they had these meetings, and I learned that firsthand from being a recruiter. I was in some of those meetings, and I witnessed some of the things that went on, you know. (Malik, 11/11-21)

"In order to increase your chances of success, Black officers may need to invest in themselves by paying for their own classes when their agency will not fund their classes" (Kamal, 40/13-14). "Officers should also realize that, if they have done everything possible to advance within their agency and have not succeeded, they should continue to excel while also seeking support, training, and career opportunities outside their respective agency" (Kamal, 42/21-43).

During our discussions, the participants discussed their passion for the job. They also noted that they understood the power of the discretion they had when performing their job of enforcing the law and how law enforcement officers use discretion. Due to the history of law enforcement officers' actions toward Blacks and racial profiling, the tension and attitude of Blacks may be negative toward police. Officers discussed how this attitude could play a role in how the discretion is used.

Could be attitude could play a very big role because you can have a very good attitude and you may you ran a light you was running late for work or whatever and, I say, hey alright, slow it down, or you could have a very bad attitude and run a light running late for work and you get the citation, not based on personal feelings, but your attitude plays a role on everything. . . . You can either give them a notice to appear if they have ID or you can just physically take them to jail. That's also discretion. So, it can be how you feel about the person. (Jamal, $16 / 4-17 / 20)$

In this instance, discretion determines if you physically go to jail and are forced to address the affect and effect of the encounter. The notice to appear allows you to go home and reduce the affect of the encounter. 
Discretion is also used when making selections for assignments or promotions. Racial profiling not only impacts career exploration, but it also affects every level of HRD. If an individual receives citations or is arrested, his job, job assignments, and promotions are jeopardized. Jabari also discussed the use of discretion and how Blacks do not receive the same amount of favorable discretion as others.

You have discretion, you know, you have discretion who you wanna stop, who you wanna arrest, who you wanna let go, who you wanna write a ticket, who you wanna give a warning, you know.... It's not used the same... . Obviously, I'm Black. ... Like I said, discretion is everything. (Jabari, 20/11-21/14)

This type of treatment from law enforcement professionals can cause people to feel helpless; victimized; and, in general, blue (down). Kobe provided additional insight into law enforcement officers.

One thing about law enforcement officers, they don't like to have their authority challenged; you know what I mean from what I've seen. You know what I mean; somebody speaks their mind, it always gets into a pissing contest. You know, hey shut the $\mathrm{f}$. . . up; you know what I mean; you know you're being $\mathrm{f}$. . . ing disrespectful, shut the f... up, sit down. (Kobe, 28/4-11)

Due to the group mentality and the close-knit nature of law enforcement, the need to fit into the group is strong. The fear of being ostracized if you do not go along with the group can create situations where officers do not back you up on calls as quickly as they can. This creates safety issues and can negatively impact your career in terms of assignments and promotions. This fear for safety can cause officers to go along with the group. Isaac expounded on this thought.

And so, we get called in the office, and we go, that's not what happened; well true enough, we get moved from that particular group to another group, and, um, I said, never the less, you can move me a hundred times; that kind of stuff is wrong. I saw it, and you're familiar with what caused the beer gate by President Obama just about 2 years ago. Regardless, a lot of cops get put in a position; you better 
back up his story, or, otherwise, you will be ostracized from the agency. (Isaac, 43/18)

Omari stated, "Law enforcement is a governmental entity, and, as such, we should share a common bond with the community, and we are to do our job in a fair, equitable, and unbiased way (Omari, 10/16-21). However, upon being hired, the new employee must learn the culture of the profession, organization, and his or her particular working unit. The fear of not succeeding and being accepted has caused some individuals to do whatever is necessary to fit in. Jabari stated,

Black officers, when they do get into this job, they kinda conform to standards; you know what I mean. You kinda want to fit in. A lot of times, certain Black officers, they do wanna fit in with the White officers. Nobody wants to be a snitch; you know what I mean or you wanna be trusted. I think they go overboard sometimes not as much as, you know, getting a little physical because they wanna be perceived as okay; you know what he's cool; you know shit hits the fan; he's down for it; he's all there; you know what I mean; he's going to uphold that tradition. (Jabari, 43/6-7, 9-17).

Even with the pressure to fit in and uphold the tradition, the participants enjoy their chosen profession and acknowledge that there is definitely a need for more Black males in the profession.

You have more White female officers than you have total Black officers within my agency. Realizing I teach at the police academy, I look at the classes that are coming through. I have yet to see a class dominated by Black males; wait, I'm sorry, Black males or females. (Martin, 25/16-21)

Additionally, the participants discussed their passion for the job; the educational and training benefits they have received; the stability of the job; and, most of all, their ability to make a difference. They have also acknowledged that, if more individuals would actively recruit and share the knowledge or benefits of a law enforcement career, 
more Black males would explore this career option and make a commitment to the profession.

Subjectivity and discretion can be used to mask bias. Subjectivity and discretion play a role in entire HRD process (hiring, training, promoting, and termination); the hiring process; training opportunities; job assignments; and, ultimately, the promotional process within law enforcement. Trey stated that his most disappointing experience has always been dealing with the bias in the department.

Just the fact that my attending a historical Black college, they think I was proBlack and I wanted everything Black and this in Black opposed to just accepting me for who I was. I think from that standpoint people are not as seeing me as different from their beliefs or their upbringing. It posed a challenge with them so, in turn, later on, people would say things that were not true, but, because of the African American number of officers within that department was very small, finding out later the turnover ratio was even higher for that department, it was very challenging because there was nobody I could go to and ask for guidance or ask for assistance. (Trey, 9/1-5)

Maalik stated that, although he had won awards for his recruiting efforts and his boss had won awards, when he put him for a leadership training program (one of the year-long developmental leadership programs), he was denied. He had observed mostly White males going to this program, and it was one that was paid for by his employer. $\mathrm{He}$ stated that his supervisor informed him that "it would be like sending an elementary school child to college" (Maalik, 12/14-22).

Maalik also stated the following:

A lot of people are promoted based on who they know and not tangible work product.... work product gets overlooked because you're a nice guy or you play golf with the 's the or you play poker with the boss or you do those kind of things and so if you're not in that crowd that you can just be excluded and not given a fair opportunity. (Maalik, 14/10-21)

After successfully earning the position of a sworn law enforcement officer, these 
men faced additional hurdles from within the organization associated with them being

Black.

Barak discussed the less than warm reception he received on his 1st day of work.

My first day on the job, I walked by a lieutenant. Good morning sir. You know, I'm trying to be the new guy; nothing. One guys tapes me on my shoulder; he probably didn't hear you. So I walked by. He walks by again; good morning lieutenant. Nothing. Another guy says, don't say anything else. So I spoke to that guy later and says, why. He says he downright racist. (Barak, 15/19-23$16 / 1)$

Martin had a similar negative experience at work and stated,

Due to an unfortunate incident on the road where someone had claimed I was a Black, Mark Fuhrman, my department, decided to send me to a human diversity class because of blackmail said I was a Black Mark Fuhrman based on a traffic stop that I had conducted. (Martin, 8/17-23)

Reflecting on his career, Martin stated that the most disappointing experience of

his career was the treatment he received from the agency. He elaborated by stating,

In 1 year, someone came to me and said, hey you want to have a picnic; we are starting to hire a lot of young Black officers. We want to assign them mentors. We want them to get a good start in the city.... it wasn't my idea. Someone came to me in this department and said, hey do this, get together, it's only a picnic. This picnic would not exclude anyone, but we were going to invite African Americans specifically. If Whites want to come, they are welcome. If Hispanics want to come, they are welcome. But the Blacks, we're going to invite. It didn't go well. It didn't go well because I was pulled in and told I was a racist trying to start a Black organization within the department. I was accused of this by the union. Needless to say, I was ostracized. I never forget coming to work during that time and felt like I was on the out.... it was cold-blooded. To go from a person that never feared nothing, never had a problem with an individual in my life, and to walk in an agency every day in fear. I had to fight internal affairs investigations. I had you name it; I had anonymous letters saying I was corrupt. It was crazy for a while; it was crazy, and I persevered. . . . at the time, I had a good chief. He's a White male chief, and he did the right thing. He brought in outside investigators to investigate my complaint because he removed himself. That's the only way it could be, you know, resolved. (Martin, 13/17-15/17) 
Although this incident occurred years ago, the emotion and anger over the issue is still very prevalent. This emotion and anger caused Martin to ask me to stop the interview to allow us to regain our composure. During this stoppage, we had an emotional conversation regarding how he felt unsafe to come to work, not knowing who was going to provide him needed support or abandon him, all because he wanted to organize a get-together. This get-together would have enhanced relationships throughout the agency. Although this picnic did not occur, this incident caused Martin to excel at his job and earn his current rank; as he stated, "Now I got the power" (Martin, 15/18).

Other participants also discussed the importance of relationships and individuals taking a personal interest in them and them making effort to assist others.

I really think that we as fellow officers, and, especially at our level, we need to definitely get the word out there and encourage more of our brothers and sisters to apply and get in to this profession. I think that's the only way we're going to make a difference and we're going to be able to address this racial profiling issue. (Kwame, 47/1)

When Kamal discussed his career and how he assists others, he stated that he tells everyone that "every position you're in is key to you getting promoted. People are always watching what you do and what kind of work you produce" (Kamal, 37/2-6). This sentiment of helping others and making a difference was noted by all of the participants.

Looking back and looking at television on a day-to-day basis, it appeared to me African Americans have always been the brunt of the news on the wrong side of the law. I didn't have a chance of leading a lot of African Americans wearing the military uniform. My negative experience with some agencies when I have been stopped in the past, the way certain terms were used, I wanted to become a solution to the problem as opposed to a part of the problem.... I looked at the power they possessed . . . and I thought maybe I could shed some light on profession that has always been ridiculed about the way things occur with our 
race being African American. ... I wanted to be part of the solution. (Martin, $3 / 23-4 / 23)$

Jamal stated, "The best part of my job is making a difference in somebody's life and just giving my best to the community" (Jamal, 14/22-23). Kamal stated, "Your whole thing is you wanna make a difference and be able to help people, and you're thinking about the things that you can do to help make the community better so" (Kamal, 8/22-23-9/1-2). "The ultimate goal is to provide quality service to the community" (Kamal, 13/16-17). "This job gives me a chance to help the community on a day-to-day basis" (Kenji, 2/21-22). Kunta stated,

I looked at law enforcement as a career that was looked upon negatively in the Black community. I felt that if . . I could at least attempt to become a police officer, then, maybe, I can fight some of those stereotypes that I had heard about prior to joining law enforcement. (Kunta, 3/1-3/3)

Trey also discussed how he made a difference in the life of people.

Just by what I mentioned earlier about the lives that I've touched. Even not just so the students from the school, but I still meet people throughout the year who I may have stopped on a traffic stop or I may have investigated something at their house or was called to the scene, and there's still a mutual respect, even "bad" kids at my school ... they still respect me even though some of them probably have gone to jail or been arrested. They still have a respect for me, and they say to me, I should've listened to you when I was in school; you were right. So that's a good feeling for me to know that I'm helping. I'm out there helping somebody; at least, it may not look like I was changing lives then, but, looking back on it now, I could see that I was. (Trey, 11/4 -12)

Many individuals may state that they made decisions because they wanted to make a difference. When asked what was the most rewarding experience on the job, the participants all referenced situations where they made a difference. Some examples of them are as follows: 
Maalik stated that "my most rewarding law enforcement experience was being a recruiter" (Maalik, 9/20). This assignment allowed him to make a positive difference in the percentage of people of color entering into law enforcement. He further stated that he was President of the Black Law Enforcement Officers Association. He was an officer of the organization for several years. In those positions, he dealt with people nationwide, trying to encourage them and give them advice if they ran into problems. He elaborated by stating,

As you know, in law enforcement, there was always a tremendous shortage of minorities, both Black males, Black females, Hispanic males, and Hispanic females or just people of color in any hue.... I was charged with aggressively trying to increase those numbers, and we did a very effective job for it. I even won an award nationally for my recruiting [and] implemented an outreach program where we adopted an inner-city school down in Miami, and we will go to mentor the kids and just helped that school out. I found that rewarding because of the interaction with people and my chances to really not only mold some people but bring in minorities that look like me and help them along to progress in their careers, and it was pretty successful. (Maalik, 10)

Chaka also enjoys being able to resolve issues and help individuals.

My most rewarding incidents were those that you resolve a situation or you help somebody, and they let you know that what you've done really helped. ... Because being a police officer sometimes, like it or not, you know you are superman. When I show up, I show up to fix it. I wanna know what the problem is, and I wanna fix the problem. (Chaka, 11/512/19)

Kunta also feels very satisfied knowing he made a difference in someone's life and his efforts are appreciated.

My most rewarding law experience has to be when I run into individuals that I had contact with whether I had to place them under arrest for breaking the law or counsel the kid at a school but, after time, had passed, you know, to hear someone say thank you, you may have saved my life. One night, I was off duty in my own personal vehicle and drove through the drive thru at a fast food restaurant, and the person serving me ... recognized me and ... told my wife ... this man saved my life ... had it not been for him, I probably would still be out on the street being involved in drugs. (Kunta, 7/10) 
Martin stated that his most rewarding experience is seeing the impact he has had

on the children.

I would say my most rewarding law enforcement experience would have been when I was in charge of the Explorers program when I was a Sergeant in youth services. ... My biggest accomplishment was during the time I was in that program, I must've had 35, 40, maybe 50 kids to go through. Out of that, I still receive calls from a majority of these kids that are now adults. I have 5 to 6 of them in the military. Four of them actually cops here in my agency. Two of them are cops in Fort Lauderdale. Two demo cops in Miami and I think another three or four are out in other agencies. The biggest thrill I got from that was I saw kids grow up. I got a chance to see kids grow up and become good law-abiding citizens. (Martin 11/18-12/12)

\section{Privilege of the Uniform}

The law enforcement profession has privileges, unearned benefits and perks, as do all professions. However, these privileges do not make Black male law enforcement officers immune to being victims of racial profiling. Chaka stated,

When I take this uniform off I'm no different than you. I'm not seen as an officer when I'm out of uniform. I'm just another Black male, and I'm gonna be treated the same way. I have to identify myself to be treated with respect still. (Chaka, 28/4)

The participants described some instances where they believed that they were racially profiled and identified themselves as law enforcement officers. After identifying themselves as officers, participants were treated with more respect and avoided tangible evidence of their negative contact with police. The tangible evidence included, but was not be limited to, citation, arrest, or death. Maasai provided another account of an incident.

Thanksgiving weekend we got stopped ... coming from a nightclub. There were four of us in my charger. It was my cousin, 2 more of my buddies in the backseat. We were stopped by a White officer. I didn't pull out my badge initially. ... I saw him coming up from behind me. There was no traffic infraction or anything but he stopped us. ... I didn't want to at the time asking why he'd stopped this 
being that I'm law enforcement myself. So, I just proceeded to just show him my ID, and, when I opened my wallet, he saw my badge and everything else, and he said you could just leave. But that incident was weird to me cause I know we didn't really do anything. I was the driver. We didn't have any infractions, and we were, like maybe, and we were, like maybe, 100 feet from the actual cloak. (Maasai, )

Chaka provided the following account:

Light turned green, proceeded to go again, and was pulled over, and I just thought it was very funny. It just blew me away that, when he pulled me over, he walked up. He asked me for my license, registration, and proof of insurance, and he told me. I gave it to him. I say I say what's going on what's wrong and then I you know what did I do why did you stop me. He said because I ran the red light. I told him that no I didn't. I stopped at the red light. He told me that if I don't shut the hell up it's gonna be more than just a ticket, and it wasn't until I told him that that my name is 1037 Chaka; 1037, to those who don't know me, is officer 1037 Chaka. I did not run the red light, and you better tell me what you stopped me for or get your sergeant out here. At that point, he backed off... He said, oh, oh, oh well, it looked like you did. I didn't realize that so where do you work. So now, he wants to have a conversation with me, and I told him where I worked, and he said, yeah, well, I guess it just looked like you did, you know, have a good night or whatever, but it took that for me to identify myself as an officer to not be violated.... So I'm an officer, and that's how I had to get things straight and be treated with respect, but the average Black guy with a hooptie coming down the street would've received at least a citation and God only knows what was gonna come next after that. But, I was a young Black male. I was a young Black officer in a regular car in plain clothes, and I had to prove myself before I could make before that officer treated me with respect, but, even with that, he still wasn't honest totally to say that he stopped me because of the Black male in the raggedy ass car. (Chaka, 25/21-27/7)

Jamal had a similar experience.

I know I didn't do anything, and, then, when I asked why I was pulled over, I'd be told, well, we was looking for a similar car in the neighborhood; some a robbery just happened, you know, a burglary just happened, and your car matched the description. When asked for my driver's license, registration, and proof of insurance and when I went in and after that, he said okay. He just saw once he saw the badge he just left it alone. It was no more questions. ... Everything changed ... knowing that I'm law enforcement, he probably knows he knows what he can and cannot do and probably wanted to prevent a lawsuit. (Jamal, $19 / 3-22 / 37)$ 
Trey was not fortunate enough to receive the full privilege of being a law

enforcement officer:

When I told him I was a police officer, he wanted me to verify that I was a police officer to the fact that wanted me to tell him who my chief was after I showed him my ID and my badge. He still asked me to tell him who my chief was and tell him the people at the department. So I just drove off. Being repeatedly asked to confirm your employer over and beyond what is customary is frustrating. However, in time, Trey was able to prove he was an officer. Maybe a year or two later, I was working the beach, and I wanted to take a stroll out on the ocean to see what was over there. As I walk across the boardwalk, I see this White guy and two other people coming my way. The guy looked at me, and I was in full uniform. Hey, you are a police officer, and I said, you are an asshole, and, if you don't pour that beer out, I'm a write you a ticket for open container on the beach. . . . So, imagine if it was somebody who didn't have the same credentials I have. (Trey, 22/5-22)

Jabari had the following incident occur while his wife was with him:

I had my wife in the car. She's pretty light skinned, but, I guess, if you see her from a distance, you might think she's a White girl. I stopped. . . . I say, hey listen man, you know what, I'm an officer. .. . The officer kinda looks at me. He says, alright, have a nice day. If I was just a normal citizen, they would've ran they whole course of their investigation; you know, there's no doubt in my mind that they could've got me out the vehicle. They would've searched my vehicle. They would've searched me. You know what I mean, even though everything would've came back clean, I still woulda had to go through that ordeal. (Jabari, 26/22-23-27/1-4)

Kamal wondered if law enforcement officers understand or care about the effect

of their actions:

They're not thinking the implication this kind of stuff have on people. . . what if I wasn't a police officer, then, who knows what might have happened. I might've been asked could he search my car or whatever else, and it was really no reason for him to stop me other than his perception of who I was and what I was up to. So you know I, I do know things like that occur. . . . you know, I know all these things are not just imaginary because this is an incident that happened to me, you know, so I know that some of this stuff does occur. (Kamal, 23/5-24/8) 


\section{Summary}

The inductive analysis was conducted to search for meaning in the data and discover what patterns, themes, and categories emerge (Patton, 2002). This analysis involved examining each statement in each participant's transcript. Three themes emerged from the inductive analysis of the data: (a) color and/or race does matter, (b) putting on the badge, and (c) too black to be blue and too blue to be black. These themes captured how racial profiling shaped Black male law enforcement officers' law enforcement career exploration and commitment. In the next chapter, the deductive and comparative findings are discussed. 


\section{CHAPTER V}

\section{DEDUCTIVE AND COMPARATIVE FINDINGS}

This chapter presents the descriptive findings from the deductive and comparative analyses based on the data collected during the participants' interviews. This chapter is divided in two sections: description of the findings from the deductive analysis and comparison of the findings from the inductive and deductive analyses.

\section{Deductive Analysis}

The deductive analysis was conducted after the inductive analysis. The purpose of the deductive analysis was to explore the participants' perspectives of racial profiling and its intersection with their decisions to explore and commit to a law enforcement career using Super's (1990) archway model (see Appendix E) as the theoretical framework. This theory uses an archway to illustrate how the complexities of individuals' lived experiences, achievements, and social learning serve as the cement of the archway and connects all complexities of the model. An individual's self-concept is formed based on the connection of the complexities of his or her life and, ultimately, influences career exploration and development. The model is composed of the following: biographical and geographical foundations of human development, personality and achievement, social policy and employment practices, social learning, and self-concept.

The biographical and geographical foundation of the human development forms the doorstep of the archway. This doorstep establishes the foundation for the left pillar, individual characteristics (personality and achievement) and the right pillar, society (social policy and employment practices; Super, 1990). Segments of both pillars act on

the individual, and the individual acts on the same segments based on their biographical 
and geographical foundation. Biographical and geographical foundations are composed of a person's personal history lived experiences or polyrhythmic realities (Sheared, 1999). The left pillar illustrates how a person's needs, values, and interests work together with intelligence, aptitudes, and special aptitudes to establish an individual's personality. The right pillar illustrates how the economy, school, family, society, peer groups, labor market, and social policy support employment practices (Super, 1990). Social learning is the cement that connects the complexities of individuals' lived experiences, achievements, and organizational employment practices with the individuals' selfconcept (Super, 1990). This connection, ultimately, impacts the decision makers and how they make career decisions. The complexity of these interactions is depicted via the archway.

The social learning theory identifies three main areas that influence an individual's decision making process: (a) instrumental learning experiences (receiving positive or negative reinforcement), (b) associative learning experiences (associating a neutral event to something meaningful), and (c) vicarious experiences (learning from others experiences (Mitchell \& Krumboltz, 1990). Social learning is the cement that connects all of the various complexities and helps form an individual's self-concept. Self-concepts "such as self-efficacy, self-esteem, and role self-concepts, being combinations of traits ascribed to oneself" (Super, 1990, p. 202) do not completely address the self-concept of marginalized and/or oppressed individuals. Black men and marginalized and/or oppressed individuals have a self-concept described as duality (DuBois, 1995; Freire, 1970; Sheared, 1990; Young, 1990) Therefore, the self concept of marginalized and/or oppressed individuals is self-efficacy, self-esteem, traits ascribed to 
oneself expanded by the individuals awareness of how others view them. (DuBois, 1995; Freire, 1970; Sheared, 1990; Super, 1990; Young, 1990)

This self-concept is used to make choices regarding career exploration and career commitment. I will discuss the various major components of the archway model as they pertain to the participants. The components are discussed in the following order: biographical and geographical foundations of human development, personality and achievements, social policy and employment practices, social learning, and self-concept.

\section{Biographical and Geographical Foundations}

A person's polyrhythmic realities (Sheared, 1999), personal history, forms their biographical and geographical foundation of human development (Super, 1990). The participants discussed their respective polyrhythmic realities, which included their experiences, discussions about where they lived, family, community, and law enforcement. The biographical and geographical foundation for our participants was largely a southern Black community with an influence from Jamaican and Haitian cultures.

Martin was born in a small town in Griffin, Georgia. In this town, Whites and Blacks got along. Blacks served as the Mayor, city council, Chief of Police, doctors, lawyers, and judges. Martin served in the military and took part in the invasion on Grenada, Panama Canal. Additionally, he served in the first war in Desert Storm and Desert Shield. He had a few jobs before entering law enforcement. They were at a hospital, a restaurant, and a juvenile boot camp, and he served as a correctional officer immediately prior to being hired by his current agency. 
Negative feelings from the community toward law enforcement occurred as a result of incidents that happened to individuals in the community at the hands of law enforcement. The actual incident, whether it was racial profiling or some other incident, demonstrates the three types of social learning. The incident occurred (instrumental learning), and individuals began associating the incident to the police (associative learning). Lastly, individuals learned of the event from others by word of mouth, media, or other means (vicarious learning). Jamal and I discussed how his family and parents felt about him going into law enforcement, and he stated,

You know at first they were worried. They were wondering, this is a dangerous job, and it's crazy out there. That's a lot of shootings and a lot of things, and I just looked at it as something ... nice to do. (Jamal, 28/13-16)

As I discussed this issue with Jabari, he agreed that the community does not hold the job of law enforcement in high esteem. This sentiment is echoed in articles and stories we hear about. Jabari stated, "How law enforcement officers treat individuals in the Black community ... police abuse within our community ... with the difficulty Black males have even if they wanted to seek a career in law enforcement” (Jabari, ). All of these sentiments cause many Black males not to explore or commit to a law enforcement career. Jabari said,

Nah man, I can't become a police officer. ... I can't do that man, nah, you know, and I think a lot of it is, you know, just where you grew up, even the way Black folks perceive the police.... So why would I wanna go do that job, you know. I feel like y'all don't like us anyway, so why would I wanna go work with you. (Jabari, 39/10-40/5)

Barak stated, "Our view, the way we were growing up the negativity around this. Growing up like I told you, where I grew up nobody liked the police" (Barak, 41/8-10). 
During his stint as a recruiter, Maalik stated that some recruits' families shunned him and cussed him. They did not want anything to do with the recruits becoming law enforcement officers.

Maalik said that he even had "one young lady that turned down the job offer because of the pressure she was getting from her family about law enforcement" (Maalik, 40/76-16). These same sentiments and information have made the participants want to make a difference in the community.

Jabari stated, “Growing up, you know, I'm thinking, hey police ... you know they're abusive. ... I didn't want to be that type of officer where I'm considered heavyhanded cause that's just not me" (Jabari, 14/7-15). These encounters and sentiments serve as hurdles to seek and maintain careers in law enforcement.

Kenji stated that he speaks to a lot of his friends and acquaintances about law enforcement career opportunities:

You know a lot of people have misconceptions of the job... I I know a lot of Black males who go to college [and] don't come out saying ... I want to be a police officer. ... as far as African Americans ... they're not ... wanting a job like that; they have the same job as someone who didn't go to college can get. (Kenji, 33/21-34/13)

Prior to working in law enforcement, Barak worked security and earned a degree in criminal justice. Jabari had served with the Marine Corps and was working with a juvenile boot camp. None of the participants mentioned that their neighborhoods or families encouraged a career in law enforcement.

\section{Race}

Race is a social and cultural construct manipulated arbitrarily to discriminate after determining the difference between individuals or groups. "Not objective, inherent 
or fixed, they correspond to no biological or genetic reality; rather, races are categories that society invents, manipulates, or retires when convenient" (Delgado, R., \& Stefancic, J., 2001, p. 7). The U.S. EEOC (2006) neither defined race nor adopted a definition of race. The racial category of Black evolved after slavery to categorize dark-skinned citizens from African countries (Omi \& Winant, 2005) and, thus, identifying them as other than White. Blacks were deemed to be inferior and were discriminated against in housing, education, and jobs (McCarthy et al., 2005). The majority of the participants were from the southern United States.

Kobe's parents were born in Jamaica. He was raised by his mother in a singleparent home. He self-identified himself as a Black male. As he identified himself, he said

I had to pause and think ... because ... folks who have been reared in the island concepts really don't consider ourselves Black Americans, but I was born here and raised here but raised under the guidelines of the country as they would call it in Jamaica, so our values are little bit different than American home values. (Kobe, 3/6-11)

Jamal stated that when people see him, they have never confused him with any other race. "They always knew I was a Black male" (Jamal, 2/12).

Barak, Maasai, Jabari, Jamal, and Kobe stated that their parents were not born in the United States. Barak, Maasai, Jabari, and Jamal stated that their parents were born in Haiti. Barak stated,

I consider myself African American. ... They don't see it. Oh, I'm supposed to look a specific way. I don't know, but I consider myself African American 'cause I've grown up the majority of my life here ... cause the stereotype of the typical thing is you have the big accent. Um, I'll say I closely identify to people from Haiti. ... Uh, I also identify with the African American community; uh, a lot of my friends are African American guys. I grew up here meeting down here when I came here. (Barak, 1/19-3/2) 
The participants also discussed the issue of race and how individuals are targeted as a result of race, being racially profiled.

\section{Racial Profiling}

According to Kwame, racial profiling is "the actions taken by not just law enforcement with anyone that prejudges and reacts just based solely on the color, the nationality, or the creed of an individual" (Kwame, 33/20). Racial profiling is having a preconceived notion or a preconceived idea that someone is up to something based on their racial characteristics or ethnic characteristics. The discussion of racial profiling involved an open general discussion followed by a discussion of discretion in law enforcement. Then, we discussed citations, detentions, and arrests. These three actions can occur as a result of racial profiling and the use of discretion.

As Chaka discussed racial profiling, he stated,

That officer is gonna look for color ... a young Black male... He's gonna look for a description dread locks, gold teeth, wheels, you know, nice rims on a car, especially an old car with nice rims on it. And, then, he's gonna find something. So in other words, he's gonna look at that person first, then, ... he's gonna find a violation whether it exists or not. (Chaka, 16/7)

Jabari stated, “Just because he's Black, you know, he's definitely dirty; you know what I mean; he definitely got drugs on him, [and] you know, that's racial profiling" (Jabari, 22/7-9). "Racial profiling is basically when you pick out a certain ethnic group basically just because he's Black or he may not live in this upscale neighborhood" (Barak 25/10-12). When these individuals have contact with law enforcement, the contact is often negative. The individuals share their experiences of their negative contact with others. Kobe viewed some of the individuals who had negative contact with police officers as casualties and stated, 
I don't wanna say casualties. ... The reason why ... I mean they were just in the wrong place at the wrong time. There are some good people out there who are just amongst bad people, you know ... unfortunately, they get that residual effect ... of this guy's bad workings and business dealings or ... they become subject victims you know to the situation so. (Kobe, 41/17)

Kamal further elaborated on the effects of racial profiling:

If you're on the receiving end of the racial profiling, not only does it leave a bad taste in your mouth about law enforcement officers in general, but the community should be concerned about it because if one person's liberty is in jeopardy, then, really, anybody, for any reason, could feel that they could be. Unless you experience that a lot of people don't fully understand 'cause most people say, alright, must've been some reason it's, you know, you're just imagining that or it had to be some reason they pulled you over until they experienced something like that. (Kamal, 19/3-13)

All of the participants, with the exception of Kobe, stated that they been racially

profiled. When I asked Kobe to describe an instance where he had been racially profiled he thought for a little while. Due to his silence, I asked, "Are you trying to think of an instance or you have so many to select?" Kobe replied,

I'm not too tolerant of it. So I really don't allow an individual to take me there but I have seen others though but I would probably say something. Have I been racially profiled? I've never been stopped. ... I don't know, maybe, I'm naïve to a certain degree because, yes, I have been stopped, but I don't believe it was, you know, it wasn't because I was Black. (Kobe, 35/1-11)

As we discussed racial profiling, many of the participants noted that what might appear to be racial profiling could be that the police officers are just doing their jobs. Jamal stated, "Because sometimes when officers pull people over sometimes the individual feels like the officer really has no reason to pull them over" (Jamal, 22/19-20).

As a supervisor, Kamal responded to an allegation of racial profiling. In this particular incident, the individual immediately believed that he was being racially profiled and did not give the officer a chance to say or do anything. Kamal stated, 
A friend of mine who's a security guard in a neighborhood was stopped, and he was off-duty at the time, but he demanded to speak with me, and he later did follow-up with me and told me, man, I've never felt so discriminated against and disrespected in my life. I have my wife with me. He was a Jamaican Black guy, and, you know, he said I never felt so disrespected, humiliated, and I said, well, you know, I'll check into it. . . . He didn't know . . . Didn't realize we have videotape in all of the cars. I reviewed the tape, and it was totally his fault. (Kamal, $26 / 13-27 / 5)$

As Kamal and I discussed racial profiling, Kamal stated,

When law enforcement officers detain cite or arrest individuals, the officer is not usually thinking about the bigger picture of what effect this has on the individual. The officer is more focused on making stats, how can I get an arrest, you know and things like that. And they're not thinking about the implication this kind of stuff has on people ... many of the officers probably have no idea of the farreaching effect of their actions. (Kamal 22/21-23/6)

Kamal also mentioned the benefits of being a police officer during an incident.

During one incident, he was stopped by a law enforcement officer for no reason. After learning that he was a law enforcement officer no action was taken. Kamal thought to himself, "What if I wasn't a police officer. . . Who knows what might have happened. . . I I might've been asked to search my car or whatever else and it was really no reason for him to stop me" (Kamal, 23/11-15). This incident demonstrates the discretion the law enforcement officer had and how he decided to use his discretion.

The majority of the actions taken by law enforcement officers is totally at the officers' discretion. There are very few times that officers must detain, cite, or arrest an individual. The use of discretion by officers as they perform their jobs can mask racial profiling.

Discretion. According to Jabari, as a law enforcement officer, "You have discretion you know you have discretion who you wanna stop, who you wanna arrest, who you wanna let go, who you wanna write a ticket, who you wanna give a warning, 
you know" (Jabari, 20/11-13). Due to the training, law enforcement officers receive they are aware of the appropriate reasons and legal justification to stop an individual. The public's knowledge that officers can use this training to mask any discriminatory, racial profiling, or any other harmful acts can create accusations of discrimination, bias, and racial profiling. Jabari expounded by stating,

Well, as long as the basis of my stop ... whatever my intentions are ... as long as you have legal justification why you stopped someone, then, the stop is legal itself. It's kind of a way to get around it ... a way to get around, racial profiling. . .. They might want to stop you because you are Black but as long as they got a legal reason for stopping you. (Jabari, 23/11-24/3)

It is this legal reason for stopping an individual that masks unconscious and conscious acts of discrimination and racial profiling. The complexity of the issue of racial profiling is further complicated by the amount of discretion law enforcement officers possess. This discretion, combined with law enforcement training, gives officers the power to make decisions that affect people's lives. Trey stated,

As a law enforcement officer, you make a decision on somebody's future. You're able to take away his or her rights right there on the spot. The charge may not stick. The prosecutor may say not enough evidence, but, for that time in their life they were arrested, they were placed into custody or they were detained or they were booked. Now, for the rest of their lives even if they were innocent, that's gonna follow that person for the rest his or her life. Now, they have to explain that situation every time something comes up. (Trey, 13/16)

As individuals explain their detentions, citations, or arrests, they are forced to relive the situation. When they apply for jobs, many times, they are asked about their detentions, citations, and arrests. This is especially true for individuals exploring or committing to careers in law enforcement.

Negative contact with law enforcement and other law enforcement issues create tension between the police and the Black community. Many of these encounters end with 
no tangible evidence or record of the counter. However, when there is tangible evidence that documents the encounter, the victim cannot merely ignore the encounter. They have been tainted. The citations or arrests prevent someone from being hired. The same citation or arrests could cause them not to receive a select job assignment or promotion. Due to the subjectivity in job assignments and promotions, even a mere negative contact can negatively impact an individual's career. Kobe said,

A citation, some type of record ... that documents that that individual was stopped by an officer, whether it's a field interview, whether it's a traffic ticket, or a loitering or prowling arrest, or something to that effect, regardless, it's something that connects that individual with in a derogatory way with law enforcement and that, ultimately, ... could be their demise in future job pool. (Kobe, 32/11)

The hiring of a law enforcement officer and the career development of law enforcement officers involves subjectivity. One of the steps in the hiring process is the background check. During this process, the applicant's entire background is examined by using references, education, credit history, traffic citations, and arrests. The process is discretionary and subjective. However, the presence of detentions, citations, and arrests are not looked upon favorably. The detentions, citations, and arrests can also hamper promotions, assignments, and career progression.

Detentions. A detention occurs when a law enforcement officer stops an individual, and no law enforcement action is taken. All of the participants mentioned that they had been detained by law enforcement officers. This section discusses the participants' personal accounts of being detained and how it impacted their career development. 
Barak described an incident that occurred to him prior to him becoming a law enforcement officer. "I was coming from the laundry mat and bags in the backseat. So they thought the bags were things that were taken out of the house and stopped me. I was prone down" (Barak, 28/12-15). Barak continued,

Laid down ... on the ground or whatever, legs on my back and slapped handcuffs on. They cleared the car and, you know, only one officer came. I felt like I was being profiled not understanding the job prior to becoming a police officer. I thought they were jerks.... I was like this is some bullshit. ... I didn't do anything wrong; why are you stopping me. ... Yeah, like, you know, I didn't do anything; why are you stopping me.... I thought I was being racially profiled. I'm like, why are you guys stopping me. I didn't do anything wrong ... a little bit upset and angry and, you know, basically, you had the frame of mind; it's a battle where you're not gonna win. ... I thought I was being racially profiled. I'm like why are you guys stopping me. I didn't do anything wrong. Not knowing what I know now, which now you look at it, it's like they were doing their job. (Barak, 28/17-31/18, 30/22-23)

After acquiring law enforcement experience, the participants now understand the complexity of law enforcement and racial profiling: frustrated victims, concerned community, and frustrated law enforcement all intertwined in an effort to reduce crime and improve the quality of life in the community. Citations and arrests are two tangible ways law enforcement reduces crime and improves the quality of life in jurisdictions.

Citations. The term citation is used interchangeably with the term ticket.

Citations can be issued for any number of offenses; however, they are most commonly issued by law enforcement officers for traffic violations. These traffic violations can include pedestrian (e.g., J-walking) and bicycle (e.g., no horn or warning device) offenses. The issuance of citations is yet another discretionary law enforcement action that can have an impact on an individual's career exploration and commitment. Maasai stated, 
When you have those tickets, those unnecessary tickets, those unnecessary arrest that didn't need to happen, but, once that individual is arrested or that individual gets a citation on their record, it's almost like a roadblock when it comes to law enforcement careers because now you have that on your record. When you apply and that's the effects of racial profiling or the end result. That individual may not be able to get that job in law enforcement based on that ... it's always going to be a hindrance. If that employer is looking to eliminate someone that comes down to your record, your background is going to be the first thing that they look at to eliminate you. (Maasai, 22/7-21)

Arrests. An arrest is a law enforcement action that deprives individuals of their freedom based on the allegation and probable cause that they committed an arrestable offense. Arrests can be a physical arrest where handcuffs are placed on them and they are physically taken to a jail holding facility, or it can be a nonphysical arrest in the form of a notice to appear. Many times, it is up to the discretion of the officer which type arrest would be made.

Barak was the only participant who stated that he had been arrested. His arrest was prior to him being employed as a law enforcement officer. Barak provided the following account:

I got in a pissing match. ... He arrested me for trespassing. Charges were dropped. My record was expunged. I think that made me a better officer now, seeing the way I was treated in that aspect when I either got the ticket or when I was arrested. I think that made me a better officer, and I think, when I was exposed to it, it made me wanna become a police officer. . . In the sense that . . . I felt I was done wrong. . . . It's not against the law, but I think it made me more so wanna become a police officer just to change that. Whoever I run across, I probably have the different frame of thought, okay this guy's just being an asshole because this is what he grew up with. I can better relate to minorities and where they came from better than other people in my department. (Barak, 42/1343/13)

This arrest was an issue Barak had to overcome in his hiring process. However, ultimately, it is this arrest that had a profound impact on his personality and him, ultimately, achieving the job of a law enforcement officer. 
All of the above discussion establishes the biographical and geographical foundation of the participants. This foundation supports the personality, achievement, social policy, and employment practices.

\section{Personality and Achievements}

Personality and achievement form the left pillar of the archway. This pillar illustrates how needs, intelligence, values, aptitudes, interests, special aptitudes, and personality support a person's achievement (Super, 1990). This pillar also considers a person's thought process, aptitudes, needs, interests, and achievements. All of the participants prepared for their chosen careers. They took steps toward helping them enter the law enforcement profession and committing to the law enforcement career.

Kobe stated that he had taken strategic steps to enter into and commit to a law enforcement career. He relocated and began working jobs that he believed would give him an advantage in law enforcement career. He stated that he worked three jobs all at the same time: a mental health specialist, a security guard, and a school bus driver. Kobe further stated,

I was trying to use each one of those jobs as a sort of nexus into the police field . . . And each one of those jobs had a reason. So I was driving buses in the morning, counseling kids in the afternoon and security work at night. I think I might've had four hours rest in between. I used to get off at midnight and be back at the job four or five in the morning, then, pick the kids up on the school bus. I was finally hired as a service aide. (Kobe, 5/5-11)

Kobe, as with other participants, took steps to prepare himself to meet or exceed employment standards. Kenji took steps to make sure he exceeded the minimum standard for a law enforcement officer candidate. He had earned a bachelor's degree in social work from Southern University and a master's degree in social work from Barry 
University and had worked as a child protective investigator. Jamal and Maalik interned with their respective agencies prior to being hired by the agencies. Barak stated, "I've mostly worked security" (Barak, 3/7). Jabari had the lowest educational attainment of the participants upon entering law enforcement; however, he knew he needed his high school diploma to have a successful career. Jabari stated the he graduated from

an alternative school where kids were about to drop out [and] where they need to make up credits. It's an alternative school that they can go to kind of catch back up. ... after that, he completed 4 years in the United States Marine Corps, sold cars, and worked in a juvenile boot camped before finally becoming a police officer. The Marine Corps, you know, I mean, I was exposed to a lot of things that other people didn't have a chance to, different cultures, different countries, different people. (Jabari, 1/13-2/12)

By these efforts, the participants made sure that they met the minimum standards

for a law enforcement candidate. The participants understood they had to do more than meet the minimum standards to be successful. Trey discussed how he prepared for an opportunity to be a school resource officer and stated,

Before I became a school resource officer, I signed up to be a substitute teacher. I was teaching inside of those schools as a substitute teacher. I made the contact with the administration and made contacts throughout the school. When the school resource officer vacated the position, the principal was, like, I want that guy. (Trey, 41/3)

The participants knew they could not control the subjectivity of job assignment

and promotions. They simply addressed the issues they could control. Martin stated,

After being on the training squad for 3 months, I was transferred to bravo (evening) shift. I, then, served in the Field Training Officer program where I served for nearly 3 years prior to taking the examination to be promoted to Sergeant. My career progressed and saw me, "by the grace of God," being promoted to Sergeant on my first attempt. I, then, served as a supervisor on road patrol, then, youth services, then, in the training division. Then, promoted to the rank of Lieutenant. I, then, commanded the following units road patrol, crime suppression team (street crime team), Internal Affairs, and Public Information Officer. I was able to obtain these positions by meeting the minimum standards 
and the receiving the subjective selection of management. (Martin 7)

The participants took the steps necessary to obtain a career in law enforcement. All of them wanted the positions in an effort to make a difference and give back to society. Kenji stated,

I had a lot of friends that were in law enforcement and a lot of the skills that I possess as far as my communication skills, my skills of getting along with others, and wanting to help a community kind of moved me toward the path. (Kenji, $3 / 15-18)$

Although the participants took steps to prepare for a law enforcement career, they knew society and employment practices intersect their personality and achievements. This intersection had to be taken into consideration when making their decisions to explore and commit to a law enforcement career.

\section{Social Policy and Employment Practices}

The participants discussed how "economic resources, economic structure, social institutions, and so on that acts on the person and on which the person acts in growing up and functioning as a unit in society" (Super, 1990 p. 201). The archway model specifically mentions the following segments: the economy, community, society (school, family), peer groups, and labor market.

Society intersected employment practices and HRD. Law enforcement HRD is very subjective. Many of the actions taken by law enforcement and HRD are influenced by society. However, if you have citations or arrests, it will negatively impact your ability to be hired, obtain select assignments, and be promoted. Law enforcement agencies are recognizing the benefits of having employees mirror the community they serve. Kobe said, 
You hear a lot of politicians talk about we need to hire more Blacks and, okay, why you know. No one wants to answer that, but they wanna use federal statistics or they wanna use officer per capita concepts. It's just like is that the reason why you want Blacks because of the population. Or do you want Blacks because you feel that they are qualified to do the job or do you ... want a really nice good picture? You know, you're trying to make wrong right or make right wrong from previous days when the guys had positions because of their friendship or because my daddy used to work here or something to that affect. Those corner pockets still exist, and that is what I'm going up against; now, you know, in this business still trying to root that out. Unfortunately, and it's been a very tedious process, and it's difficult to get anyone to admit that they've done wrong. Very difficult to get them to admit that, and they will never admit that. They will never admit that. (Kobe, 23/2-21)

In some instances, it appears that agencies are more concerned with hiring

individuals to give a diverse look to the organization. As we discussed racial profiling, many of the participants noted that what might appear to be racial profiling could actually be the police officers doing their jobs. Jamal said, "Because, sometimes, when officers pull people over, sometimes, they feel like the officer really has no reason to pull them over" (Jamal, 22/19-20)

The requirements for entering law enforcement on the local, state, and federal levels were largely the same. Applicants driving records, arrest records, and education levels were all factors. The number of citations and arrest could be cause for individuals not meeting the minimum hiring standards for law enforcement. These citations and arrests could make others without those issues appear to be better candidates.

Jamal stated that some basic requirements are "19 years of age, at least a GED or high school diploma, you have to be a U.S. citizen ... No felonies" (Jamal, 24/14-16). Kenji said,

Nowadays, jobs ask have you ever been arrested. They used to ask have you ever been convicted. Now, they ask have you ever been arrested cause a lot of people 
don't get convicted of these crimes. So they're asking have you ever been arrested ... to hinder you for the rest of your life. (Kenji, 20/21)

Changing the question to Have you ever been arrested? from Have you ever been convicted? is a tremendous difference. All an officer needs to make an arrest is probable cause. This simply means the officer is able to articulate that you probably committed the crime. However, a conviction requires proof beyond a reasonable doubt. If there is reasonable doubt, there is no conviction. Therefore, the arrest, as Kenzi stated, hinders the individual's employment opportunities for the rest of his or her lives.

As I discussed the employment practices and hiring requirements with Kamal, he also discussed how he felt going through the hiring process and stated,

One of the biggest barriers ... they had at the time I continued to run into ... is to pass a swimming test and, unfortunately, that was a big stumbling block for a lot of African Americans. That, alone, eliminated quite a few, otherwise, qualified applicants. (Kamal, 8/4-9)

Law enforcement agencies in south Florida require officers to pass a swimming test prior to submitting their applications. This requirement had a tremendously negative impact on Blacks; they were successfully passing other portions of the application process and failing this portion in a disproportionate number compared to White applicants. Law enforcement agencies justified this portion of the application process by stating that it is needed due to all of the waterways in the area. Officers should know how to save themselves if they fall into the water. However, no swimming is taught in the academy or during the remainder of an officer's career unless assigned to a waterborn team (e.g., dive or Special Weapons and Tactics). Originally, the test was 100 yards (any stroke other than back stroke), no time limits, and tread water for 5 minutes immediately after. Organizations interested in increasing the success of minorities in this 
portion of the process began suggesting that individuals take swimming lessons and practice prior to taking the exam. As more minorities began passing the exam, the exam was changed. One of the biggest changes is the exam now has a 2-minute time limit. Individuals must also pass a background check and psychological exam. Both of these processes are subjective. The individual conducting the tests can interpret and report their findings according to their interpretation of the facts. Kamal stated,

The criminal background check and that's an important part, you know, that you definitely have to consider.... I've also seen some very qualified minority officers get knocked out of consideration because they had some kind of minor criminal incident that happened, you know, early in their teenage years or something held against them and the reason for them not being hired when I thought that otherwise they would make a very good officer and probably learned lessons from the experience that would be valuable to them on the streets, you know. (Kamal, 32/15-33/2)

This reflects on the impact of asking about arrests versus convictions. Arrests can become a determining factor, and this can have a tremendous psychological impact on the applicant. Kamal further expounded on the psychological exam.

You know, I think the psychological can be very ... subjective, and, sometimes, it really has to do with your culture upbringing, ... you may have a question on there that one person from one cultural background may answer totally differently from someone coming from another cultural background; you know, ... they can be very subjective. (Kamal, 32/4-10)

This portion of the hiring process can, ultimately, determine if a candidate is suitable to be hired. Subjectivity is in many areas of the human resource process. However, if human resource personnel are making hiring and promotional decisions in the best interest of the organization, they will select more suitable applicants, applicants with fewer documented negative encounters with law enforcement. Kamal indicated,

Within these processes, subjectivity can be conscious and/or subconscious. Individuals tend to favor people that look like them, think like them, and promote 
those same people. This tends to maintain a certain mindset that just permeates through the department where they think only someone that looks like them and thinks like them can do a good job, and, therefore, you alienate the minorities within your police department. To me, everything should be done based upon that person's performance. However, you can get into performance issues because a lot of times performance evaluations are considered to be very subjective. (Kamal, 30/13-31/3)

Due to the subjectivity and discretion within the profession, once Black males have been hired, their chances for attending select training and being selected for prime jobs or specialized assignments that could lead to promotion are still a challenge.

Additionally, without being in the selected positions and positions of power, they are not able to impact formally the number of Black males in law enforcement and address issues of racial profiling, disparate treatment, and marginalization from a policy standpoint.

One way to address marginalization is by mentoring and building relationships. Mentoring can be formally set by the organization or informally encouraged. After becoming a law enforcement officer, Martin met his first mentor, a White female. She pushed him to continue his education. His career blossomed. He served as a FTO; a Sergeant; and, currently, as a Lieutenant. One of his assignments was in Internal Affairs. He has earned additional degrees and has become certified to teach high-liability courses. These courses include, but are not limited to, firearms, emergency vehicle operations, and defensive tactics. If it was not for the relationship he built with his mentor and her support, his career would not be where it is today.

Kwame is in management and stated, "I'm in a position now and I'm trying constantly to reach and pull other blacks up and prepare them" (Kwame, 30/11). Although mentoring is not formalized, as law enforcement professionals, it is or can 
become a practice within organizations. Kwame also discussed how he is encouraging one of his subordinates:

What I do is I try to encourage her. I help her as much as possible. Just the other day, I told her you are taking the next test right, and she goes, yes. I said, and when you do apply, come see me because I'll do everything in my power to help you prepare to pass and to make that next step, and I said I'm obligated to do that, and I'm honored, and I wanna do that. (Kwame, 30/18)

Giving back and making a difference was key to everyone. The desire to make a difference was also a major factor in the participant's job selection process. Kwame stated,

They said we need to know on Monday. Well, Monday came, and they offered me the position. So, I had to make a decision which one did I want. It was weird because I always had that desire to touch people, to reach out, and to make a difference in the community. So, I had to decide where can I make the biggest impact, and I said, you know, local law enforcement is where I need to be, and I accepted the position with the local agency. So, I went to the academy, and the rest is history. (Kwame, 5/21)

Kwame continued by saying,

Every opportunity that I get when I see a young African American officer, I ask them have they prepared themselves for any supervisory positions, and, very often, I get the response, oh well, I'm not sure if I wanna do that. My next question is why ... a lot of their answers are very disappointing, and a lot of times they say, oh, because I wouldn't get it anyway. For me, and I tell 'em, if I took that attitude, I wouldn't be where I am now. (Kwame, 29/20)

The responses Kwame received of "I wouldn't get it anyway" is common. These responses and corresponding actions also show how the participants' social learning is also influencing the participants' career development. Trey discussed the importance of the network to break down organizational barriers. He provided his view from the position of a recruiter and how this position helped establish relationships and bonds that facilitate career development. As a recruiter, Trey stated, 
You build a bond because I brought you all the way through to your first year, so I had more time with you than anybody else in the department up until this point. You'll be more prone to come to me that recruiter and say. ... "I really wanna go in to bomb squad how can I get in that." Since I been here I'm a seasoned officer here. I would be able to speak to others on your behalf -- hey, uh, Dale, Greg over here, wanna go in to bomb unit what can we do?" As a seasoned officer, I can provide a personal reference and break down some barriers. Alright, these are the days we train tell him to come out; we'll show him some stuff. That barrier has been broken down. If Greg just go ask Tom, he's gonna get rejected 'cause Tom don't know Greg. (Trey, 40/2)

\section{Social Learning}

The previous examples show how the participants were impacted and how they, as members of the organization, acted on others and influenced individuals' career development. Some of their actions involved social learning. The participants discussed how most of what they learned was not in a formal learning setting. Most of the learning occurred as a result of information they gained due to positive and negative feedback, by associating various bits of information, and by speaking to others about their experiences.

Kenji mentioned what he learned from his FTO:

My field training officer was very, very instrumental . . . for showing me you know the different techniques and different things, but a lot of it is on the job dayto-day seeing how other people react to certain situations in finding out how things that you like from that person and finding out things that you dislike from another person, and, saying, I will do this differently. (Kenji, 30/16-22)

Kenji further stated,

One of the things I learned when I first arrived in Florida is that I was in for a culture shock. I must be honest. I have traveled the world: Japan, China, The Philippines, Thailand, Korea . . . but I had never faced racism 'til I came to Florida. ... while I was in the academy, someone asked me how could you be going to a racist police department like from the agency that you are at certain agencies do things a certain way. (Kenji, 31/16-17)

When Barak discussed lessons he had learned, he discussed the use of discretion.

He learned that officers nearly have sole discretion when determining whether to tell 
someone to "have a good day or here's your citation. The discretion is totally up to you.

I've seen it where ... some officers give citations to certain ethnic groups every time they stopped them" (Barak, 21-22).

This coincides with what other participants have stated. They learned how officers' use of discretion more than often results in a negative encounter for Blacks.

When Barak discussed his encounter with law enforcement with others, he stated,

They felt the way I felt. They were like, aw dude, they did you wrong. Man, they did you wrong. They shouldn't have done that 'cause you ain't do anything. I think, at first, when I shared the story, I think it may have had a negative impact. I don't think they would've wanted to be in law enforcement. Because the view of where I grew up from ... cops were viewed as, I guess you could say, oppressive. People didn't like the police. I think it's getting spoon fed to them through family, through their education, through family hearing what other people have to say. It's always a negative aspect when it comes to law enforcement. (Barak, 32/7-34/6)

Kobe learned the power and value of law enforcement at a young age. He stated

that he

used to pick up the phone and dial 911 and play on the phone and ... they would show up to the house because you're playing with 911 phone number. So, as they show up ... the guys downstairs that are hanging out selling the narcotics and the drugs they would scatter and they would run when the cops would come around. . .. I'd hide, you know, be very, very quiet, and, when they left, all the guys were gone. So, that gave me an opportunity to run outside and enjoy the outside, have a great time, and shoot the ball or whatever the case may be. The guys weren't hogging the basketball hoop or whatever. So, that was instilled in my life early . . . these guys come in a uniform would just make all these really bad guys go away. (Kobe, 10/10)

Kobe quickly learned by watching the reactions of others the effect of men in uniform and how they improved the quality of life in his community. As a result, he wants also to become an officer and make a difference. In some instances, individuals may have had a negative contact with law enforcement and believe that that particular 
contact will cause them not to be hired; therefore, they do not even apply. Many times, this belief is based on misinformation. Some individuals believe that all negative law enforcement encounters automatically means they cannot become officers. Some even believe that minor traffic infractions can disqualify them from employment. Jamal stated,

Some individuals may have a negative law enforcement encounter in their past that has tainted them, and it automatically discourages them. Some may say, you know what, I was arrested for marijuana in the past. I wonder will they ever hire me or which they probably won't or it'll be example it could be some may have like four or five tickets, hey, I got a bad driving record. I'm not even going to waste my time, or some may say, I have a bad reputation with the police officer in the neighborhood where I don't want to even apply. Things like that. ... It's not automatic disqualifications, but, if you don't know if you are not educated on it, you'll automatically be discouraged ... and not apply. (Jamal, 26/8-22)

When officers and agencies actively inform of their standards, it will have a positive impact on the agency. The information could cause more individuals to submit their applications and cause others who do not meet the qualifications not to submit applications. Barack stated that other Black male law enforcement have assisted him in his career. Barak also said, "There are guys who actually are there to teach you. ... What I learn from them, I tried to teach the younger guys" (Barak, 24/15-19).

However, he also stated that he had a negative encounter with officers. After believing that the officers were jerks after an encounter, he shared information about the event with others.

This sharing of information perpetuates the negative feelings about law enforcement in the Black community. When Jabari was with other officers as they were making an arrest of a Black male for burglary, he stated, "The officers kinda ... Went a little overboard ... after that. ... he looked at me. He goes, "man you know ... That 
was $f$... ed up, you let them do that to me. I think that kinda touched me" (Jabari, 9/1823).

In this instance, Jabari felt touched or bad and helpless. Barak stated,

If there were other Black officers, would this incident have happened? The lack of color [other minorities] there. I'm like, wow, there is no brothers here, no sisters. I was kind of shocked. I was like, okay, you know, just be quiet do your job. You here to do a job. (Barak, 9/11-14)

Barak had heard that the only previous Black officer had been run out of the agency and said, "So, I'm like, they are probably going to do the same thing to me; of course, you run into people you learn to stay away from" (Barak, 10/1-8). Martin stated that seeing Blacks being the brunt of the news and depicted on the wrong side of the law on television on a day-to-day basis impacted his decision to become a law enforcement officer. Martin said,

It appeared to me being that I have traveled the world, African Americans have always been the brunt of the news on the wrong side of the law. I didn't have a chance of leading a lot of African Americans wearing the [military] uniform. My negative experience with some agencies when I have been stopped in the past, the way certain terms were used, I want to be a solution to the problem as opposed to a part of the problem. I looked at the power they possessed, and I thought, maybe I could shed some light on a profession that has always been ridiculed about the way things occur with our race being African American. I wanted to be a part of the solution. (Martin, 4/1-15)

Individuals learn based on what they have seen growing up. Martin stated that some of these individuals are not able to separate professionalism from their personal experiences and may unconsciously act on their prejudices. While serving in the military, he met a White male from Wichita, Kansas. While they were showering, Martin stated,

I'll never forget being in the shower and having a man look at my ass. He said, where's you tail? He said, my parents told me that you know Black people are 
monkeys, and, at night, y'all tail come out. In the day time, you hide 'em. His ignorance or his limited access to Black people, he only went by what he was told. (Martin, 21/21-22/20)

All of the participants shared their experiences and were familiar and affected by other individuals' experiences. Kwame related how the election of the first Black President of the United States affected him and said,

The night that Obama won the election, my dad cried because my dad was one of those guys in the Civil Rights Era that was marching on college campuses. My dad and my uncle got arrested in Maryland. My uncle went to college in Maryland, and they got pulled over. They got racially profiled, and they got put in jail they said for speeding, and they had to come up with like $\$ 300$ or else they were gonna stay in jail 'til they came up with the money. They had to call to have money wired. My grandmother wired money to them, and, then, they let them out, you know. (Kwame, 51/7)

These accounts show how the participants learned their direct experience by one of three ways: (a) instrumental learning experiences (receiving positive or negative reinforcement), (b) associative learning experiences (associating a neutral event to something meaningful), and (c) vicarious experiences (learning from others' experiences; (Mitchell \& Krumboltz, 1990). All of this social learning intertwines all of the individual and society and employment practices pillars.

The interaction between these two pillars and the arch encompasses one's lived experiences and the various roles and stages in an individual's life (Super, 1990). These lived experiences formulate one's self-concept. This self-concept will determine what options an individual will exercise. These options include to what careers they will explore and commit. 


\section{Self-Concept}

Expressions of interests are a result of self-concepts (Super 1990). The participants entered law enforcement or progressed in law enforcement due to the relationship they had with someone else or the organization reaching out to them.

Although the participants became interested in law enforcement or various career moves, it was the action of others and how those individuals felt about them and their decisions that, ultimately, influenced the participants' self-concept. Barak stated,

A good friend on mine got me into law enforcement. I ran in to him while working at the mall. He said, you should try law enforcement. I'm like, okay, let me go see what's up. I went on a ride along, and I liked it. . . yes, I believe the lady I spoke about was my contact at. I believe she knew somebody there that helped me with the process. (Barak, 5/21-6/23)

Barak was informed of the law enforcement career option by a friend, and he believes as though one of his female instructors, along with other individuals, helped him begin his law enforcement career. Jabari stated, "The reason I went into the military police is because my brother had gotten hired by a police department and I looked up to him. However, he was not successful in completing the police academy" (Jabari, 3/12-

4/7). Jamal has been focused on a law enforcement career for the majority of his life.

While attending school, he interned with his eventual employer. Jamal stated,

Then, after interning, then, I get hired right after my internship. ... I interned and after the internship was expiring, then, I applied, and I went through the process. I worked in detention approximately 1 year. I began applying for jobs as a law enforcement officer and was eventually hired as a law enforcement officer by the same agency. (Jamal, 5/10-7/18 60)

Kenji's career was also influenced by others. Kenji stated that he had "approximately three to four friends who work for various agencies.... We had a lot of conversations in reference to law enforcement, and I applied" (Kenji, 3/21-23). 
Kobe was already employed with one agency. However, as Kobe stated, an officer of another agency said to me, come over here; we'll treat you a little better than they would. The officer got in touch with the training officer who gets in touch with the chief or whoever. They said, come on over and talk to you, what's going on.... I went over and had lunch with the chief, and the rest is history.... I joined their agency. (Kobe, 15/6 -18)

\section{Summary}

The participants' career exploration was influenced by their knowledge of racial profiling and how others viewed them. Many times, this knowledge was obtained via social learning such as (a) instrumental learning experiences (receiving positive or negative reinforcement), (b) associative learning experiences (associating a neutral event to something meaningful), and (c) vicarious experiences (learning from others' experiences) (Mitchell \& Krumboltz, 1990). The information and confirmation they learned via social learning regarding racial profiling and law enforcement career opportunities caused them to want to explore and commit to a law enforcement career. This exploration and commitment was driven by their desire to make a positive difference by treating people fairly and improving the image and professionalism of law enforcement. The participants also made an effort to build relationships; share information; and provide others the same type of information, support, and encouragement they continue to receive.

\section{Comparative Analysis}

Comparative analysis involves comparing and contrasting the findings from the inductive and deductive analyses to verify consistency in the findings, identify patterns, and answer the research questions (Strauss \& Corbin, 1998). The three themes that emerged from the inductive analysis were (a) color and/or race does matter, (b) putting 
on the badge, and (c) too black to be blue and too blue to be black. The deductive findings were analyzed using Super's (1990) archway model of (a) biographical and geographical foundation, (b) personality and achievement, (c) social policy and employment practices, (d) social learning, and (e) self-concept.

The comparisons between the inductive themes and deductive analysis revealed the theme "color and/or race does matter" was present in the relationships between and within all segments of Super's (1990) model. The comparisons also revealed an expanded notion of self-concept for Black males. - marginalized and/or oppressed individuals.

\section{Biographical and Geographical Foundations}

The biographical and geographical foundation of human development is the individuals' lived history (Super 1990). Lived history includes where participants grew up and issues associated with their color and/or race. Most of the participants grew up or lived in neighborhoods where the majority of their personal encounters with police were negative. All of the participants were familiar with racial profiling first hand, or they had learned of it from others. Racial profiling stories were shared with family and friends and in neighborhood gossip. This sharing of information is consistent with the Afrocentric world view and social nature of Blacks (Osigow \& Littlejohn, 1995).

Media outlets often portrayed Black men in a negative light, and this, too, influenced the lived histories of the participants. The lived histories of being racially profiled and observing others being racially profiled caused tension between participants growing up and law enforcement. This tension caused the participants to want to make a difference after a careful consideration of law enforcement as a possible career. If it was 
not for the lived histories of the participants, the decision to make a difference as a law enforcement officer would not have been a difficult one. When the participants became law enforcement officers, they learned that police are sent to neighborhoods to address with high crime rates to address crime. In many instances, these neighborhoods are Black. This tactic may seem to foster racial profiling, yet, this is simply sound law enforcement, addressing a crime or quality of life issue, and directing the resources where needed. However, the participants observed other officers going into Black neighborhoods to help improve the department's statistics (e.g., citations and arrests), and they also did this themselves. The pursuit of arrests in high crime areas increases transfer and promotion opportunities. Thus, this lived history at once is tied to participants' career progression and is suspect as an act of racial profiling.

\section{Personality and Achievements}

Personality and achievement address how one's needs, values, and interests work together to support one's ultimate goal or achievement (Super, 1990). Participants were aware that they were seeking employment in a White male-dominated profession. They took steps to help them enter the law enforcement profession such as earning associate's and bachelor's degrees, working in security jobs, and serving in the military. Realizing the subjectivity and discretion when it came to selecting candidates for certain opportunities, the participants did whatever it took to eliminate hurdles to being selected for training courses, lateral moves, and promotions. They needed to be three times as good to get the same opportunities; therefore, they earned advanced degrees and certifications, often paying for these opportunities themselves. 


\section{Social Policy and Employment Practices}

Social policy and employment practices are concerned with the "economic resources, economic structure, social institutions, and so on that acts on the person and on which the person acts in growing up and functioning as a unit in society" (Super, 1990, p. 201). Alexander (2012) discusses this issue by stating "The notion that giving a relatively small number of people of color access to key positions or institutions will inevitably redound to the benefit of the larger group is belied by the evidence"...radical changes are needed in our social policies; the privileged should not fear change in the status quo (p. 249). The segment social policy includes the community, society (school and family), peer groups, economy, and labor market.

The effects of racial profiling permeated every aspect of the social policy and employment practices segment. Detentions, citations, arrests, and psychological effects of the negative police encounters took a toll on the participants. As law enforcement works in partnership with the community to reduce crime and improve the quality of life, law enforcement must also hire qualified law enforcement officers. Qualified potential officers who experience racial profiling are hesitant, if not resistant, to the notion of becoming an officer. Their families and community often influence qualified Black candidates' decisions. Community members will request police action in their neighborhoods, and law enforcement responds and takes action by detaining, citing, and arresting the Black individual. This action could taint an innocent individual while deterring criminals and begins to fulfill the self-fulfilling prophecy of racial profiling, thus, causing the tainted Blacks to be casualties in law enforcement's effort to reduce crime and improve the quality to life in the community. 
Racial profiling fosters HRD policies and practices that consciously or unconsciously encourage racial nepotism and subjective discrimination. Bell (1992) described racial nepotism as a preference for one's own race. Law enforcement hiring policies, procedures, and practices set forth guidelines that deem individuals with detentions, citations, and arrests less qualified than individuals without those issues. Although one might think that police actions occur in White neighborhoods, frequently, the suspicious person is still Black. Therefore, Whites rarely are personally affected by being wrongly detained. The tainting of Blacks by racial profiling creates an institutionalized preference for Whites who have not been subjected to racial profiling. Subjective discrimination occurs when someone does not seek an opportunity because they believe a factor not related to the job or task such as race affects how they will be evaluated and treated for various employment opportunities (Naff, 2001).

When law enforcement agencies attempt to hire, retain, and promote Blacks, they face numerous challenges. Racial profiling has tainted the applicant pool, created tension between the Black community and law enforcement, and limited opportunities of Black officers. Existing hiring standards consider the number of citations and arrests the candidate has had in the hiring process. However, there is no way to take into consideration which citations and arrests were as a result of racial profiling. There are also other portions of the hiring process that are very subjective (e.g., background checks and polygraphs). The issue of detentions, citations, and arrests, along with officer statistics, arises when individuals are being selected for special training classes; special assignments; and, ultimately, promotions. If a participant was detained, issued citations, or arrested, his chances at the prized opportunities are reduced. However, if he has a high 
number of citations and arrests to his credit, the chances at the prized opportunities are increased. If it was not for the tangible effects of racial profiling (e.g., citations and arrests), individuals would need to address only the mental aspect of the encounters. Social policy and employment practices provide guidelines that penalize individuals for having citations and arrests, even if they were the result of racial profiling.

Career development, as a part of HRD, is a subjective process monitoring and facilitating a person's career from recruitment and selection to retirement. A finite amount of jobs are open to a large number of candidates. However, if one has citations or arrests, they will negatively impact one's ability to be hired, obtain select assignments, and be promoted. Law enforcement agencies are recognizing the benefits of having employees mirror the community served, yet, law enforcement agencies are slow to recognize the impact of racial profiling on the applicant pool.

All of the participants made sure they exceeded the hiring requirements by taking courses and working jobs that would prepare them for a law enforcement career and lateral or promotional opportunities. Although the participants were more than qualified and prepared for their respective career moves, the majority of the moves occurred after someone else's moved, were career moves based on the acknowledgment, or recruitment from someone else. The term marginalized is used because they exist outside of, marginal to, or are oppressed within the system due to historical, social, cultural, and economic realities (Freire, 1970).

Many of the participants would have remained outside of or marginal to the law enforcement career if it had not been for others reaching out to them. Now, many are finding themselves outnumbered or oppressed within the system. From their oppressed 
positions, all of these Black male participants actively recruit, mentor, serve as role models, motivate other individuals to explore law enforcement as a career, and prepare for lateral and promotional opportunities. During Black males' life spans, they begin to develop perceptions of educational, employment, and economic barriers (Anderson, 1990; Dyson, 2004; Kunjufu, 2004). The recruiting, mentoring, role modeling, and motivating of others help to reduce and eliminate any perceived barriers.

\section{Social Learning}

Social learning theory addresses how individuals learn by three different methods: (a) instrumentally via positive and negative reinforcement, (b) associatively by relating or associating experiences, and (c) vicariously through others' experiences (Mitchell \& Krumboltz, 1990). This finding was consistent with Super's (1990) archway theory, which states that social learning is the cement that connects and holds the entire model together. Osipow and Littlejohn (1995) noted that social learning addresses many issues faced by ethnic minorities in their vocational context.

\section{Self-Concept}

Super (1990) defined self-concept as "self-efficacy, self-esteem, and role selfconcepts, being combinations of traits ascribed to oneself' (p. 202). Super (1990) acknowledged that his definition of self-concept does not completely address the selfconcept for Black, marginalized, and/or oppressed people. Traditionally, the self-concept is based in a Eurocentric (White culture) view. The Eurocentric world view values competition, effort optimism, and individualism and focuses on self (Boykin, as cited in Scott, 2003). The self-concept of Blacks and marginalized and/or oppressed individuals extends beyond merely self and how they see themselves to include their awareness of 
how others see them. The self-concept of Blacks has two aspects: personal self-reflection and an awareness of how others view them. The term self-concept should not be confused with the term self-esteem (Super, 1990).

Historically, Blacks have been subjected to the following racial injustices in the United States: slavery, racial lynching, and racially motivated abuses of police authority (Delattre, 2002). "Any consideration of the progress of civil rights remedy in the United States must acknowledge that slavery, real slavery, didn't end until 1945" (Blackmon, 2012, p. 402) abuses at the hands of law enforcement are currently being reported. The participants were keenly aware of the power of law enforcement. When they were driving (off the job as officers) and saw police cars, they always made sure they were obeying the law. Although they were obeying the law, some of them were stopped for alleged traffic violations. However, the officers conducting the traffic stops began asking questions regarding drugs and, on some occasions, other crimes. During traffic stops when they believed they were racially profiled and they identified themselves as law enforcement officers, the officer would give them a minor reason for stopping them and, then, let them go. The participants all recognized the contrast in treatment they received based on the color of their skin versus once they were identified as law enforcement officers. This recognition of law enforcement power caused and still causes Blacks to avoid or become invisible to law enforcement as a means of self-preservation (Anderson, 1990).

Blacks use information regarding racial profiling and the differential treatment to determine how others view them and use this information to form their self-concept. Both aspects of their self-concept are used to make career decisions. 


\section{CHAPTER VI}

\section{DISCUSSION}

This chapter is divided into three sections: (a) responses to the research questions (b) implications for research and practice, and (c) recommendations for future research.

\section{Research Questions}

The discussion begins with responses to the subsidiary research questions. The response to the primary research question will conclude the discussion.

Subsidiary Research Question 1. This research question was, How do Black male law enforcement officers define racial profiling? The participants defined racial profiling similarly with slight variations. The following are some examples:

Kamal stated, "Just having a preconceived notion or a preconceived idea that someone's up to something or doing something wrong just based on their racial characteristics or ethnic characteristics" (Kamal, 18/1-5).

Chaka said, "That officer's individual decision to stop everybody that looks a certain way. He's not stopping the vehicle. He's not stopping for the infraction. He's stopping the person" (Chaka, 20/23).

Kwame replied, "It is the actions taken by not just law enforcement [but] anyone that prejudges and reacts just based solely on the color, the nationality, or the creed of an individual" (Kwame, 33/20-22).

Although the participants provided different definitions, the essence of their definitions was the same: the use of race as the primary determining factor for any actions, especially those of the law enforcement officers or organizations due to their ability to taint an individual or a group of individuals permanently. The definitions were 
geared toward the actions of an individual. However, the participants provided examples that further show the complexity of racial profiling. Participants also discussed how everyone is subject to search while in the various ports traveling in and out of the United States. One of the participants even discussed how he observed federal law enforcement officers with drug sniffing dogs randomly sniff Blacks for drugs more often than Whites in various customs areas. This complexity can cause racial profiling to appear to be consciously or unconsciously systemic and woven into the criminal justice system.

As the participants discussed racial profiling, they acknowledged the insight they have gained as law enforcement officers has provided them with a different perspective of racial profiling. After becoming law enforcement officers, they learned, via training, how officers work with the public to identify potential problems and individuals who have or may have committed a crime. They now understand that, in some instances, the public may believe they are being racially profiled when, in fact, the officer is merely doing his or her job. The criminal justice system is partial and impartial due to imperfect individuals who are influenced by social, economic, and cultural factors and by interpreting and applying established laws (Cureton, 2000).

This insight further shows racial profiling has resulted in detentions, citations, and arrests. The victims of racial profiling were tainted and viewed as casualties. They were casualties because they received tangible evidence (citations, arrests, etc.) of their negative encounter with law enforcement.

Subsidiary Research Question 2. This research question was, What role has racial profiling played in Black male law enforcement officers' career exploration? The participants acknowledged that racial profiling played a role in their law enforcement 
career exploration by motivating them to pursue such a career to make a difference. Racial profiling fulfilled this role by creating a set of experiences such as being treated with suspicion and detained. Barak was even arrested prior to exploring law enforcement as a career. These experiences caused them to want to become law enforcement officers and make a difference in the profession and community.

Chaka and Omari were racially profiled when driving to and from college and in the presence of friends and family members. Their experiences confirmed the negative stories others had shared with them about law enforcement and its treatment of Blacks. Some of the participants' friends and family continued to view law enforcement negatively. Due to this negative view of law enforcement and the perceived danger of the profession, many of the friends and family did not strongly support the idea of a law enforcement career.

The participants discussed other effects of racial profiling such as the negative reputation of law enforcement within the Black community, law enforcement's assumption of guilt and suspicion, and marginalization of Blacks. They are additionally aware that, if they meet the minimum hiring standards, racial profiling and the use of race as a determinant will cause them to have a difficult task of passing the numerous subjective steps in the hiring and career development process. Subjective steps can be taking the polygraph, the background check, and the assessment of the FTO. Whether or not an applicant succeeds in any of these is based on the subjective decision of a person interpreting the data. This subjectivity will continue throughout their careers (Bolton \& Feagin, 2004). 
One of Kunta's Black friends fostered a negative view of law enforcement due to his experience during his polygraph exam as he explored his law enforcement career; some view this exam as subjective. Kunta's friend informed Kunta that he failed his polygraph exam because the examiner believed that he was lying about not using drugs although he had never used drugs. When Kunta arrived at the same point in his exploration, he faced the same issue. He believed that he was being racially profiled, and it became a hurdle he eventually overcame as he explored law enforcement as a career. Kunta and the other participants used their experiences of racial profiling to fuel their desire to become law enforcement officers and make a difference.

Subsidiary Research Question 3. This research question was, What career adaptive mechanisms do Black male law enforcement officers believe enhance their integration into law enforcement? The participants were all strong Black men and utilized various career adaptive mechanisms to address their hurdles and enhance their integration into law enforcement. In addition to the normal hurdles individuals experience in a career, these participants faced hurdles associated with their race while putting on the badge and while living with the badge. These hurdles included issues such as being treated with suspicion, being ostracized on the job, not being selected for special assignments, being treated as second-class employees, and having their employment questioned by the public. Through all of the experiences, the participants realized they must be three times as good as their coworkers to have the same opportunities.

On Barak's first day of work, his greeting to a supervisor was ignored. He was later informed that the supervisor was racist. Maalik's request to attend a prized training class was denied. A less qualified White coworker was selected. Maalik's supervisor 
told him sending him "would be like sending an elementary school child to college." When some of the participants were denied training opportunities due to budget constraints, they paid for their own classes and took classes on their own time. Kamal went to a call with his White partner, and the victim treated him as a criminal, not as a detective. Kuumba failed a portion of his training with one agency and was not afforded an opportunity to work in another job classification. He was informed this was not an option. However, he learned other similarly situated White candidates were afforded that option. All of the participants take a proactive role in their careers. They understand nothing will be given to them.

The participants echoed the sentiments that they must be three times as good as their counterparts to receive the same opportunities. Chaka stated, "We, as Blacks, need to prepare and perform to a level that will make our counterparts insignificant.” Kamal did not want education to be a barrier, so he earned two master's degrees. Martin obtained certification in nearly every high-liability course. Trey wanted to be a school resource officer. In an effort to make himself a better candidate, he became a substitute teacher in the school and began networking from outside the agency. His efforts earned him the position.

They also recognized the benefit of networking and the influence of others on their careers. There observations were consistent with Phillips et al.'s (2001) study that identified the following three themes that described how others influenced career exploration: action of others, the recruitment of others, and pushing others away. The participants mentioned role models, White members of law enforcement, and family members that assisted their integration into law enforcement. Jabari mentioned that his 
brother was exploring law enforcement and he followed in his footsteps. He was more successful than his brother. Jamal was encouraged to apply when White members of the agency saw him working a security job. Isaac was working in retail, when a coworker began referring to him as her son, told him he should be in law enforcement, and introduced him to her son who was in law enforcement. White officers at a neighboring agency informed Kobe that they would treat him better than his current agency and arranged meetings with their Chief. Kobe made the transfer to their agency and has been very successful.

The participants all took personal responsibility for enhancing their integration into law enforcement. They were open to and sought out input from others. They also realized that, by being three times as good as their counterparts, their chances of being recognized and provided opportunity would be increased.

Subsidiary Research Question 4. This research question was, How has racial profiling influenced Black male law enforcement officers' process of career decision making within the organization? Racial profiling has influenced Black male law enforcement officers' process of career decision making within the organization by motivating them to want to make a difference. The participants wished to show that all Black males are not criminals and should not be treated as such. They also wanted to make a difference by showing others that law enforcement is a rewarding career and by creating opportunities for others. Lastly, they realized that they had to self-monitor their career progression.

In order to make a difference, they recognized every position that they are in is critical to their career progression. They also recognized some classes and positions are 
given more respect than others. The participants mentioned attending the prestigious Federal Bureau of Investigations National Academy, Southern Police Institute, obtaining instructor certification in high-liability classes, and making sure they are exceeding training requirements. These Black males have worked in positions such as Internal Affairs, school resource officers, and recruiting. Some of the participants also realized that, to make a difference, they should seek promotions. Our participants included first line supervisors and Sergeants up to and including Kamal who served as a Deputy Chief, second in charge of an agency.

As these Black males serve the public, they also take every opportunity to explain the job of law enforcement to individuals. Omari often spoke to various organizations and discussed issues such as racial profiling. Kamal had to address a situation where a friend of his believed he was racially profiled. However, after he reviewed the tape of the incident, he had to explain to his friend he was not racially profiled. Although the participants are aware of racial profiling and how it can negatively impact their career exploration and progression, they take responsibility for their careers and address those issues they can control.

Primary Research Question. This research question was, What are Black male law enforcement officers' perspectives of how racial profiling shaped their decisions to explore and commit to a law enforcement career? The participants acknowledged that racial profiling is a complex issue and has consciously or unconsciously been woven into the criminal justice system. They defined racial profiling as the use of race as the primary determining factor for any actions, especially those of the law enforcement 
officer or organization due to their ability to taint an individual or a group of individuals permanently.

Prior to becoming law enforcement officers, the participants were all aware of racial profiling. Most of them had experienced racial profiling, and one participant had been arrested as a result of racial profiling. These incidents frustrated them and motivated them to become law enforcement officers. They wanted to make a difference in the community and change the negative reputations of law enforcement officers in the Black community.

Once they became law enforcement officers, they learned more about law enforcement, how officers perform their jobs, and the amount of discretion they have when performing their duties. The participants also learned that, in some instances, what may appear to be racial profiling is not racial profiling; it is sound police work. Barak even better understood why he was detained after he learned more about the profession. These participants also observed other officers racially profiling individuals, and they were also sent into high crime, Black neighborhoods to reduce crime (i.e., detain, cite, and arrest individuals).

The participants use their experiences as victims of racial profiling to inform their style of policing. They attempt to treat everyone fairly. They also speak to various groups and individuals about racial profiling. They also attempt to recruit more Blacks in law enforcement and encourage other Blacks to seek career advancement and promotions. The participants also understand that they must be three times as good as their counterparts to receive the same opportunities. 
The participants also began progressing in their careers and worked assignments such as Internal Affairs, school resource officer, supervisors, and managers. The participants did whatever they could to reduce racial profiling. This included speaking to various groups and investigating allegations of racial profiling. All of the participants wish to be a part of the solution to reduce and eliminate racial profiling and its tainting effects.

\section{Implications for Research and Practice}

This study revealed the essence of racial profiling from the Black male law enforcement officer's perspective. The participants addressed the issue on local, county, and federal levels. The study implies the following: color and/or race does matter, and racial profiling negatively impacts Blacks' career options.

Racial profiling is a complex issue, and it intersects many areas of Blacks' lives. The amount of discretion law enforcement officers possess when conducting their job further complicates the issue of racial profiling. There are very few occasions that an officer must write a citation or arrest an individual. Merely living in a high crime area increases the likelihood of an individual having negative contacts with law enforcement; many of these neighborhoods are Black communities (Anderson, 1990). Withrow (2004) stated that, as a result of the increased police activity in the Black neighborhoods, the minority population will receive more citations and arrests than members in other communities.

Racial profiling occurs based on an individual's perception that the individual is Black. This perception occurs based on the persons' skin color, the type car they drive, the type music coming from their vehicle, hair styles, and so forth. Once they are 
perceived to be Black, individuals begin to stereotype them as suspicious. This suspicion can lead citizens to contact police who, ultimately, respond and take law enforcement action. Law enforcement could be the first to see the individual, and the officer takes some type of action. On some occasions, individuals may believe that they have been racially profiled when, in actuality, they were not. They may have actually fit the description of a suspect.

Current human resource policies and practices do not take into consideration that negative police contact, especially the contact that results in traffic citations and arrests, which could be the result of racial profiling. Current human resource hiring guidelines penalizes individuals who have had negative police contact, thus, perpetuating the discriminatory effects of racial profiling. Therefore, racial profiling is a discriminatory act that can effectively circumvent U.S. EEOC laws and serve as a boundary mechanism to employment (Rocco \& Gallagher, 2004). The negative police contact associated with racial profiling can occur prior to being employed, while seeking employment, or while employed.

Organizations should have training to discuss the essence of racial profiling from a human resource standpoint. The training should be broad, including supervisors and managers who will be participating in the hiring process and the officers. Officers should be included in this training so that they are more aware of the impact of their actions. The officers may not be aware of the long-lasting implications of their discretionary actions on others. "People do not enter the police because they are racist; rather, they acquire racial prejudice through a process of professional socialization" (Zauberman \& Le'vy, 2003, p. 1065). Organizations may also wish to establish accountability and 
assessment measures to detect the essence of racial profiling and address the issue with the officer and within the law enforcement agency. The organization should also recruit and retain individuals who reflect the demographics, visually and mentally, of the community they serve. Currently, organizations' diversity efforts appear to be focused on visual diversity.

Organizations should also consider implementing community internships where employees work with a community-based organization to provide them a better appreciation of the community. Mentorship programs should also be considered for officers who are unfamiliar with the dynamics of the community they serve. Psychological training could also be provided to discuss the effects of racial profiling on the victim, Black males, and perpetrators.

\section{Recommendations for Future Research}

Further research should be conducted regarding the intersection of racial profiling and HRD policies and practices such as an examination of the policies and practices that allow for subjective assessments of individuals' capabilities during the hiring process (e.g., polygraphs, field training assessments, and background checks). Will training of the assessors improve the fairness of the process? If results of these assessments are compared by race, what will be the results? Are policies in place that discourage or encourage racial profiling of job applicants? How does human resource take into consideration citations or arrests that were the result of racial profiling? Research should be conducted on why qualified Blacks do not explore law enforcement as a career as well as why Latinos and Latinas, women, and sexual minorities do not (Scholarios et al., 2003). Another area of research could be to mirror this research with other groups such 
as White male law enforcement officers and members of marginalized communities.

Additionally, a quantitative analysis of the data collected for this study could be utilized to determine the relationship between exploring and committing to a law enforcement career and the segments of Super's (1990) archway model.

As we continue to research the essence of racial profiling and the presence of race in our everyday lives, we must continue to question practices that others may be consciously or unconsciously perpetuating. Racial profiling was coined in 1999; prior to that, we had Jim Crow.

Even those herculean efforts we hail as successful will produce no more than temporary "peaks of progress," short-lived victories that slide into irrelevance as racial patterns adapt in ways that maintain White dominance. This is a hard-toaccept fact that all history verifies we must acknowledge it, not as a sign of submission, but as an act of ultimate defiance. (Bell, 1992, p. 12)

\section{Limitations of the Study}

Racial profiling affects more than just Black males seeking jobs in law enforcement. It affects Black males seeking to explore and commit to other careers. It also affects Black females and White individuals. However, this research was limited to Black male law enforcement officers' perspectives of how racial profiling shaped their decisions to explore and commit to a law enforcement career.

\section{Summary}

Chapter 6 concluded the study with the responses to the research questions, implications for practice, and recommendations for future research. This phenomenological study sought to explore Black male law enforcement officers' perspectives of how racial profiling shaped their decisions to explore and commit to a law enforcement career. 


\section{REFERENCES}

Abramovsky, A., \& Edelstein, J. I. (2000). Pretext stops and racial profiling after Whren v. United States: The New York and New Jersey responses compared. Albany Law Review, 63, pp. 725-748.

Alpert Group. (2004). Miami-Dade Police Department racial profiling study. Miami, FL: Miami-Dade Police Department.

Alexander, M. (2012), The new Jim crow:Mass icarceration in the age of colorblindness. New York, The New Press,

American Civil Liberties Union. (2004). Sanctioned bias: Racial profiling since 9/11. Retrieved from http://www.aclu.org/files/FilesPDFs/racial\%20profiling\%20report .pdf

American Civil Liberties Union. (2005). The persistence of racial profiling in Rhode Island: An update. Retrieved from http://www.aclu.org/FilesPDFs/profiling_ri_ update.pdf

Anderson, E. (1990). Streetwise: Race, class, and change in an urban community. Chicago, IL: The University of Chicago Press.

Asumah, S. N. (2004). Racial identity and policy making: Redefining whiteness. The Western Journal of Black Studies, 28, 501-510.

Barlow, D. E., \& Barlow, M. H. (2002). Racial profiling: A survey of African American police officers. Police Quarterly, 5, 334-358. Retrieved from http://www.pqx .sagepub.com

Bell, D. (1992). Faces at the bottom of the well: The permanence of racism. New York, NY: Basic Books.

Bell, D. (1995). Racial realism. In K. Crenshaw, N. Gotanda, G. Peller, \& K. Thomas (Eds.), Critical race theory: The key writings that formed the movement (pp. 302312). New York, NY: The New Press.

Bell, D. (2001). In R. Delgado \& J. Stefancic (Eds.), Critical race theory: An introduction. New York: New York University Press.

Berg, B. L. (2001). Qualitative research methods for the social sciences. Needham Heights, MA: Allyn \& Bacon 
Bjerk, D. (2004). Racial profiling, statistical discrimination, and the effect of a colorblind policy on the crime rate. Journal of Public Economic Theory, 9, 521-545.

Retrieved from http://www.claremontmckenna.edu/econ/dbjerk/jpet_reprint.pdf

Blackmon, D. A. (2008). Slavery by another name:The re-enslavement of black Americans from the civil war to world war II. New York The Doubleday Publishing Group.

Blustein, D. L. (1997). A context-rich perspective on career exploration across the life roles. The Career Development Quarterly, 45, 260-274.

Boehm-Hill, C. (1993). Empowering an endangered species: The African-Caribbean/ Canadian male. Education Canada, 33(2), 31-35.

Bolton, K., \& Feagin, J. R. (2004). Black in blue: African American police officers and racism. New York, NY: Routledge.

Brace, C. L. (2008). Races ranked by early scientist. In J. H. Moore (Ed. in Chief), The encyclopedia of race and racism (pp. ). Farmington Hills, MI: Thomson Gale.

Broward College, Institute of Public Safety. (n.d.) Police academy. Retrieved from http:// www.broward.edu/ips/IPS/PoliceAcademy/page5964.html

Browne-Marshall, G. J. (2007). Race, law, and the American society: 1607-present (Criminology and justice studies). New York, NY: Routledge.

Chung, Y. B., Baskin, M. L., \& Case, A. B. (1999). Career development of Black males: Case studies. Journal of Career Development, 25(3), 161-171.

Civil Rights Act of 1964. Pub. L. 88-352, 78 Stat. 241. (1964). Document No.: PL 88352 Date: 02 JUL 64 88th Congress, H. R. 7152. Retrieved from U.S. Department of Transportation, Civil Rights website: http://www.dotcr.ost.dot.gov/Documents $\% 5 C Y C R \% 5 C C I V I L R 64 . H T M$

Civil Rights Act of 1991. (1991). Retrieved from U.S. Equal Employment Opportunity Commission website: http://www.eeoc.gov/eeoc/history/35th/thelaw/cra_1991 .html

Civil Service Reform Act of 1978. Pub. L. 95-454, 92 Stat. 1111 (1978). Retrieved from U.S. Office of Personnel Management website: http://www.opm.gov/biographyof anideal/PU_CSreform.htm

Colon, E., Appleby, G. A., \& Hamilton, J. (2001). Affirmative practice with people who are culturally diverse and oppressed. In G. A. Appleby, E. Colon, \& J. Hamilton 
(Eds.), Diversity, oppression and social functioning: Person-in-environment assessment and intervention (pp. 239 - 256). Needham Heights, MA: Allyn \& Bacon.

Cose, E. (1995). The rage of a privileged class: Why are middle-class blacks angry? Why should America care? New York, NY: Harper Collins.

Creswell, J. W. (1998). Qualitative inquiry and research design: Choosing among five traditions. Thousand Oaks, CA: Sage.

Creswell, J. W. (2003). Research design: Qualitative, quantitative, and mixed methods approaches (2nd ed.). London, England: Sage.

Cureton, S. R. (2000). Justifiable arrests or discretionary justice-Predictors of racial arrest differentials. Journal of Black Studies, 30, 703-719.

Delattre, E. J. (2006). Character and cops: Ethics in policing (5th ed.). Washington, DC: AEI Press.

Delgado, R., \& Stefancic, J. (2001). Critical race theory: An introduction. New York: New York University Press.

Delpit, L. (1995). Other people's children: Cultural conflict in the classroom. New York, NY: The New Press.

Diller, J. V. (2004). Cultural diversity: A primer for the human services (2nd ed.). Belmont, CA: Brooks/Cole-Thomson Learning.

DuBois, W. (1995). The souls of Black folk. New York, NY: Signet Classic.

Dyson, M. E. (2004). The Michael Eric Dyson reader. New York, NY: Basic Civitas.

Equal Pay Act of 1963. Pub. L. No. 88-38, 77 Stat. 56. (1963). Retrieved from U.S. Department of Labor Office of the Assistant Secretary for Administration and Management website: http://www.dol.gov/oasam/regs/statutes/equal_pay_act.htm

Florida Department of Law Enforcement. (n.d.). Officer requirements: How to become a certified officer in Florida. Retrieved from http://www.fdle.state.fl.us/Content/ getdoc/16b5a8f6-412c-4c72-817e-d26cb05b2e3d/how-to-become-an-officer .aspx

Florida International University. (2007). Florida International University regulations for thesis/dissertation preparation manual. Retrieved from http://www.gradschool .fiu.edu/thesis.html 
Fort Lauderdale Police Department. (n.d.). Police officer. Retrieved from City of Fort Lauderdale Police Department website: http://www.flpd.org/index.aspx?page=82

Freeman, A. D. (1995). Legitimizing racial discrimination through antidiscrimination law: A critical review of supreme court doctrine. In K. Crenshaw, N. Gotanda, G. Peller, \& K. Thomas (Eds.), Critical race theory: The key writings that formed the movement (pp. 29-46). New York NY: The New Press.

Freire, P. (1970). Cultural action for freedom. Cambridge, MA: Harvard Educational Review.

Freire, P. (2000). Pedagogy of the oppressed. New York, NY: Continuum.

Fridell, L., Lu., R., Diamond, D., Kubu, B., Scott, M., \& Laing, C. (2001). Racially biased policing: A principled response. Washington, DC: Police Executive Research Forum.

Gibson, S. K., \& Hanes, L. A. (2003). The contribution of phenomenology to HRD research. Human Resource Development Review, 2, 181-205.

Gilley, J., Eggland, S., \& Gilley, A. (2002). Principles of human resource development. New York, NY: Basic Books.

Goldstein, H. (1990). Problem-oriented policing. New York, NY: McGraw-Hill.

Gordon, N. S. (2000). Researching psychotherapy, the importance of the client's view: A methodological challenge. The Qualitative Report, 4(3/4), 1.

Halley, J. (2012). Brian Banks has rape and kidnapping convictions overturned. Retrieved from http://www.usatoday30.usatoday.com/sports/preps/football/story/ 2012-05-24/brian-banks-rape-conviction-overturned/55192420/1

Hamilton, J. (2001). Racism: People of color. In K. Hanson (Ed.), Diversity, oppression, and social functioning: Person-in-environment assessment and intervention ( $\mathrm{pp}$. 53-69). Needham Heights, MA: Allyn \& Bacon.

Harris, D. A. (2002). Profiles in injustice: Why racial profiling cannot work. New York, NY: The New Press.

Harrison, P. M., Minton, T. D., \& Sabol, W. J. (2007). Prison and jail inmates at midyear 2006 (NCJ 217675). Washington, DC: U.S. Department of Justice, Office of Justice Programs, Bureau of Justice Statistics. Retrieved from http://www.bjs.ojp .usdoj.gov/index.cfm?ty=pbdetail\&iid=1006

hooks, b. (1994). Teaching to transgress: Education as the practice of freedom. New York, NY: Routledge. 
Howard, T. C. (2003). A tug of war for our minds: African American high school students' perceptions of their academic identities and college aspirations. The High School Journal, 87(1), 4-17.

How your driving record impacts your insurance rate. (2008). Retrieved from http:// www.insurance.com/Article.aspx/How-Your_Driving_Record_Impacts_Your_ Insurance

Johnson, K. (2000, November 21). Police struggle to find next generation: Hot economy forces recruiters to lower bar, even to the point of accepting past drug use. USA Today, p. A5.

Jonsson, P. (2009, July 23). Police and Blacks: Old tensions slow to heal. The Christian Science Monitor, 0, 2.

Karunanayake, D., \& Nauta, M. M. (2004). The relationship between race and students' identified career role models and perceived role model influence. Career Development Quarterly, 52, 225-234.

Kunjufu, J. (2004). Countering the conspiracy to destroy black boys (Vols. 1-4). Chicago, IL: African American Images.

Laine, R. B. (2009, September). Law enforcement and public perception: Race, ethnicity, and community policing. The Police Chief, 76, 6.

Lamb, G. (2008, April 17). Columbine high school. New York Times. Retrieved from http://www.topics.nytimes.com/topics/reference/timestopics/organizations/c/ columbine_high_school/index.html

Lawrence, C. R. (1995). The id, the ego, and equal protection reckoning with unconscious racism. In K. Crenshaw, N. Gotanda, G. Peller, \& K. Thomas (Eds.), Critical race theory: The key writings that formed the movement (pp. 235-257). New York, NY: The New Press.

Lincoln, Y. S., \& Guba, E. G. (1985). Naturalistic Inquiry. Thousand Oaks, CA: Sage.

Lynch, J. P., \& Sabol, W. J. (2004). Assessing the effects of mass incarceration on informal social control in communities. Criminology \& Public Policy, 3, 267-294.

McCarthy, C., Crichlow, W., Dimitriadis, G., \& Dolby, N. (2005). Race, identity, and representation in education (2nd ed.). New York, NY: Routledge Falmer. 
McIntosh, P. (2004). White privilege: Unpacking the invisible knapsack. In M. L. Andersen \& P. H. Colllins (Eds.), Race, class and gender (5th ed., pp. 103-108). Belmont, CA: Thomson Wadsworth.

McMahon, J., Garner, J., Davis, R., \& Kraus, A. (2002). How to correctly collect and analyze racial profiling data: Your reputation depends on it! Washington, DC: The CNA Corporation.

Meeks, K. (2000). Driving while Black: What to do if you are a victim of racial profiling. New York, NY: Broadway.

Mentzer, M. S. (2002). How Canada promotes workplace diversity. In C. Harvey \& M. J. Allard (Eds.), Understanding and managing diversity: Readings, cases, and exercises (2nd ed., pp. 89-94). Upper Saddle River, NJ: Prentice-Hall.

Miles, M. B., \& Huberman, A. M. (1994). An expanded sourcebook: Qualitative data analysis (2nd ed.). Thousand Oaks, CA: Sage.

Mitchell, L. K., \& Krumboltz, J. D. (1990). Social learning approach to career decision making: Krumboltz's theory. In D. Brown, L. Brooks, \& Associates (Eds.), Career choice and development: Applying contemporary theories to practice (2nd ed., pp. 145-196). San Francisco, CA: Jossey-Bass.

Muharrar, M. (1998). Media blackface: Racial profiling in news reporting. Fairness \& Accuracy in Reporting. Retrieved from http://www.fair.org/index.php?page=1431

Naff, K. C. (2001). To look like America. Boulder, CO: Westview.

National Organization of Black Law Enforcement Executives. (2001). NOBLE's mission, vision, and guiding principles. Retrieved from NOBLE website: http://www .noblenatl.org/index.php?option $=$ com_content\&view $=$ category\&layout $=$ blog\&id $=$ 106\&Itemid $=97$

Neuman, W. L. (1997). Social research methods: Qualitative and quantitative approaches (5th ed.). Boston, MA: Allyn \& Bacon.

Nevillo, D. (1997). Career Development Quarterly, 45, 288-292.

Newport, F. (1999, December 9). Racial profiling is seen as widespread, particularly among young Black men. Gallup Daily News. Retrieved from http://www.gallup .com/poll/3421/Racial-Profiling-Seen-Widespread-Particularly-Among-YoungBlack-Men.aspx 
Omi, M., \& Winant, H. (2005). The Theoretical status of the concept of race. In McCarthy, C., Crichlow, W., Dimitriadis, G., \& Dolby, N. (Eds.). Race, identity, and representation in education (2nd ed.). New York, NY: Routledge Falmer.

Osipow, S. H., \& Littlejohn, E. M. (1995). Toward a multicultural theory of career development: Prospects and dilemmas. In F. T. L. Leong (Ed.), Career development and vocational behavior of racial and ethnic minorities (pp. 251261). Mahwah, NJ: Lawrence Earlbaum.

Pager, D. (2003). The mark of a criminal record. The American Journal of Sociology, $108,937-975$.

Park, E. J. (1999). Racial ideology and hiring decisions in Silicon Valley. Qualitative Sociology, 22, 223-233.

Patton, M. Q. (2002). Qualitative research and evaluation methods (3rd ed.). Thousand Oaks, CA: Sage.

Peregrine, P. N. (2008). Racial hierarchy: Overview. In J. H. Moore (Ed. in Chief), The encyclopedia of race and racism (pp. ). Farmington Hills, MI: Thomson Gale.

Phillips, S. D., Christopher-Sisk, E. K., \& Gravino, K. L. (2001). Making career decisions in a relational context. The Counseling Psychologist, 29, 193-214.

Reaves, B. A. (2007). Census of state and local law enforcement agencies, 2004. (NCJ 212740). Washington, DC: United States Department of Justice, Office of Justice Programs, Bureau of Justice Statistics.

Rocco, T. S., \& Gallagher, S. (2004). Discriminative justice: Can discrimination be just? In L. Martin \& E. Rogers (Eds.), Adult education in an urban context: Problems, practices, and programming for inner-city communities (pp. 29-41). San Francisco, CA: Jossey-Bass.

Rocco, T. S., \& West, G. W. (1998). Deconstructing privilege: An examination of privilege in adult education. Adult Education Quarterly, 48(3), 171-184.

Rothenberg, P. S. (2002). White privilege: Essential readings on the other side of racism. New York, NY: Worth.

Salamone, D. (1998). Miami-Dade cop's stop by deputy ruled illegal. Orlando Sentinel. Retrieved from http://www.articles.orlandosentinel.com/1998-04-02/news/ 9804020122_1_aaron-campbell-resisting-arrest-campbell-failed 
Scholarios, D., Lockyer, C., \& Johnson, H. (2003). Anticipatory socialisation: The effect of recruitment and selection experiences on career expectations. Career and Development International, 8(4), 182-197.

Schram, T. H. (2003). Conceptualizing qualitative inquiry: Mindwork for fieldwork in education and the social sciences. Upper Saddle River, NJ: Merrill Prentice-Hall.

Scott, L. D. (2003). Cultural orientation and coping with perceived discrimination among African American youth. Journal of Black Psychology, 29, 235-256.

Scott v. Sandford, 60 U.S. 393 (1856). Retrieved from http://www.caselaw.lp.findlaw . com/scripts/getcase.pl?court=US\&vol=60\&invol $=393$

Scoville, D. (2000, August 6). A view askew: A sideways look at racial profiling. Police, 16-23.

September 11: Chronology of terror. (2001). Retrieved from http://www.archives.cnn .com/2001/US/09/11/chronology.attack/index.html

Shapira, I., \& Jackman, T. (2007, April 17). Gunman kills 32 at Virginia Tech in deadliest shooting in U.S. history. Washington Post. Retrieved from http://www .washingtonpost.com/wp-yn/content/article/2007/04/16/AR2007041600533.html

Sheared, V. (1999). Giving voice: Inclusion of African American students' polyrhythmic realities in adult basic education. In T. C. Guy (Ed.), Providing culturally relevant adult education: A challenge for the twenty-first century (pp. 33-48). San Francisco, CA: Jossey-Bass.

Shusta, R. M., Levine, D. R., Harris, P. R., \& Wong, H. Z. (2002). Multicultural law enforcement: Strategies for peacekeeping in a divers society (2nd ed.). Upper Saddle River, NJ: Prentice-Hall.

Slonaker, W. M., Wendt, A. C., \& Kemper, M. J. (2001). Discrimination in the ranks: An empirical study with recommendations. Police Quarterly, 4, 289-317.

Smith, W. A., Allen, W. R., \& Danley, L. L. (2007). Assume the position . . you fit the description. American Behavioral Scientist, 51, 551-578.

Strauss, A., \& Corbin, J. (1998). Basics of qualitative research (2nd ed.). Thousand Oaks, CA: Sage.

Sue, D. W. (2003). Overcoming our racism: The journey to liberation. San Francisco, CA: Jossey-Bass. 
Sue, D. W., \& Sue, D. (2003). Counseling the culturally divers theory and practice (4th ed.). New York, NY: John Wiley \& Sons.

Super, D. E. (1980). A life-span, life-space approach to career development. Journal of Vocational Behavior, 16, 282-298.

Super, D. E. (1990). A life-span, life-space approach to career development. In D. Brown, L. Brooks, \& Associates (Eds.), Career choice and development: Applying contemporary theories to practice (2nd ed., pp. 197-261). San Francisco, CA: Jossey-Bass.

Tabulation Working Group of the Interagency Committee for the Review of Standards for Data on Race and Ethnicity. (2000). Provisional guidance on the implementation of the 1997 standards for the collection offederal data on race and ethnicity. Retrieved from Office of Management and Budget official website: http://www.whitehouse.gov/omb/inforeg/re_guidance2000update.pdf

The Unofficial DMV Guide. (n.d.). Driving records guide. Retrieved from http://www .dmv.org/driving-records.php

Thomann, D. A. (2001). The decision to implement traffic stop data: Data collection in systemic efforts to prevent bias-based profiling. Retrieved from http://www.calea .org/newweb/newsletter/No77/decioninmplemettraffic.htm

Tillyer, R., Engel, R. S., \& Wooldredge, J. (2008). The intersection of racial profiling. Journal of Criminal Justice, 36(2), 138-153.

Title VII of the Civil Rights Act of 1964. Retrieved from U.S. Equal Opportunity Employment Commission website: http://www.eeoc.gov/laws/statutes/titlevii.cfm

Trayvon Martin's friend on phone sought after by George Zimmerman's attorneys as key deposition in case. (2013). Retrieved from http://www.huffingtonpost.com/news/ trayvon-martin

Trujillo, M. (2009). Henry Louis Gates, Jr. arrested, police accused of racial profiling. Retrieved from http://www.huffingtonpost.com/2009/07/20/henry-louis-gates-jrarre_n_241407.html

Twine, F. W. (2008). Racial formations: Changes in U.S. race classification schemes. In J. H. Moore (Ed. in Chief), The encyclopedia of race and racism (pp. 460-461). Farmington Hills, MI: The Gale Group.

U.S. Department of Justice. (2006). Bureau of Justice statistics fact sheet. Washington, DC: Author. 
U.S. Department of Justice. (n.d.) About DOJ. Retrieved from http://www.justice.gov/02 organizations/about.html

U.S. Department of Justice, Office of Justice Programs, Bureau of Justice Statistics. (2002). Contacts between police and the public: Findings from the 2002 national survey. Retrieved from http://www.bjs.ojp.usdoj.gov/content/pub/pdf/cpp02.pdf

U.S. Department of Justice, Office of Justice Programs, Bureau of Justice Statistics. (2010). The justice system: What is the sequence of events in the criminal justice system? Retrieved from http://www.bjs.ojp.usdoj.gov/content/justsys.cfm

U.S. Equal Employment Opportunity Commission. (n.d.a). Definition of terms. Retrieved from http://www.eeoc.gov/eeoc/statistics/enforcement/definitions.cfm

U.S. Equal Employment Opportunity Commission. (n.d.b). Title VII of the Civil Rights Act of 1964. Retrieved from http://www.eeoc.gov/laws/statutes/titlevii.cfm

U.S. Equal Employment Opportunity Commission. (n.d.c). Title VII of the Civil Rights Act of 1964 charges (includes concurrent charges with ADEA, ADA and EPA) FY 1997 - FY 2009. Retrieved from U.S. EEOC website: http://www.eeoc.gov/ eeoc/statistics/enforcement/titlevii.cfm

U.S. Equal Employment Opportunity Commission. (2006). Compliance Manual Section 15 on race and color discrimination (Publication No. 915.003). Retrieved from http://www.eeoc.gov/policy/docs/race-color.pdf

Walker, S. (1997). Popular justice: A history of American criminal justice (2nd ed.). New York, NY: Oxford University Press.

Wang, L. (2006). Discrimination by default: How racism becomes routine. New York: New York University Press.

West, C. (2000). The Cornel West reader. New York, NY: Basic Civitas.

West, C. (2001). Race matters (2nd ed.). New York, NY: Vintage.

Wexler, C. (2009). 63 percent of local police departments are facing cuts in their total funding, survey shows. Police Executive Research Forum, 4. Retrieved from http://www.policeforum.org/upload/perf\%20survey\%20on\%20policing\%20\&\%2 0economy_908860847_222009153254.pdf

Whitaker, B. (2000, October 1). San Diego police found to stop Black and Latino drivers most. New York Times, p. 1.31.

White, J., \& Glod, M. (2009, November 11). Muhammad is executed for sniper killing. Washington Post. Retrieved from http://www.washingtonpost.com/wpdyn/ content/article/2009/11/10/AR2009111001396_3.html?sid=ST2009110903795 
Wilkins, V. M., \& Williams, B. N. (2008). Black or blue: Racial profiling and representative bureaucracy. Public Administration Review, 68, 654-664.

Withrow, B. L. (2004). Driving while different: A potential theoretical explanation for race-based policing. Criminal Justice Policy Review, 15, 344-364.

Wise, T. (2005). Membership has its privileges: Thoughts on acknowledging and challenging whiteness. In P. S. Rothenberg (Ed.), White privilege: Essential readings from the other side of racism (2nd ed., pp. 119-122) New York, NY: Worth.

Woodson, C. G. (1933). The miseducation of the Negro. Philadelphia, PA: Hakim's.

Wright, U. T. (2003, October). Institutional ethnography: A tool for merging research and practice. Paper presented at the Midwest Research to Practice Conference in Adult, Continuing, and Community Education, Columbus, $\mathrm{OH}$.

X, M. (1964). The autobiography of Malcom X. New York, NY: Random House.

Young, I. M. (1990). Justice and the politics of difference. Princeton, NJ: Princeton University Press.

Zauberman, R., \& Le'vy, R. (2003). Police, minorities, and the French republican ideal. Criminology, 41, 1065-1101. 


\section{Appendix A}

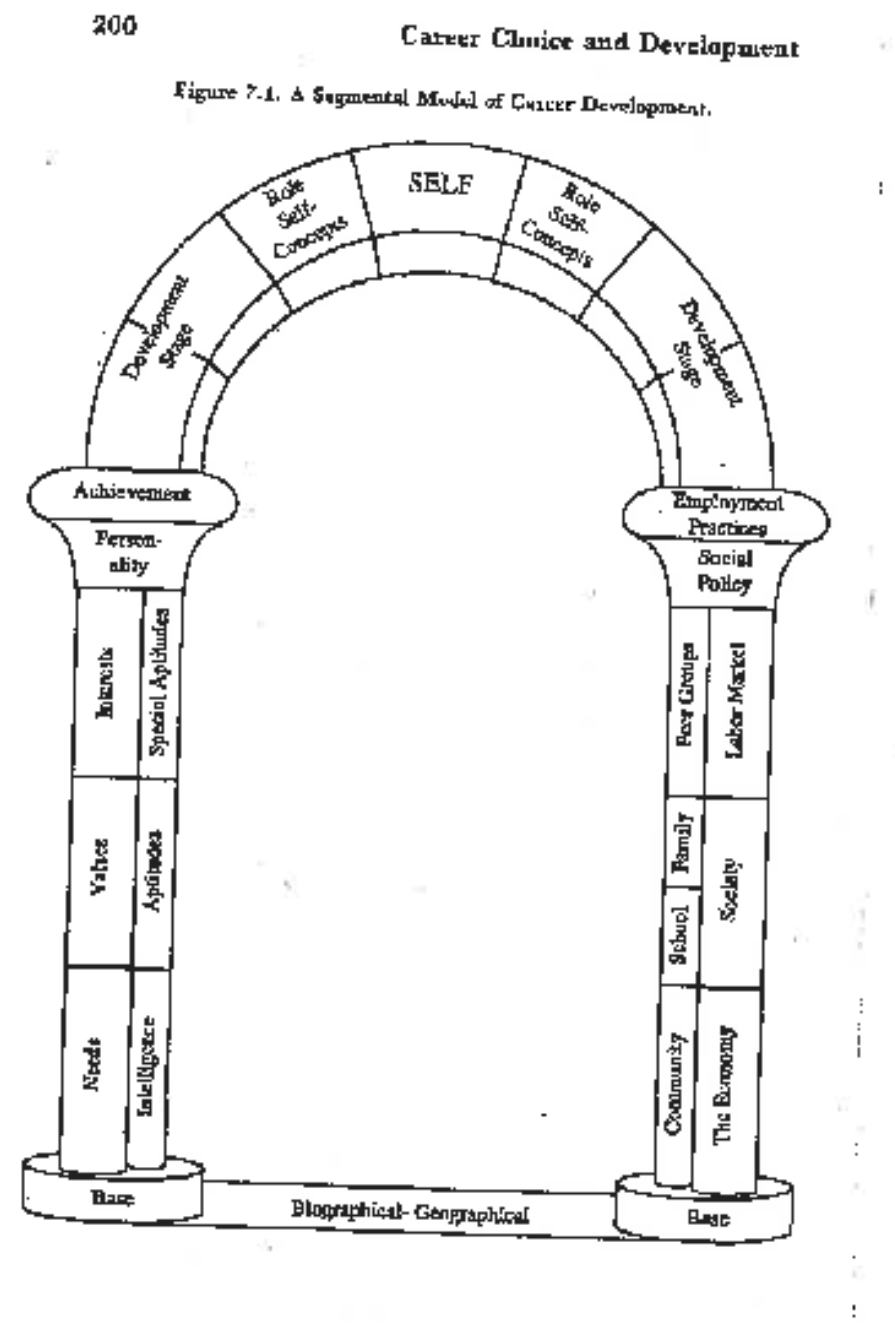




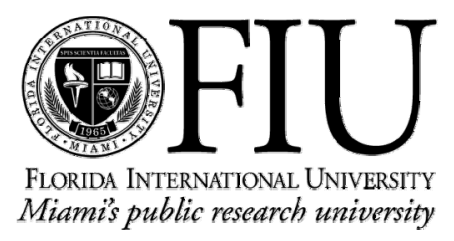

\section{Appendix B}

\section{Screening Questionnaire}

\section{Title: A Phenomenological Exploration of Black Male Law Enforcement Officers'} Perspectives of Racial Profiling and Their Law Enforcement Career Exploration

Please save your completed screening questionnaire and send it to me at

$$
\text { Salters06@comcast.net }
$$

1. What is your name?

2. Are you a Black male?

3. How many years of law enforcement experience do you have?

4. Are you a member of the National Association of Black Law Enforcement Executives (NOBLE)?

5. Are you currently employed as a law enforcement officer? If so, explain.

6. Have you ever worked at the same agency as the researcher? If so, explain.

7. Have you ever been supervised by the researcher? If so, explain.

8. Have you ever supervised the researcher? If so, explain.

9. Are you aware of racial profiling? 


\section{Appendix C}

\section{Semi-structured Interview Guide}

\section{$\underline{\text { Individual (Personal) }}$}

Tell me about yourself.

Where were you born?

Where were you educated?

What is your highest level of education?

Where were your parents born?

How do you describe yourself ethnically, racially and culturally?

How do others describe you ethnically, racially and culturally?

How would you describe your complexion, light, medium or dark?

Which culture do you most identify with?

What is your age? Under 25

$25-35$ $36-45$ over 45

How many jobs have you had?

What is your ideal career?

What type of organizations do you hold membership?

Do you hold leadership positions within the organization(s)?

How long have you been in law enforcement? Why did you become a law enforcement officer?

Please describe your recruitment and hiring process.

How did you feel while going through the hiring process?

Please describe your law enforcement career?

Training

Assignments

What has been your most rewarding law enforcement experience? Why? 
What has been your most disappointing law enforcement experience? Why?

How do you view yourself as a law enforcement officer?

\section{$\underline{\text { Law Enforcement }}$}

What is law enforcement?

How does law enforcement differ from corrections?

Job description

Demographics of employees

Can you discuss how a law enforcement officer decides when and what type of action they will take?

In your professional opinion how is discretion used in law enforcement?

\section{$\underline{\text { Racial Profiling }}$}

What is racial profiling?

What is evidence of racial profiling?

What are consequences of racial profiling?

What is the difference between racial profiling and profiling?

Please describe an instance(s) where you have been racially profiled.

How old were you, where did it occur, what was the result of the encounter (i.e., citation, arrests), how did the encounter make you feel? Were you an officer at the time?

Describe what it was like to share your experience with others? How did you feel? What was their reaction?

Can you discuss instances where you know racial profiling occurred? Can you discuss instances where you know false allegations of racial profiling occurred?

Why do you believe individuals make allegations of racial profiling?

How have you addressed the issue of racial profiling?

How have you addressed the issue of Black males in law enforcement?

In your professional opinion how can racial profiling be used as a viable law enforcement tool? 


\section{What is race?}

\section{Can you discuss the difference between race, ethnicity and culture?}

\section{What is discrimination?}

\section{Career Development}

What are the minimum qualifications for a law enforcement officer?

Describe your agency's law enforcement recruitment and selection process?

Describe your law enforcement training?

Instructors

Courses

How did you receive the opportunity to attend the various training?

Are there positions/assignments within your agency that are key to advancement? If so, what are they?

How are selections for key positions made?

Please describe your law enforcement career.

Why do you believe there are not more Black males in law enforcement?

What are the demographics of your agency?

What are the demographics of your Supervisors? (i.e., Sgts., Lts., Capts., etc.)

How do you feel when you think about the number of Black males in law enforcement? What about in supervisory or management levels?

What strategies do you think would be helpful to increase the number of Black males in law enforcement?

Why do you believe there are not more Black males in law enforcement?

Is there anything I should have asked?

Is there anything you would like to add? 


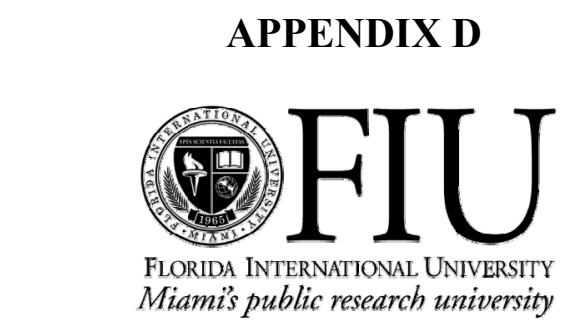

Consent to Participate in an Interview

\section{Title: A Phenomenological Exploration of Black Male Law Enforcement Officers' Perspectives of Racial Profiling and Their Law Enforcement Career Exploration}

You are being asked to participate in a research study designed to explore the essence of racial profiling and your law enforcement career choice. The investigator of this study is Gregory A. Salters, and he is a student at Florida International University. This study will include 15 Black male law enforcement officers and may require up to 2 hours completing a semi-structured interview. As a Black male law enforcement officer, you possess a unique knowledge of racial profiling and career choice. Your participation in this study will provide valuable insight into racial profiling and career exploration, from a Black man's perspective.

If you decide to be a part of this study, the interview will be audio recorded. The face-to-face or telephone interview will be guided by a list of questions. You will be asked to answer questions about your perceptions of racial profiling and your choice of law enforcement as a career. You will not be compensated for participating in the study. This research is not intended to harm you, and you may skip and/or not answer any question(s) that you do not wish to answer. The risk and harm associated with this research is not greater than the risk and harm encountered in daily life.

All your responses to the interview questions will remain anonymous and confidential, unless required by law, and your name will not be disclosed. Your interview will be professionally transcribed. A code and/or pseudonym will be used instead of your name. You may ask questions about the study at any time. If you would like more information about this research after you are done, you can contact me at 954-214-7960 or Salters06@comcast.net. If you would like to talk with someone about your rights of being a subject in this study, you may contact Dr. Patricia Price, the Chairperson of the FIU Institutional Review Board at 305-348-2618 or 305348-2494. Dr. Price is the designated person to receive calls from all research participants regarding the rights of human subjects.

Your signature below indicates that all of your questions have been answered to your liking, you are aware of your rights, and you would like to be in the study.

$\overline{\text { Signature of Participant }} \quad$ Printed Name $\quad \overline{\text { Date }}$

I have explained the research procedure, participant rights and answered questions asked by the participant. I have offered him/her a copy of this informed consent form.

Signature of Witness

\section{Date}




\section{APPENDIX E}

\section{Coding Rubric}

\begin{tabular}{|c|c|c|c|}
\hline Codes & $\begin{array}{c}\text { Key Blocks of Super's } \\
\text { Archway Model }\end{array}$ & Definitions & \\
\hline $\mathrm{BG}$ & $\begin{array}{c}\text { Biographical/Geographical } \\
\text { Foundations of Human } \\
\text { Development }\end{array}$ & Personal history & \\
\hline $\mathrm{PC}$ & $\begin{array}{l}\text { Psychological } \\
\text { Characteristics }\end{array}$ & $\begin{array}{l}\text { A persons thought } \\
\text { process, } \\
\text { aptitudes,, needs, } \\
\text { interests and } \\
\text { achievements. }\end{array}$ & \\
\hline $\mathrm{S}$ & Society & $\begin{array}{l}\text { How the } \\
\text { economy, school, } \\
\text { family, society, } \\
\text { peer groups, labor } \\
\text { market, and social } \\
\text { policy support } \\
\text { employment } \\
\text { practices. }\end{array}$ & \\
\hline $\mathrm{SC}$ & Self-Concept & $\begin{array}{l}\text { How an individual } \\
\text { views himself and } \\
\text { how he feels } \\
\text { others view him }\end{array}$ & \\
\hline SL & Social Learning & $\begin{array}{c}\text { Instrumental } \\
\text { learning } \\
\text { experiences, } \\
\text { associative } \\
\text { learning } \\
\text { experiences and } \\
\text { vicarious learning } \\
\text { experiences }\end{array}$ & \\
\hline
\end{tabular}




\section{APPENDIX F}

\section{Copyright Permission}

\section{Campbell, Brenton - Hoboken}

From: $\quad$ Goldweber, Paulette - Hoboken on behalf of Permissions - US

Sent:

To:

Tuesday, March 05, 2013 4:13 PM

Campbell, Brenton - Hoboken

Subject:

FW: Permission to use Super's Archway Model (1990) in dissertation

Categories:

Permissions

Thesis.

From: Gregrory A. Salters [mailto:Salters06@comcast.net]

Sent: Tuesday, March 05, 2013 2:36 PM

To: Permissions - US

Subject: Permission to use Super's Archway Model (1990) in dissertation

I am a doctoral candidate at Florida International University in Miami Florida. I am requesting permission to use the illustration of Donald Super's Archway Model (1990) as depicted on page 200 in my dissertation. The illustration is in the following book:

Super, D. E. (1990). A life-span, life-space approach to career development. In D. Brown, L. Brooks, \& Associates (Eds.), Career choice and development: Applying contemporary theories to practice ( $2^{\text {nd }} \mathrm{ed}$., pp. 197-261). San Francisco: Jossey-Bass.

I greatly appreciate your consideration in this matter. If you need to reach me, I may also be reached via cell phone - (954)214-7960.

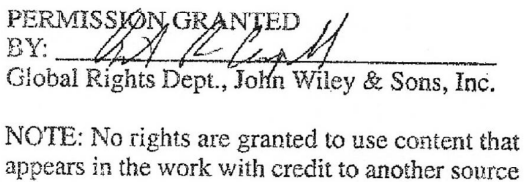


VITA

\section{GREGORY A. SALTERS}

Born, Atlanta, Georgia

1987

Bachelor of Science in Business Administration

Florida Agricultural and Mechanical University

Tallahassee, Florida

1998

Master of Science in Public Administration

Florida Atlantic University

Boca Raton, Florida

PUBLICATIONS and PRESENTATIONS

Salters, G. A. (2013, February). Minority Forum. Florida Department of Law Enforcement, Mount Dora, FL.

Salters, G. A. (2012, September). Ethics and Law Enforcement - To Be or Not to Be! Presenter at National Internal Affairs Investigators Association National Conference, Orlando, FL.

Salters, G. A., Rocco, T. S., \& Reio, T. (2011, July). Racial Profiling and Law Enforcement as a Career Choice. The 7th International Critical Management Conference, Faculty of Economics, University of Naples Federico II, Naples, Italy.

Salters, G. A., (2011, April). Ethics. Presented to sworn personnel employed at the Coconut Creek Police Department, Coconut Creek, FL.

Salters, G. A. (2004, April). Ethics in Urban Research. Panelist at 3rd Annual Florida International University College of Education Research Conference. Florida International University, Miami, Florida.

Rocco, T. S., \& Salters, G. A. (2004, September). Expanding the Boundaries of Urban Education. Presented at Race, Gender, and Class Conference. State University of New York, New Orleans, LA

Salters, G. A. (2004, September). Cultural Competence and Law Enforcement in an Urban Environment. Presented at Race, Gender, and Class Conference. State University of New York, New Orleans, LA

Salters, G. A., \& Gallagher, S. (2004, March). Work, Self and the Profession. CPE and the Inner Life by Dr. John Dirkx. Presented reactant paper at Academy of Human Resource Development, Austin, TX. 
Salters, G. A. (2003, October). Adult Education and Work, Family and Community. Closing Panelist at the 22nd Annual Midwest Research-to-Practice Conference in Adult, Continuing and Community Education. The Ohio State University. Columbus, Ohio.

Salters, G. A. (2003, April). Decreasing Law Enforcement Applicants and Racial Profiling - Reversing the Trends. Presenter at the Supporting Interdisciplinary Inquiry: The 22nd Annual College of Education Research Conference. Florida International University, Miami, Florida.

Salters, G. A., (2003). Can We Talk? Cultural Diversity presentation covering topics including cultural competence and communication skills.

Lauderhill Police Department, Lauderhill, FL.

2007

to Present

Florida Department of Law Enforcement

Facilitator

Facilitate courses in the Florida Leadership Academy. These classes are in the areas of Leadership, Performance Management, Accountability and Professional Presentations etc. I have also assisted with various curriculum updates.

May 2001

Broward College

To Present

Davie, Florida

Adjunct Professor

Instruct Police Recruits, Corrections Recruits and Public Service Aides in the areas of Ethics, Human Diversity and Report Writing. 